5. Die Biocönosen . . . . . . . . . . . . . . . . . . . 159

a) Zusammenfassende Übersicht $\ldots$

b) Die Lebensgemeinschaft der Austernbank und ihr Verhältnis zu der der Tiefen Rinne . . . . 159

c) Die Epibiose der Austernbank . . . . . . . . . . . . . . . . . . . . 160

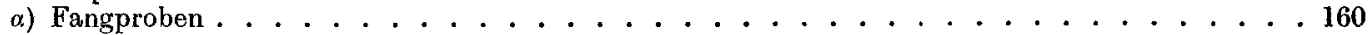

B) Der Zustand der heutigen Austern . . . . . . . . . . . . . 161

IV. Verảnderungen der Austernbank-Bioconose . . . . . . . . . . . . . . . . . . . 162

1. Allgemeine Gesichtspunkte . . . . . . . . . . . . . . . . . . 162

2. Vergleich der alten Angaben (außer Austern) . . ................ . 162

3. Die erhaltenen Reste im Sedıment (Siebrest-Untersuchungen) . . . . . . . . . . . . . . . 162

4. Änderungen durch den Ruckgang der Austern . . . . . . . . . . . . . . . 166

V. Die Austern als Glied der Lebensgemeinschaft . . . . . . . . . . . . . . . . . . . . 166

E. Zusa m men $\mathrm{f} a \mathrm{ssung} \ldots \ldots \ldots \ldots \ldots \ldots$

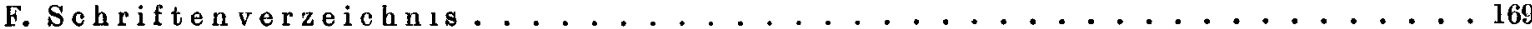

\section{A. Einleitung.}

\section{A ufgabe der Untersuch ung 1 ).}

Die vorliegende Untersuchung ${ }^{2}$ ) befaßt sich mit einem Meeresgebiet, dessen ökologische Bearbeitung aus mehreren Grunden lohnend erschien.

Die Biocönose einer Austernbank ist das erste Studienobjekt gewesen, an dem der Begriff der Lebensgemeinschaft herausgearbeitet worden ist. K. MoвIUs kennzeichnet in seiner Schrift „Die Auster und die Austernwirtschaft“ (1877) den neuen Gesichtspunkt in der Überzchrift zu Abschnitt 10: „Eine Austernbank ist eine Bioconose oder eine Lebensgemeinde“ und gab eine erste Definition. 1892 stellte er auf der Helgolander Bank Untersuchungen an, die er in seiner Arbeit ,UÜber die Thiere der schleswig-holsteinischen Austernbänke, ihre physikalischen and biologischen Lebensverhaltnisse" (1893, Kapitel 7) beschrieb; ferner enthalt diese Schrift Erweiterungen der Biocönosen-Definition. Es mußte wertvoll erscheinen, an einer von Moвrus untersuchten Bank mit quantitativen Methoden und einem regional erweiterten Arbeitsgebiet die Verhảltnisse der Lebensgemeinschaft naher zu untersuchen, ahnlich wie dies auf den Wattenmeerbänken durch HAGMeIER und KändLen (1927) geschehen ist.

Eine vom Verfasser ausgefuhrte Bcarbeitung der Bodenfauna der der Austernbank benachbarten „Tiefen Rinne" (CASPFRs, 1938) hatte gezeigt, daß in dieser isoliert eine eigene Bio¿önose, die ,Nucula nucleus-Gemeinschaft" besteht. Es war nun seit HeInck E (1894) bekannt, daß die für die Lebensgemeinschaft der Tiefen Rinne namengebende Muschel auch auf der Austernbank zu finden ist, und manche andere faunistischen Eigenarten wiesen darauf hin, daß wir es hier mit einer abseits gelegenen Siedlung dieser Biocönose zu tun haben. Eine Bearbeitung dieser Fragen stellte also eine Erweiterung der Untersuchungen in der Tiefen Rinne dar und hatte zur Aufgabe, die Stellung der Austernbank-Lebensgemeinschaft zur Bioconose der Tiefen Rinne zu ermitteln.

1) Anm. des Herausgebers (HAGMEIER).

Die Helgolander Austernbank war das Ziel vieler Fxkursionen, seitdem H[elgoland von Biologen besucht wurde. Sie war ja in jenen Zeiten, wo man die Bodenfauna nur nach Dretschfangen untersuchte, die ergiebigste Fang-telle und brachte stets reiche Auswahl an großeren Tieren, namentlich eine Fulle von festsitzenden Formen. Fs war daher natiurlich, daß auch die Biologische Anstalt gleich beim Beginn uhrer Arbeiten im Jahre 1892 die Fauna der Austernbank untersuchte. Die schonen faunistischen Arbetten von HEINCKE und HARTLAUb geben hiervon ein beredtes Zeug nis. Noch großer war aber der Wert der Austernbank fur die Biologische Anstalt, wenn es galt, Material fur Museen and fur den Universitatsunterricht zu sammeln. Die ersten auf Anregung von HEINCKE*) im Nordseemuseum der Anstalt gezeigten okologischen Praparate, sogenannte „Alkoholarien“ waren von Oberpraparator HiNRIcus mit Tieren der Austernbank hergestellt. Zur Versorgung der Arbeitsplatze an der Anstalt wurden immer wieder Tiere von der Austernbank geholt und manche wertvolle Arbeit $\mathrm{kam}$ auf diese Weise zustande. Als die Anstalt dann nach dem 1. Weltkriege ihre Kurse emrichtete, wurde auch für diese die Austernbank das Ziel der beliebtesten Exkursioren und brachte jedesmal reiches Anschauungsmaterial. Es war daher schon lange geplant, die Bank auch nach neueren Mcthoden zu untersuchen. Den Anfang dazu soll die vorliegende Arbeit von Dr. CASTERS bilden, der sıch durch seine Arbeit uber die Helgolander Tiefe Rinne in die Fauna eingearbeitet hat.

Die wirtschaftliche Bedeutung der Helgolander Austernbank ist schon vor dem 1. Weltkrieg stark zurickgegangen und ist jetzt ganz verschwunden. Da sie im tiefen Wasser liegt und von einem starken Gezeitenstrom bestrichen wird, ist es nicht praktısch, sie in Kultur zu nehmen, wie dies z. B. bei den nordfriesischen Austernbanken moglich und aussichtsreich ist. Fine eingehende, besonders auf das Vorkommen und die Beschaffenheit der Austern auf der Helgolander Bank gerichtete Untersuchung mußte noch durchgefuhrt werden. Einige Angaben werden von Dr. CASPERS bereits gemacht, doch erlaubte es ihm die Küre der hiesıgen Arbeitszeit nicht, die Beobachtungen uber die Auster selbst auf eine breitere Grundlage zu stellen. Immerhin ist durch die Bearbettung der Bodengreiferfange eine Grundlage für die Beurteilung des als Austernbank anzusehenden Meeresbedens geschaffen.

*) Vgl. die Angaben von Plate in Verhandlungen der Deutschen Zoologischen Gesellschaft 1903.

2) Die Arbeiten wurden ausgeführt auf Grund emes Stipendiums der Deutschen Forschungsgemeinschaft. 
Es war bekannt, daß auf der Austernbank früher eine ausgedehnte Austernfischerei betrieben wurde, die aber zwischen 1910 und 1923 gänzlich eingestellt werden mußte, da die Zahl der Austern in starkem Maße abnahm, so daß der Fang nicht mehr lohnte; auch heute sind nur noch ganz wenige Austern dort zu finden.

Das Problem war, wieweit das Verschwinden eines der wichtigsten Glieder der Biocönose eine Veränderung auch der übrigen Fauna zur Folge gehabt hat.

\section{Das bearbeitete Gebiet.}

Die Untersuchungen wurden 1938 an der Biologischen Anstalt Helgoland durchgeführt; die Ausfahrten fanden mit dem Stationsschiff „Makrele" statt1). Die quantitativen Bodenproben wurden mit dem $1 / 10 \mathrm{qm}$ erfassenden Petersen-Bodengreifer (100 kg) gewonnen (vergl. CasPeRs, S. 4) $)^{2}$.

Fur eine Untersuchung uber die Stellung der Austernbank-Lebensgemeinschaft war es erforderlich, auch die Fauna der näheren umliegenden Meeresgebiete zu kennen, um die Grenzen festlegen zu konnen und die mannigfachen Úbergänge zu ermitteln, vor allem, da das Areal der eigentlichen Austernbank recht klein ist.

In Karte Abb. 1 ist das bearbeitete Stationsnetz eingetragen worden. Es enthält die Umgebung der Austernbank nach allen Seiten, im Norden bis zur Loreleybank, im Sudwesten bis zur Tiefen Rinne (genaue Lage der Austernbank s. Abschn. B IIJ). Insgesamt umschlieBt die Bearbeitung einen Meeresraum von $25 \mathrm{~km}^{2}$. Die Zahl der Stationen beträgt 44, die Reihenfolge der Numerierung ergab sich durch die Folge der Ausfahrten. Einige Stationen wurden mehrfach untersucht. Bei dem engen Stationsnetz und den schroffen faunistischen Übergangen mußte die Peilung recht genau sein und richtete sich nach den vorhandenen Marken: zunächst verschiedene Punkte von Helgoland und der Dune (Peilung der Austernbank s. Abschn. B III), ferner im Norden 2 Tonnen am Rande der Loreleybank. Bei dem unruhigen Relief war auch eine Tiefenkontrolle von Wert (Echolot).

\section{B. Der Lebensraum.}

\section{Morphologie.}

Die Grundlage zur Kenntnis der Morphologie des bearbeiteten Gebietes bildet die Deutsche Adm.-Karte Nr. 88, Helgoland 1 : 15000 (1913, berichtigt 1935), die das bearbeitete Meeresgebiet enthailt, und nach der die Tiefenlinien im Abstand von $2.5 \mathrm{~m}$ gezeichnet wurden: $\mathrm{Abb} .1$ (im Westen am Steilabfall zur Rinne wurden einige 2.5-m-Linien nicht ganz durchgezeichnet). Abb. 2 zeigt das bearbeitete Gebiet in plastischer Darstellung und soll eine leichtere Übersicht uber die morphologischen Verhältnisse ermöglichen.

Das Gebiet wird durch zwei Gegensätze charakterisiert: Im Norden die Loreleybank mit Tiefen $<17.5 \mathrm{~m}$ und im Süden ein Ausläufer der Tiefen Rinne $>40 \mathrm{~m}$ (die großte Tiefe der Rinne beträgt $60 \mathrm{~m}$ ). Zwischen Loreleybank und Rinne schiebt sich nun ein zweites flaches Gebiet, das sich an zwei Stellen bis $20 \mathrm{~m}$ erhebt, im ganzen aber durch Tiefen von $20-25 \mathrm{~m}$ gekennzeichnet ist. Zwischen dieser Erhebung und der Loreleybank liegt ein bis $32 \mathrm{~m}$ herabreichendes Tal, das die Loreleybank im Halbkreis umschließt. Das südliche flache Gebiet fallt dann gleichmäßig zu dem Ausläufer der Tiefen Rinne ab (die Haupterstreckung der Rinne ist weiter westlich, die größte Tiefe findet sich südlich vom Helgolander Leuchtturm).

Im Osten treten Tiefen von $25-27.5 \mathrm{~m}$ auf, die in das allgemeine Niveau des weiteren Meeresgebietes übergehen. Im Westen ist die Grenze durch den Helgolander Felssockel gegeben, vor den sich aber noch eine weite nördlich gerichtete Ausbuchtung der Rinne schiebt, die in allerdings flachem - Zusammenhang mit dem südlich die Loreleybank abschließenden Tal steht.

1) Es ist mir mehr als eine Pflicht, allen Herren der Bielogischen Anstalt, die mich wieder weitgehend bei meinen Arbeiten unterstïtzten, hier meinen Dank zu sagen, besonders dem Direktor Prof. Dr. A. HAaMETER. der mir die Institutsmittel zur Verfügung stellte, meine Untersuchungen stets mit großem Interesse verfolgte und mit vielex Ratschlagen zu ihrem Gelingen beitrug. Der Kapitan der ,Makrele", Herr Fischmeister J. Horrmans, hatte die see. mannische Leitung der Arbeiten und machte mir manche wertvolle Mitteilung uber den fruheren Zustand der Austernbank. Hierfur schulde ich auch Herrn Oberpraparator J. HirnicHs Dank, der eine Fülle von alten Aufzeichnungen nach eigenen Beobachtungen gesammelt hat, die in der Faunenliste Aufnahme fanden. Herr Dr. HeRTLING ubernahm wieder die Nachbestimmung einiger Muscheln und Schnecken.

2) Die oft notwendigen Vergleiche mit der Tiefen Rinne beziehen sich auf die Arbeit des Verfassers (Caspers. 1938), und Hinweise hierauf sind im Text dureh ein $C$. und die Seitenangabe gekennzeichnet. Auf diese Arbeit muB auch in bezug auf die benutzte Technik, Systematik der Biocönosen usw, verwiesen werden. 


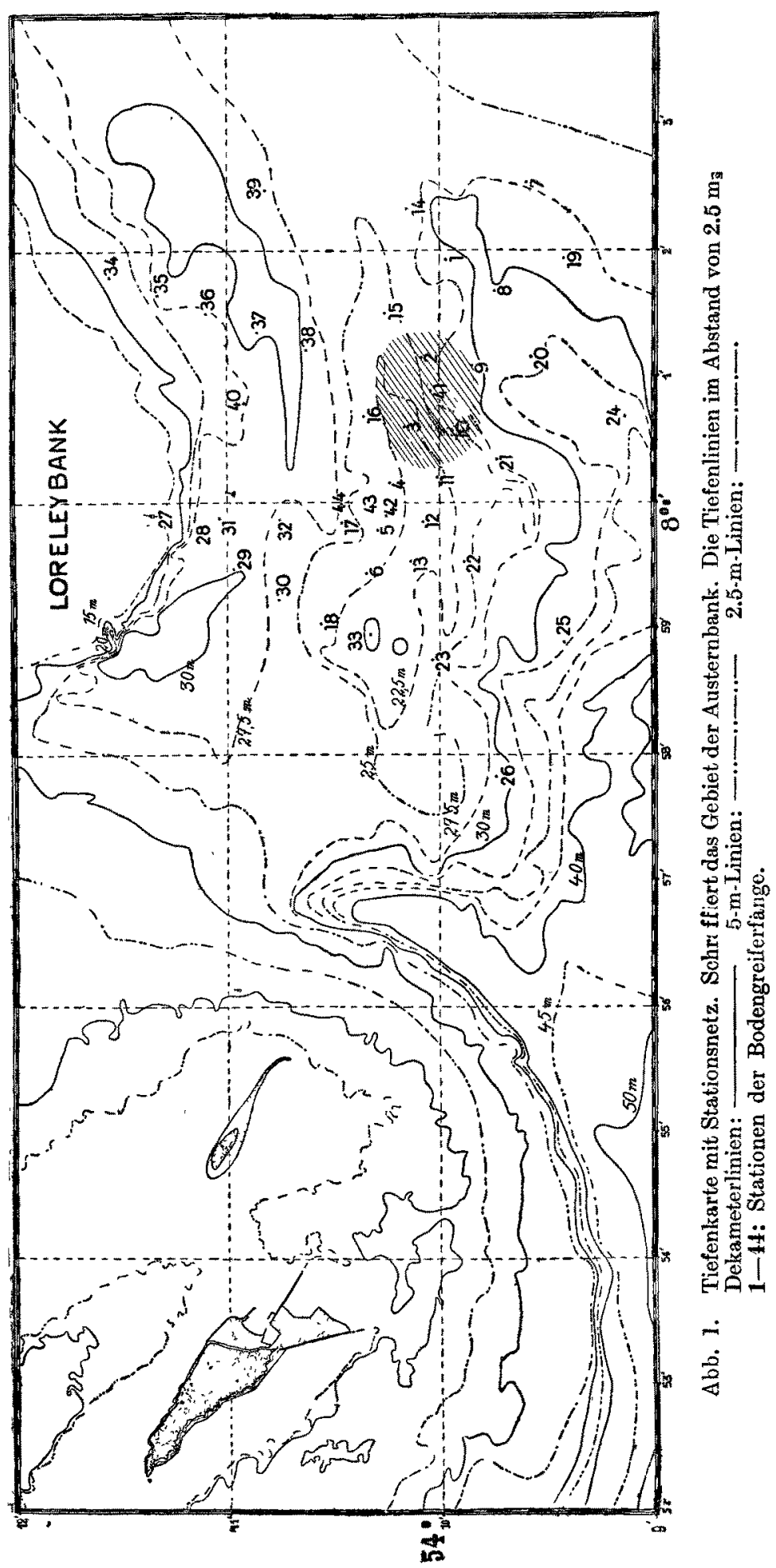

In Abb. 12 und 13 sind drei überhöhte Querschnitte durch das bearbeitete Gebiet gezeichnet. Der Schnitt in Abb. 12 geht etwa ostwestlich, von Stat. 7-13 und berührt die Austernbank an ihrem Südende bei Stat. 10. Der Schnitt von Abb. 13 a geht von der Loreleybank aus und schneidet die südliche Erhebung an ihrer flachsten Stelle westlich der Austernbank. Der Schnitt Abb. 13 b führt ebenfalls von der Loreleybank aus nach Suden bis zur Austernbank 
(Stat. 34-41). In beiden Profilen tritt die Senke zwischen der Loreleybank (Stat. 27 und 34) und der südlichen Erhebung (Stat. 15 und 33) deutlich hervor. Am südlichen Abfall dieser Erhebung liegt die Austernbank (Stat. 41 in 13 b). Diese Beziehung zum Hang ist auch in Abb. 12 $\mathrm{zu}$ erkennen.

Im ganzen haben wir es im Vergleich zu den sonstigen, erst bei großen Strecken Höhenunterschiede aufweisenden Gebieten der südlichen Nordsee mit einem recht unruhigen Relief zu tun. Wenn auch die Austernbank als am südlichen Hang des zwischen Loreleybank und Rinne gelegenen flachen Gebietes gekennzeichnet wird, so ist doch aus der Morphologie kein weiterer Hinweis für eine genauere Lageangabe möglich.

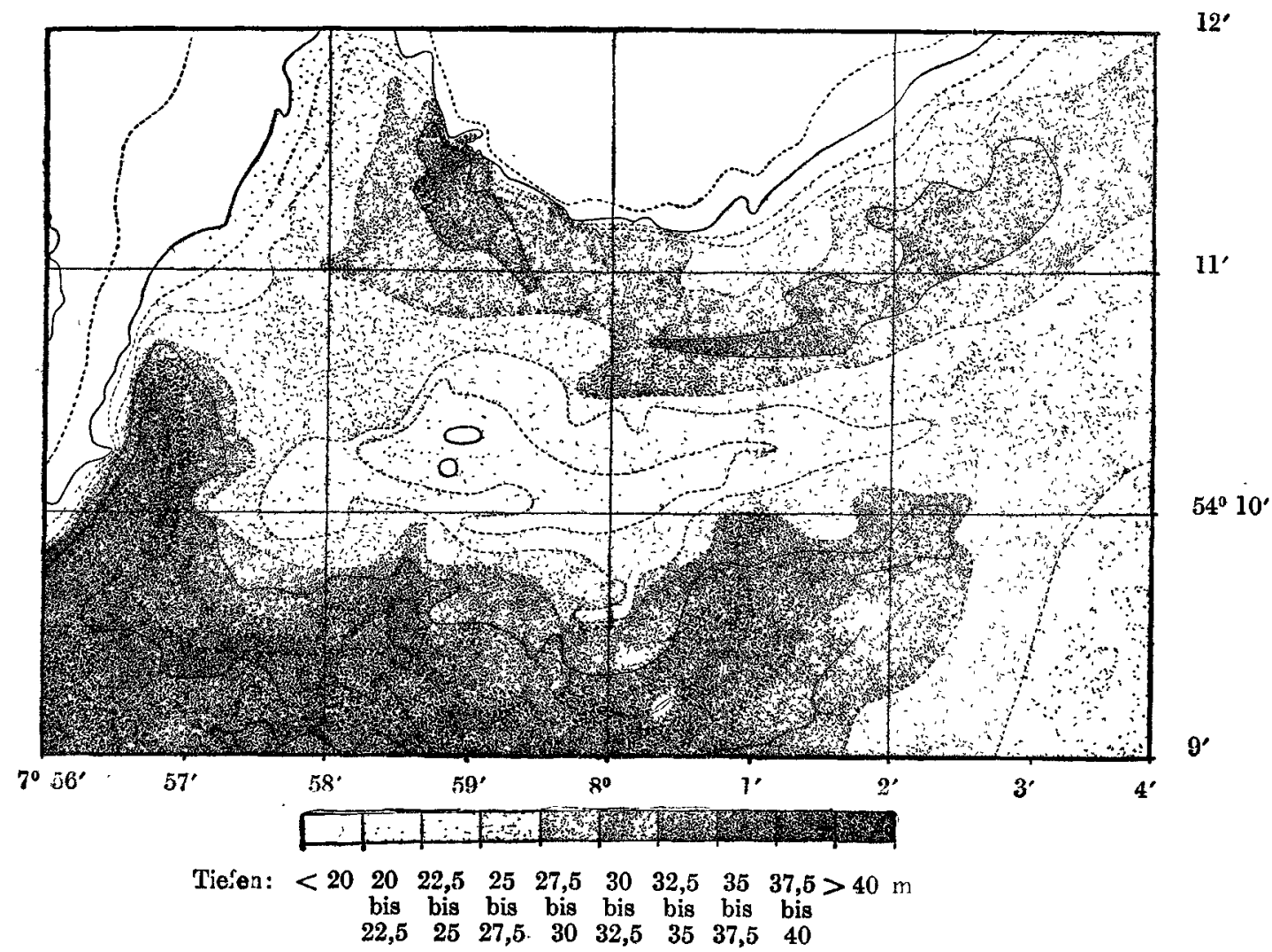

Abb. 2. Tiefenkarte der Umgebung der Austernbank (hierin liegendes Stationsnetz in Abb. 1).

\section{Das Sediment.}

a) Allgemeine Verteilung.

Die Verteilung der Sedimenttypen im untersuchten Gebiet weist eine große Mannigfaltigkeit auf, deren Bedeutung für die Verbreitung der Fauna noch durch sehr schroffe Über. gänge vergrößert wird.

Als Unterlage für die Aufstellung der Sedimentkarte Abb. 3 dienten die bei jedem Boden greiferfang gemachten Notizen über die Beschaffenheit des Bodens, vermehrt durch die Untersuchung des Siebrestes, d.h. aller Bestandteile über $1 \mathrm{~mm}$ (s. C., S. 16) ${ }^{1}$ ), dessen Menge und Größe wichtige Aufschlüsse über die groben Bodenbeimischungen erlauben. Von jedem Siebrest wurd $\mathrm{n}$ daher neben der zoologischen Bearbeitung (s. Abschn. D IV 3) das Gesamtgewicht und die vor. handenen anorganischen Beimischungen festgestellt. - Hinzu kamen Korngrößenbestimmungen von 9 Stationen, deren Lage in $\mathrm{Abb} .3$ mit eingezeichnet ist.

In der Karte Abb. 3 sind drei Haupt-Bodentypen zu erkennen:

1. Das reine Sandgebiet im Norden, das die Loreleybank kennzeichnet. Ein zweites kleines Sandgebiet findet sich in den flachsten Teilen der Erhebung zwischen Loreleybank und Tiefen Rinne (zwischen Stat. 17 und 23).

2. Das reine Schlickgebiet im Südosten.

3. Das auf eine kleine Fläche beschränkte Schillgebiet am Südhange der mittleren Er. hebung zu dem Rinnenausläufer.

1) s. Anm. 2, S. 121 


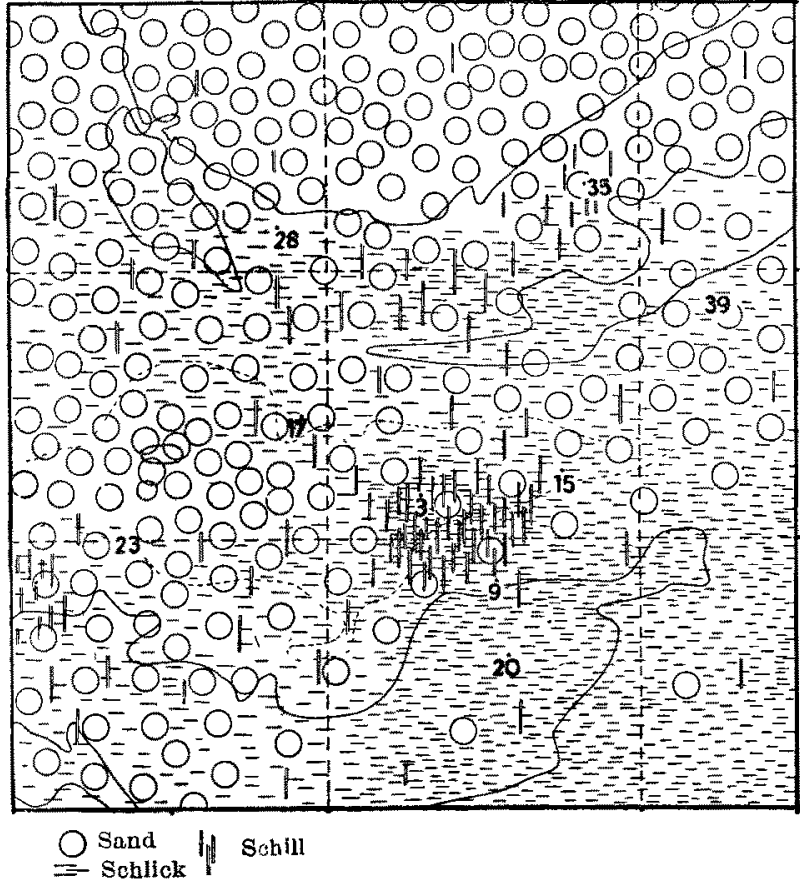

Abb. 3. Karte der Sedimentrerteilung im Untersuchungsgebiet Die drei Komponenten Sand - Schlıck - Schill in verschiedenen Mischungsgraden entsprechend den natürlichen Verhaltnissen (vergl. C., S. 28). Lage der Stationen, von denen Korngroßenbestimmungen vorliegen (vergl. Abb. 4).

Diese Gebiete treten auch a $\mathrm{f}$ den drei Querschnitten $A b b .12$ und 13 deutlich hervor.

In den ubrigen Tailen findet man verschedene Mischungsgrado der drei Komponenton Schlick Sand - Schill. An der tiefsten Stel des südlich der Lorelcybank gele $54^{0} 11^{\prime}$ nen Tales ist noch ein kleines $C_{c-}$ biet reineren Schlicks zu beotachten (s. auch den Querschnitt Abb. $13 \mathrm{~b}$ ), ferner findet sich bier stellenweise auch eine Schillanreicherung. $\mathrm{Zu}$ bemerken ist, dals die Vertcilur g der Bodentypen nicht durch die Morphologie gegeben ist. Lediglich der reine Sand der Loreleybank findet im Norden seinen Abschluß durch die 20-m-Linie.

Das als dritter Bodentyp genannte, auf eine kleine Flàche beschrankte Schillgebiet besitzt sehr scharfe Grenzen und wird von andersartigen Boden umgeben. Dieses Schillgebiet ist die A usternbank! Das Sediment bildet neben der lebenden Faur a dus einzige Kennzeichen, das die Bank festlegt.

b) Der Anfbau des Sedimentes.

Wie bereits oben gesagt, konnte die erste Übersicht, die auf Grund der bei jedem Greiferfang gemachten Notizen über die Bodenbeschaffenheit gewonnen wurde, vertieft werden durch geologische Korngroßßenbestimmungen und Untersuchungen uber die Menge der groben Bestandteile im Siebrest.

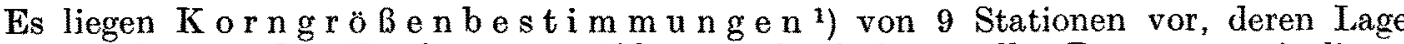
in $\mathrm{Abb}, 3$ angegeben ist. Das Ergebnis ist in Abb. 4 graphisch dargestellt. Zusammen mit diest $n$ Bestimmungen wurden von den Stationen, bei denen ein großerer Anteil von Fraktionen unter $0.1 \mathrm{~mm}$ enthalten war, Gluhverlust und $\mathrm{CaCO}_{3}$ bestimmt, so daß ein Anhalt uber die Menge der organischen Substanz und der beigemischten organischen Schalen gegeben ist. Die Ergebnisse sind folgende:

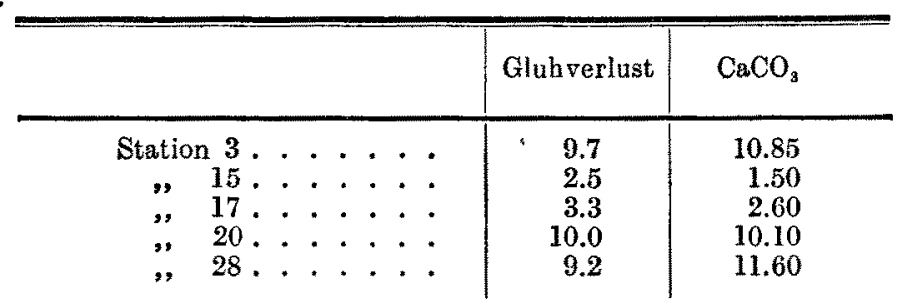

Die Korngrößenanalyse von Stat. 3, die am Rande der Austernbank gelegen ist, zeigt den starken Anteil der Staubfraktionen $(a-c)$. Die Menge des beigemischten Schills trat in der eingewogenen Menge nicht in Erscheinung, da kleine Schalenbruchstucke nur wenig enthalten sind. Die Fraktionszusammensetzung ergibt also für den Schill der Austernbank kein charakteristisches BiJd. Deutlich ist aber auch der hohe Anteil der Fraktion d zu erkennen,

1) Fur die Ausfuhrung dieser Bestimmungen im Laboratorium der Deutschen Seewarte, Hamburg, danke ioh Herrn Prof. O. Pratis.

Die Stufen a-c wurden im Kopecky-Apparat geschlảmmt, die ubrigen gesiebt (vergl. Pratje, 1931). Die bei Proben aus der Tiefen Rinne ausgefuhrte Trennung der Stufe $a_{\text {in }} a_{1}<0.003 \mathrm{~mm}$ und $a_{2} 0.003-0.01 \mathrm{~mm}$ ( $\mathrm{s}$. C., S. 18) wurde hier weggelassen. (Über die Bezeichnung der Fraktionen vergl. C., S. 18.) 
Tabelle 1 .

Gewicht des Siebrestes a us Bodengreifer-Fàgen

von versehiedenen stationen.

\begin{tabular}{c|c|c|c|c|c|c}
\hline & \multicolumn{2}{|c|}{ Austernbank } & Loreleybank & $\begin{array}{c}\text { Sandgebiet } \\
\text { ostlich der } \\
\text { Austernbank }\end{array}$ & Schlickgebiet \\
\hline Station. . . & $\mathbf{1 0}$ & $\mathbf{4 1}$ & $\mathbf{2 7}$ & $\mathbf{3 3}$ & $\mathbf{7}$ & $\mathbf{1 9}$ \\
\hline $\mathrm{g} . . . .$. & $\mathbf{1 4 5 0}$ & $\mathbf{1 2 0 0}$ & $\mathbf{7 0}$ & 90 & 230 & 310 \\
\hline Hauptanteil . . & Grober Schill & Sand & Sand & Feiner Schill \\
\hline
\end{tabular}

die vorwiegend als Sand angesprochen werden muß, wie er fast ausschließlich bei Stat. 28, also am Sudrand der Loreleybank, auftritt. - Eine hohe Beimischung der Staubfraktionen ist besonders bei Stat. $20 \mathrm{zu}$ bemerken, durch die das Schlickgebiet im Südosten der Austernbank gekennzeichnet ist. Bei Stat. 23 ist die Fraktion e vorherrschend. Die Probennotiz lautet hier ,Grober Sand, ganz wenig Schlick". Diese Fraktion hebt sich auch bei Stat. 39 hervor, hat ferner bei Stat. 9, 15, 17 und 35 einen großen Anteil. Dieser grobe Sand, der im Umkreis der Austernbank dem Boden in verschiedenen Mischungsgraden beigcmengt ist, ist also eine Fraktionsstufe gröber $(0.25-0.5 \mathrm{~mm})$ als der von der Loreleybank $(0.1-0.25 \mathrm{~mm}$, Stat. 28).

Die groben Bestandteile des Bodens treten starker in Erscheinung in der Me $\mathrm{nge} d$ es $\mathrm{Si}$ ebrestes (über $1 \mathrm{~mm}$ ) aus den BodengreiferFangen. In Tabelle $l$ ist das Gewicht von Siebresten aus verschiedenen Gebieten angegeben. Bemerkt sei, daß dies keine absoluten, auf die gleiche eingewogene Bodenmenge sich beziehende Zahlen sind, sondern daß sie durch die Menge des jeweils vom Bodengreifer gefaßten Sedimentes beeinfluBt werden. Durchschnittlich handelt es sich um $8 \mathrm{~cm}$ Bodentiefe bei einer Fläche von $1 / 10 \mathrm{qm}$.

Der starke Anteil des Schills am Aufbau des Sedimentes auf der Austernbank ist deutlich zu erkennen, besonders im Gegensatz zu den Sand-

Abb, 4. Korngrößenbestimmungen aus dem Untersuchungsgebiet. Lage der Stationen s. Abb. 3. Anteil der Fraktionen in \%.

$$
\begin{array}{ll}
\mathrm{a}=00.01 \mathrm{~mm} & \mathrm{e}=0.25-0.50 \mathrm{~mm} \\
\mathrm{~b}=0.01-0.05 \mathrm{~mm} & \mathrm{f}=0.50-1.00 \mathrm{~mm} \\
\mathrm{c}=0.05-0.10 \mathrm{~mm} & \mathrm{~g}=1.00-2.00 \mathrm{~mm} \\
\mathrm{~d}=0.10-0.25 \mathrm{~mm} & \mathrm{n}=\quad>2.00 \mathrm{~mm}
\end{array}
$$
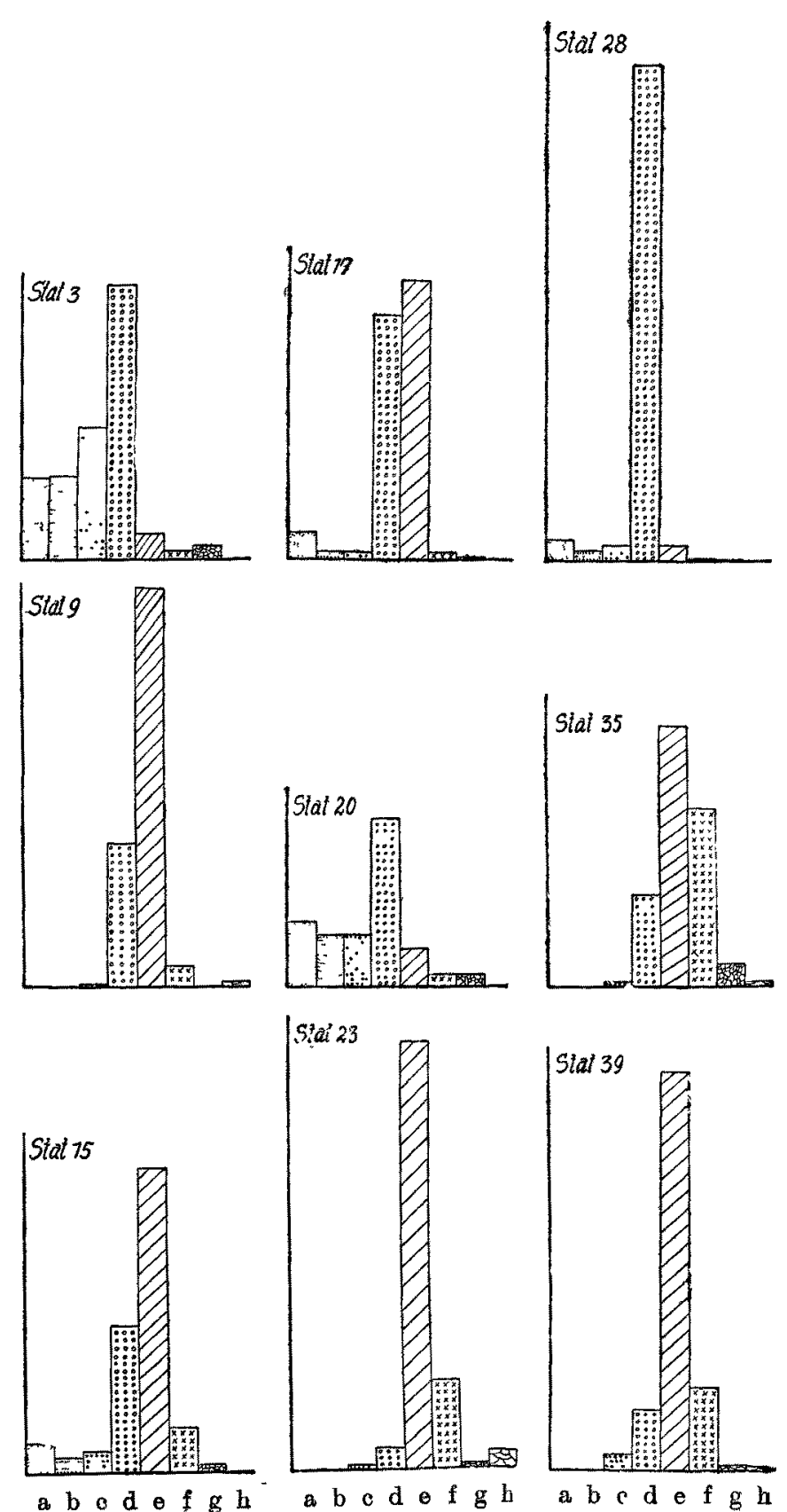

a b c d e f g h

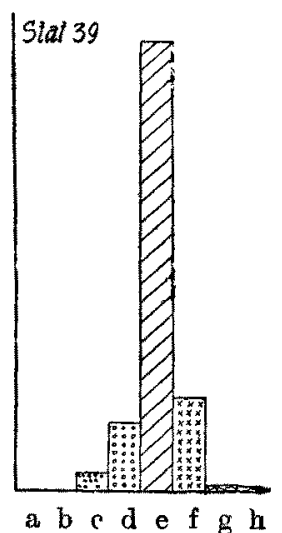


und Schlickgebieten. Bezeichnend ist, daß sich im Schlick stets auch eine größere Anzahl von Schalen der hier lebenden Muschel- und Schneckenfauna findet. Die an lebenden Tieren der Makrofauna sehr armen Sandböden weisen auch eine entsprechend geringe Beimischung von organischen Resten auf. Von den mineralischen Beimengungen haben in Sandgebieten die groben Sandkorner den starksten Anteil (über $1 \mathrm{~mm}$ ). Kleine Steine und Schlackestücken sind recht selten (vergl. Tabelle 8). Wurmröhren spielen außer von Sabellana quantitativ keine Rolle.

\section{c) Der Boden der Austernbank.}

Das Sediment der Austernbank, das ja, wie oben festgestellt wurde, neben der lebenden Fauna das einzige Mittel zur Festlegung der Bank ist, wird durch mehrere Eigenarten gekennzeichnet:

1. Durch die Menge des Schills überhaupt (s. Tabelle 1: Stat. 10 und 41, ferner Tabelle 8: Stat. 10). Einen entsprechenden Schillreichtum findet man in den tiefergelegenen Gebieten der südlichen Nordsee nur noch in der benachbarten Tiefen Rinne (vergl. C., S. 21), so daß schon hierdurch eine enge Beziehung zu dieser besteht. Allerdings ubertreffen die schillreichsten Gebiete der Rinne die Austernbank beinahe um das Doppelte (bis $3000 \mathrm{~g}$ in einer Probe).

2. Durch die Große der Siebrestbestandteile. Dies ist besonders durch die große Zahl der Austernschalen bedingt, die auch gewichtsmäBig unter den Schalen vorherrschen (vergl. Tabelle 8: Stat. 10). Auch in der Rinne finden sich Austernschalen, jedoch nicht in dieser Anhäufung, so daß wir hierin eine besondere Eigenart der Austernbank sehen mussen, welche sie mit den Wattenmeer-Austernbänken gemeinsam hat. Für die Rinne ist die große Zahl der kleineren Muschelbruchstucke kennzeichnend, die auf der Austernbank stark zurucktreten, so dals die großen Schalen unmittelbar dem sandigen Schlick eingelagert sind. Hieraus ist auch das Korngrößenbild von Stat. 3 (Abb. 4) zu erklären.

3. Durch die beigemengten Pümp-Mengen (Röhren von Sabellaria). Diese bilden einen der charakteristischsten Bestandteile der Austernbank; in Stat. 10 (s. Tabelle 8) wird $68 \%$ des Gesamtsiebrest-Gewichtes von ihnen eingenommen, wahrend die Austernschalen nur einen Gewichtsanteil von $20 \%$ haben. Für einen Teil der Tiefen Rinne ist früher viel der Name ,Pümp-

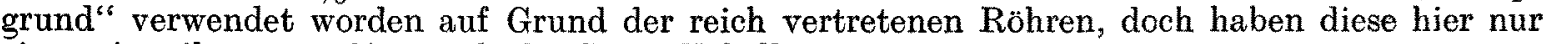
einen Anteil von $3.6 \%$ (vergl. C., S. 98, Tabelle 20).

Zusammenfassend zeigt sich also, daß das Sediment der Austernbank durch den Schillreichtum Übereinstimmungen mit der Tiefen Rinne aufweist. Die Rinne zeigt die grỏßere Schillmenge, hervorgerufen durch viele kleine Bruchstücke, doch treten auf der Austernbank mehr größere Schalen auf, die unmittelbar dem sandigen Schlick eingelagert sind. Ferner ist auf letzterer ein viel stärkerer Anteil an Pümp festzustellen. Das Grundsediment, der sandige Schlick, ist in beiden Gebieten das gleiche, die Unterschiede beruhen auf der verschiedenen Größe und Menge der Schill- und Wurmröhren-Einlagerungen. Für die Grenze des Austernbank-Sedimentes ist noch der schroffe Übergang zu den benachbarten, gánzlich anders aufgebauten Böden charakteristisch. Unmittelbar im Südosten schließt das weiche, nur wenig Schill enthaltene Schlickgebiet, im Westen der grobe, fast völlig schillfreie Sand an, wie es auch die Bodenkarte Abb. 3 und der Querschnitt in Abb. 12 zeigt. Die Grenze zwischen dem Schlickgebiet und der Austernbank läuft zwischen Stat. 9 und 10, also innerhalb einer Strecke von rund $650 \mathrm{~m}$; eine Ubergangszone ist hier kaum vorhanden.

Im Norden liegen schlickige Sande mit geringer Schillbeimischung, im Suden zieht sich der reine Schlick bis zu Gebieten mit stärker sandiger Beimischung hin.

\section{Die Lage nnd Größe der Austernbank.}

Wie bereits mehrfach bemerkt, nimmt die Austernbank einen sehr kleinen Raum am Abfall der Erhebung südlich der Loreleybank zu einem Rinnenausläufer ein. Da die Bank keine morphologischen Besonderheiten kennzeichnen, ist eine sehr genaue Peilung auf Grund von Landmarken auf Helgoland und der Dune notwendig, die nur bei sehr sichtigem Wetter möglich ist.

Die wichtigste Landmarke, die auch von den früheren Austernfischern stets benutzt wurde, wird durch die Nordkante der Insel gebildet, welche genau vom Leuchtturm der Düne gedeckt werden muß. Auf dieser Linie fährt man bis zur Bank, die dann durch Loten ermittelt wird; sie liegt bei einer Tiefe von $23-28 \mathrm{~m}$. Auch Henring, der in seinem nicht veroffentlichten Dienstbericht ủber die Helgoländer Austernbank (1900, vergl. Abschn. C I) genaue Angaben über die Lage der Bank macht, gibt für diese 14-16 Faden an ${ }^{1}$ ). Henking erwähnt als Anhalt

1) Den Dienstbericht konnte ich in der Biologischen Anstalt einsehen. Die Anstalt bewirkte auch die Genehmigung zur Veroffentlichung einiger Angaben des Brrichtes. 
für die Orientierung noch den Pümp, „Zusammen mit dem Pümp kommen alsbald leere Austernschalen und lebende Austern in das Fanggerät und stellen damit die Bank sicher." Heute ist noch eine Querpeilung zur Tonne Loreleybank-Süd móglich.

Aus dem Bericht Henkrngs ist auch das Ergebnis einer Vermessung der Bank, die 1900 vorgenommen wurde, zu ersehen. Diese ist damals von der Biologischen Anstalt mit Unterstützung der Kommandantur von Helgoland mit Hilfe von Winkelmessungen ausgefuhrt worden. Die Enden der Bank wurden durch Bojen gekennzeichnet.
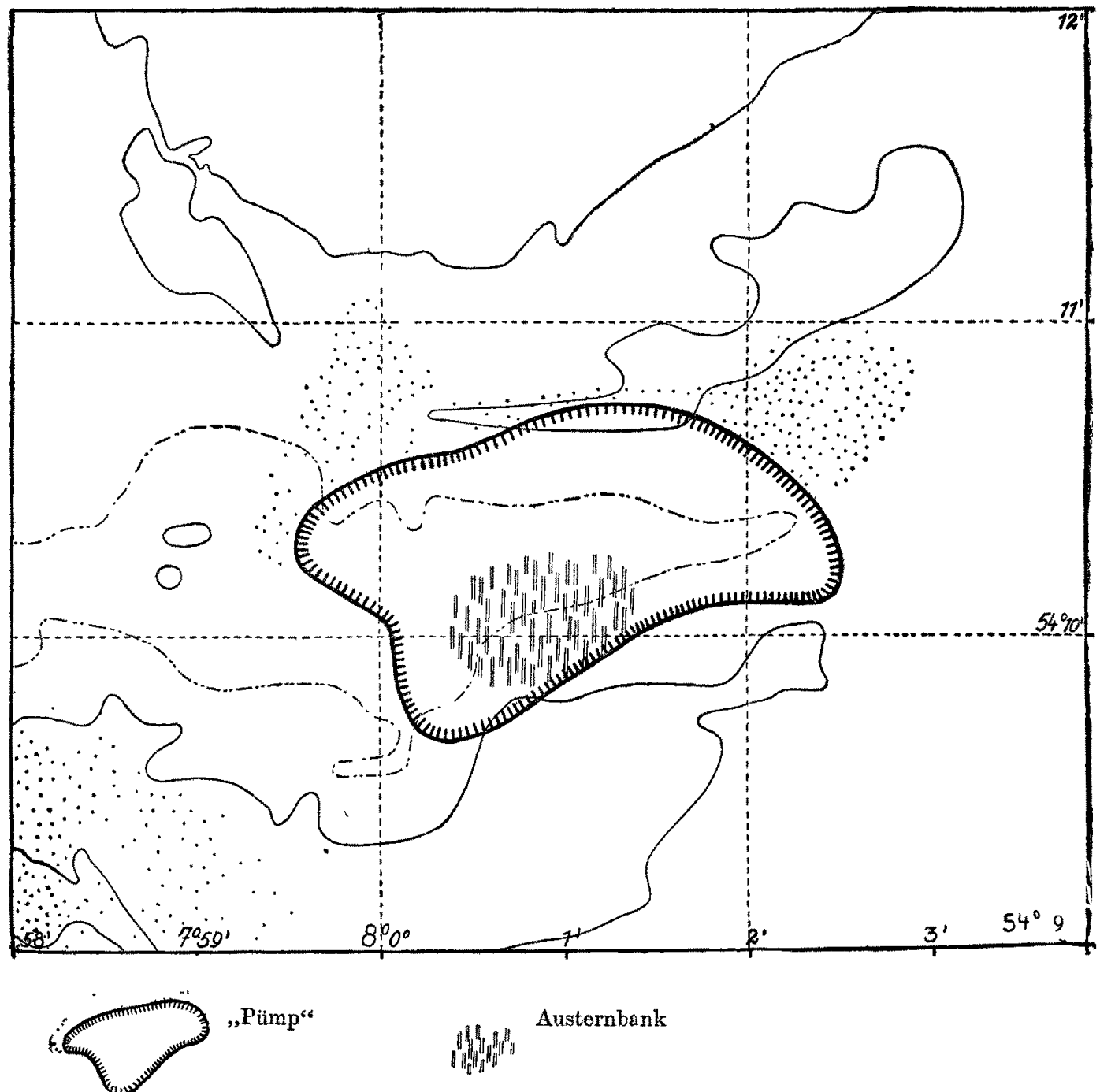

Abb. 5. Verbreitung der Sabellaria-Röhren (Pümp) im Sediment. Mit eingezeichnet ferner das Schillgebiet der Austernbank.

Auf Grund verschiedener Messungen gibt Henk die ziemlich genau von Westen nach Osten verläuft, mit $1700-1800 \mathrm{~m}$ an. Dies stimmt nicht mit meinen Bodengreifer-Untersuchungen überein, nach denen die größte Ausdehnung nur rund $1000 \mathrm{~m}$ (maximal $1150 \mathrm{~m}$ ) beträgt. Es wird dies an der Schwierigkeit der genauen Peilung und besonders daran liegen, daß natürlich die Festlegung einer Grenze lediglich nach der Bodenbeschaffenheit sehr ungenau sein muß und dem persönlichen Eindruck überlassen bleibt. Der Unterschied ist auch darauf rückführbar, daß meine Ermittlungen auf den Bodengreiferfängen beruhen, wobei zur Angabe ,Sediment der Austernbank" gehörte, daß die Probe wirklich eine große Zahl von Schalen, besonders auch Austernbruchstücke, enthielt. Henkings Grenzen wurden mit dem Austernkratzer ermittelt, der natürlich auch vereinzelt liegende Austernschalen noch erfaßt.

Die nördliche und südliche Grenze war von Henking ebenfalls durch Bojen festgelegt und ihre Entfernung auf rund $1000 \mathrm{~m}$ angegeben worden, während sie nach meinen Ermittlungen 
nur etwa $750 \mathrm{~m}$ beträgt. Nach Henkrngs Maßangaben nimmt die Bank eine Fläche von 175 ha ein, nach den meinen nur von 80 ha. Man kann diese beiden Angaben als die Extremwerte bei verschiedenen Gesichtspunkten - reich im Sediment vorhandener Schill oder nur einige noch vom Austernkratzer gefaßte Austernschalen - auffassen. Eine bedeutend vergrößerte Grund. fläche der Austernbank gewinnt man dann, wenn die Häufigkeit des Pumps als Kriterium genommen wird, dessen Hauptverbreitung Abb. 5 zeigt, doch kann wohl dieses ganze Gebiet nicht mehr als eigentliche Austernbank aufgefaßt werden. Nur im Südosten fällt die Grenze des Pümps mit der der Austernbank zusammen.

Auch bei einer Große von 80 ha kann die Bank noch als sehr groß bezeichnet werden; bei den nordfriesischen Bänken werden 10 ha große als klein und 25 ha umfassende als mittelgroß bezeichnet ${ }^{1}$.

Auf der Austernbank liegen die Bodengreiferstationen 2-3-10-41, in der nächsten Umgebung Stat. 9-11-15-16. Stat. 41 kann als Mittelpunkt genommen werden. Die Lage am Südhang der Erhebung zwischen Loreleybank und dem Ausläufer der Tiefen Rinne ist schon mehrfach erwähnt worden. Diese tritt auch deutlich auf den drei überhöhten Querschnitten in $\mathrm{Abb} .12$ und 13 hervor, bei denen zu erkennen ist, daß die Bank - gekennzeichnet durch den Schillreichtum - auf den mittleren Teil des Hanges beschränkt ist.

\section{Hydrographische Bemerkungen.}

Die Sonderstellung der Fauna in der Tiefen Rinne war zu einem Teil auf die besonderen hydrographischen Verhältnisse in diesem Gebiet zuruckgeführt worden (C., Abschn. II b), da 1. die sommerliche Aussußung des Wassers in der Tiefe vermieden wird und 2. fremde Wasserkörper mit ihren mitgefuhrten Bodentierlarven gesammelt werden. Dies hat kürzlich durch GOEDECKE (1940) eine weitere eingehende Behandlung gefunden. Die Sonderverhaltnisse der Rinne sind auch zeitweise in deren Umgebung zu bemerken (vergl. ferner Goedecke, 1939). und für die Austembank müssen ebenfalls besondere hydrographische Bedingungen angenommen werden, die deren Lage und die biologischen Verhàltnisse bedingen. Allerdings liegen hierüber keine direkten Beobachtungen vor.

Die vielfältige und nicht auf das Relief beziehbare Sedimentverteilung muß zu einem Teil auf die Strömungen zurückgefuhrt werden; allerdings fehlen auch hieruber gesicherte Anhalte. Besonders für die Austernbank muß eine Stromung angenommen werden, welche den Tieren hier besondere Lebensbedingungen bietet. Die beschrảnkte Erstreckung an dem Hang wird hierauf beruhen, wie ja von Untersuchungen aus dem Wattenmeer (z. B. HagmeIER und KäNDLER, 1927) bekannt ist, daß flache Hänge an Prielen von Austern wegen den hier herrschenden Strömungsbedingungen bevorzugt werden. Es kann wohl angenommen werden, daß der Wasserwechsel der Rinne zum Teil durch den Auslaufer vor sich geht, an dessen Nordhang die Austernbank liegt. Hierdurch wird eine ständige Wasserbewegung mit reicher Zufuhr von Plankton erzeugt, wie es fur das Bestehen einer Austernbank Voraussetzung ist.

Allein durch die hydrographischen Verhàltnisse ist aber die Lage der Austernbank wohl nicht erkläbar. Es muß hierbei auf die in tieferen Gebieten der sudlichen Nordsee vorhandenen Austerngründe hingewiesen werden (die sogenannten ,wilden Austern"), für deren Lage bisher keine hydrographischen Ursachen anzugeben sind.

\section{Der frühere Zustand der Austernbank.}

Fur eine Beurteilung der heutigen faunistischen Verhảltnisse der Austernbank ist eine Untersuchung des fruheren Zustandes Voraussetzung. Besonders muß uns auch die Frage beschäftigen, welche Grunde fur den Rückgang der Bank bis zu ihrem heutigen, eine wirtschaftliche Befischung nicht mehx ermoglichenden Zustand angefuhrt werden konnen. Zum Gluck liegt auch eine Reihe von Angaben noch aus der Hochblute der Bank vor ${ }^{2}$.

\section{Die Austernfischerei vor 1886.}

Die früheren Ertràge der Helgolànder Austernfischerei gibt eine Fischereistatistik des Helgolander Lehrers TH. Schunt an. die von 1875-1886 reicht, also die Hauptzeit der Helgo. länder Austernfischerei umfaßt ${ }^{3}$ ).

1) Nach Mitteilung von Prof. Hagmeier konnten auf der 23 ha großen Ellenbogenbanz (Sylt) 1/2 Million Austern gemastet werden (s. auch Hagmeizr, 1941).

2) Es ses auch bier betont, daB die Untersuchung der Austern und der Austernfischerei eine Nebenaufgabe war und nur so wert unternommen wurde, wie sie zum Verstandnis der Lebensgemeinschaft notwendig schien (vergl. die Anmerkung des Herauggebers, S. 120). geholfen hat.

3) Die Statistik war im Besitz von Oberprāparator Hinrichs, der als Schüler noch bei der Zusammenstellung 
Die auch die sonstige Fischerei enthaltende Statistik (s. auch Schnakenbeck, 1927) reicht bis 1894, wurde aber für die Austernfischerei nur bis 1886 durchgeführt, da die vordem gemeinschaftlich befischte Bank danach an einzelne Pächter vergeben wurde, die ihre Fänge nicht mehr angaben. Für die Jahre 1873-1874 beruht die Statistik auf der Veröffentlichung: ,Jahresbericht der Commission zur wissenschaftlichen Untersuchung der deutschen Meere, Kiel (Ergebnisse an den Deutschen Küstenstationen), 3. u. 4. Jahrgang". Die Helgoländer Fischerei fand mit den bekannten schweren Helgoländer Booten, ferner mit Schaluppen statt.

Dic Statistik fuhrt die Zahl der Fahrzeuge und gefangenen Austern fur jeden Fangtag auf; in der folgenden Zusammenstollung (Tabelle 2) ist nur die Gesamtzahl der Fanotage, ferner die Gesamtzahl der stattgefundenen Aus. fahiten angegeben, wobei die Zahl der beiden Fahrzeugtypen jedes Tages zusammengezogen wurde. Die berechneten Gesautcalilen bezichen sich nicht auf ein Jahr, sondern auf eine Fangsason, also von September bis April/Mai.

Tabelle 2 .

Alte Fischerei auf der Helgolander Austernbant. Nach der Statistik von Tr. SoumidT.

\begin{tabular}{|c|c|c|c|c|c|c|c|c|c|}
\hline Fanys & aiso & & & $\begin{array}{c}\text { Zahl } \\
\text { der } \\
\text { Fangtage }\end{array}$ & $\begin{array}{c}\text { Gesamtzahl } \\
\text { der } \\
\text { Ausfahrten }\end{array}$ & $\begin{array}{c}\text { Hochstzahl } \\
\text { der } \\
\text { Fahrzeuge } \\
\text { an einem } \\
\text { Tag }\end{array}$ & $\begin{array}{c}\text { Höchstzahl } \\
\text { der } \\
\text { Austern } \\
\text { an einem } \\
\text { Tag }\end{array}$ & $\begin{array}{l}\text { Durchschnittszahl } \\
\text { der von jedem } \\
\text { Boot bei einer } \\
\text { Ausfahit ge- } \\
\text { fangenen Austern }\end{array}$ & $\begin{array}{l}\text { Gesamtzahl } \\
\text { der } \\
\text { gefangenen } \\
\text { Austern }\end{array}$ \\
\hline $\begin{array}{l}\left.1872 / 73^{1}\right) \\
1873 / 74 \\
1874 / 75 \\
1875 / 76 \\
1876 / 77 \\
1877 / 78 \\
1878 / 79 \\
1879 / 80\end{array}$ & 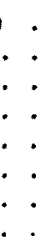 & $\begin{array}{l}: \\
\dot{:} \\
\dot{:} \\
\dot{:}\end{array}$ & $\begin{array}{l}\dot{5} \\
\dot{:} \\
\dot{:}\end{array}$ & $\begin{array}{r}5 \\
15 \\
9 \\
16 \\
21 \\
9 \\
3\end{array}$ & $\begin{array}{l}\overline{299} \\
-\overline{348} \\
515 \\
602 \\
232 \\
37\end{array}$ & $\begin{array}{l}\overline{55} \\
50 \\
56 \\
55 \\
50 \\
19\end{array}$ & $\begin{array}{l}35000 \\
23000 \\
56100 \\
58800 \\
53350 \\
33500 \\
13200\end{array}$ & $\begin{array}{c}\overline{734} \\
\overline{1007} \\
775 \\
841 \\
402 \\
428\end{array}$ & $\begin{array}{r}160000 \\
219600 \\
166600 \\
350000 \\
399070 \\
506380 \\
93275 \\
15840\end{array}$ \\
\hline $\begin{array}{l}1882 / 83 . \\
1883 / 84 . \\
1884 / 85 \\
1885 / 86 .\end{array}$ & $\begin{array}{l}\cdot \\
\cdot \\
\cdot \\
\cdot\end{array}$ & $\begin{array}{l}\dot{.} \\
\dot{.}\end{array}$ & $\dot{0}$ & $\begin{array}{l}9 \\
3 \\
1 \\
1\end{array}$ & $\begin{array}{r}312 \\
26 \\
1 \\
3\end{array}$ & $\begin{array}{r}72 \\
13 \\
1 \\
2\end{array}$ & $\begin{array}{r}36300 \\
5100 \\
550 \\
2000\end{array}$ & $\begin{array}{l}565 \\
431 \\
550 \\
833\end{array}$ & $\begin{array}{r}176190 \\
11200 \\
550 \\
2500\end{array}$ \\
\hline
\end{tabular}

1) Nur fur Marz 1873 angegeben.

Aus der Zusammenstellung ist die frühere Bedeutung dor Austernfischerei für die Helgolànder zu ersehen, denn z. B. die 506000 in der Saison 1877/78 gefangenen Austern stellten einen beträchtlichen wirtschaftlichen Gewinn dar, besonders wenn man bedenkt, da $B$ die aufgewendete Arbeit im Vergleich zur sonstigen Fischerei recht gering war. In der als Beispiel genommenen Saison war ja auch nur an 21 Tagen gefischt worden. Bei der Gesamtzahl von 602 Ausfahrten kamen auf jedes Boot bei einer Ausfahrt 841 Austern, die das Ergebnis von etwa 10-15 Zügen mit dem Austernkratzer gewesen sein werden. Zwei Jahre fruher betrug dic Durchschnittszahl wahrend der Saison sogar 1000 für jedes Boot bei einer Ausfahrt. An gunstigen Fangtagen wurden von jedem Boot bis 1400 Austern gefischt (1876). Diese hohen Fangzahlen sind ein Beweis für die fruhere Produktivitat der Bank.

Aus der Statistik ist nun seit 1878 ein starkes Abnehmen der Gesamtanlandeziffer festzustellen. Die Listen sind von Schmidr bis 1886 unverändert weitergefuhrt worden, so daß nicht anzunehmen ist, daß dies auf einer Vernachlässigung der Meldungen für die Statistil beruht. Wir müssen also die Verringerung der Fangerträge als Tatsache nehmen. Seit 1878 ist nun auch ein Absinken der Durchschnittszahlen der von jedem Boot bei einer Ausfahrt gefangenen Austern festzustellen, was klar darauf hinweist, daß die Ergiebigkeit der Bank nachgelassen hatte. Der Fang schien nicht mehr so lohnend wie früher, so daß auch plötzlich die Gesamtzahl der Ausfahrten stark zuruckging.

Vom 24. Nov. 1879 bis 21. Sept. 1882 ruhte der Fang vollkommen. Wieweit dies als eine Schonzeit gedacht war oder andere Ursachen hatte, ist nicht mehr festzustellen, jedoch wàre das erstere nicht ausgeschlossen, da den Helgoländern schon früher an einer Schonung der Bank gelegen war, wie aus einer Notiz Schmids vom Oktober 1874 hervorgeht: „Es wurden nur ausgewachsene Austern mitgenommen, kleinere wurden über Bord geworfen. Es war viel junge Brut angesetzt."

Nach dieser Ruhezeit fanden in der Saison $1882 / 83$ wieder 318 Ausfahrten statt, die ein recht gutes Ergebnis brachten, wenn es auch weit unter den alten Fangzahlen blieb. Der Fang verringerte sich dann in den folgenden Jahren sehr stark, was mehrere Ursachen haben wird, jedoch auch $z$. T. darauf zurückzufuhren ist, daß man die Fischerei auf Austern nicht mehr 
als lohnend ansah. Politische Verhältnisse und ungünstige Witterungsperioden mögen weitere Gründe sein, die durch Zollmaßnahmen vermehrt wurden. Leider endet die Statistik, als die Bank 1886 an einzelne Pächter vergeben wurde. Diese Aufteilung an Pàchter wird auch ein Versuch gewesen sein, den Fang wieder wirtschaftlich zu gestalten.

Für die Zeit vor 1886 muß man den Rückgang der Austernfischerei zu einem Teil auf die Überfischung der Bank besonders in den Jahren von 1873-1878 zuruckfuihren. Bei der auch später fortgesetzten Befischung war der Bank keine Móglichkeit der gründlichen Erholung gegeben, die vielleicht damals bei einer planmäßigen Fangeinschränkung noch einen Erfolg gehabt hätte' $)$.

\section{Der Rückgang und die Beschaffenheit der Austern nach 1886.}

Boi der Übergabe Helgolands an das Deutsche Reich (1890) war der Gemeinde Helgoland das Eigentumsrecht an der Bank ausdrucklich zugesichert worden. Gleich nach Gründung der Biologischen Anstalt im Jahre 1892 hat K. Morius mit deren Unterstützung die Bank untersucht. Er fing in einigen Netzzügen 15 Austern, die mit Balanus besetzt waren. Sie hatten einen Durchmesser von $127 \mathrm{~mm}$ und eine Dicke von $25-35 \mathrm{~mm}$. Mósius erkannte, daß die Schalen dicker und gewolbter als die der Kustenaustern sind und dadurch eine Übergangsform $\mathrm{zwischen}$ den großen wilden Austern der tieferen Nordsee und den Wattenmeeraustern bilden. Auch geschmacklich sollen sie zwischen den guten nordfriesischen und den zähen Tiefenaustern stehen.

Bedeutungsvoll für den spateren Zustand der Bank ist der unveröffentlichte Bericht von Henkivg (s. S. 126-127), der die Bank mit den Mitteln der Biologischen Anstalt im Jahre 1900 untersuchte. An 3 Tagen in zusammen 16 Austernkratzerfängen von 10-20 Minuten fing er 462 Marktaustern und 42 Stuck Junggut. Henking hat danach eine Berechnung über die Menge der vorhandenen Austern angestellt ${ }^{2}$ ) und gibt den Bestand an Marktaustern und Junggut auf der gesamten Bank zu etwa 1500000 Stück an. Die Ergiebigkeit stellt er danach mit den damaligen zweitrangigen nordfriesischen Bànken gleich. Auch Henking bemerkt, daß die Helgoländer Austern den großen und dickschaligen Typus der wilden Nordseeaustern haben. Er hebt aber auch hervor, daß in den von ihm untersuchten Fảngen die alten Austern ein überraschendes Übergewicht haben, wahrend es an Junggut mangelt: Die Hauptmasse war sicher 20-30 Jahre alt mit einer Dicke von $30-50 \mathrm{~mm}$. Die Aussichten für die Zukunft sah Henking danach als sehr ungünstig an, da die Fischerei lediglich auf die alten Austern angewiesen war. Er hoffte aber, daß der Bank wieder eine reichere Ansatzperiode bevorsteht.

Henkang teilt mit, daß uber die Hálfte der alten Austern einen Befall vom Bohrschwamm hatte. Ferner waren auch die lebenden Austern stark von Sabellaria-Kolonien und Seepocken besetzt.

Nach dem Bericht Henkings hat es den Anschein, als wenn der weitere Rückgang der Austern auf dem Ausblejben von ansatzreifen Larven oder dem Absterben von Junggut beruht. Es sind dies biologische Verhältnisse, die im einzelnen heute nachzuprüfen naturlich unmöglich ist. Es scheint sich aber um eine Entwicklung zu handeln, die auch auf den Küstenbänken stattfand, nur bereits damals für die Helgolander Bank schwerere Folgen hatte.

Von der Biologischen Anstalt liegt eine Aufstellung uber die von den Anstaltsschiffen von 1901-1914 gefangenen Austern vor $\left.{ }^{3}\right)$. Durchschnittlich wurden bei einer Ausfahrt 500 Austern gefangen, in 14 Jahren zusammen 15150 Stück bei 25 Ausfahrten.

Herr Prof. Hagmeier stellte mir eine Austernmessung aus dem Jahre 1924 von der Helgolànder Bank zur Verfugung. Es handelt sich um 66-106 mm lange Stucke mit einer Schalendicke von $23-59 \mathrm{~mm}$. Junggut war in diesem Fang nicht vertreten.

Die durch den 1. Welthrieg bewirkte Schonzeit hatte nicht die vollige Erholung der Bank zur Folge. Unter den noch vorhandenen Austern trat 1923/24 ein starkes Sterben ein. In dem Tagebuch des Fischereisachverständigen der Biologischen Anstalt, das seit 1923 in sorgfaltiger Weise von Kapitän J. Holtuans gefuhrt wird, ist am 19. März 1923 folgende Eintragung von der Austernbank enthalten $\left.{ }^{4}\right)$ :

1) Die Schonzeit der fiskalischen Austernbanke Nordfrieslards hatte allerdings keinen Erfolg gebracht.

2) a) Austernkratzerbreite $80 \mathrm{~cm} \times$ Lange der Austernbank $1750 \mathrm{~m}=1400 \mathrm{gm}$. Ergebnis: 146 Austern.

b) Quer zur Austernbank befischte Flache $1400 \mathrm{gm}+1190 \mathrm{gm}=2590 \mathrm{qm}$. Ergebnis: 213 Austern. Henkiva nimmt an, daß auf den befisehten Streifen etwa der zehnte Teil der vorbandenen Austern gefangen wird (,natirlich eine recht willkurliche Annahme, da Ermittlungen daruber fehlen").

3) Es war ublich da $B$ an einigen Tagen fur die Institutsangehörigen und die Gaste Austern gefischt wurden.

4) Die Helgolander Austernbank wurde von den Anstaltsfahrzeugen regelmaßig mehrmals im Jahre befischt, namentlich um Kursmaterial zu beschaffen. Das wichtigste Fangobjekt dabei war der Seeigel Echinus esculentus. Wenn nebenbei noch Austern gefangen werden sollten, wurde der Austernkratzer verwendet; kam es lediglich auf die Seeigel an, so wurde das Helgolander Trawl benutzt (vergl. HAOME1ER und KANDLER, 1927, S, 47, Anm.). 
„,Motorkutter ,Augusta“ Austernbank $24 \mathrm{~m}$ Tiefe.

Gerät Austernkratzer 15 Zuge.... 113 Echinus esculentus

Helgol. Trawl 2 Zuge..... . 117 Echinus esculentus

Im ganzen 78 Stück Austern gefangen, dazu viele leere Schalen, darunter viele eben abgcstorbene, in denen das Fleisch noch drinnen war." . . .

Zur Deutung dieses Befundes macht mir Prof. HAGmerer folgende schriftliche Mitteilung: „Aus dieser Peoba zhtung kann noch nicht geschlossen werden, daß die sogenannte Austernkrankheit, die 1921 aut den englischen Bänken beobachtet wurde, nun auch auf der Helgoländer Austernbank eingetreten war. Es ist eine den Austernfischern bekannte Erscheinung, daß man im Frühjahr, besonders nach einem kälteren Winter, viele eingegangene Austern findet. In den Wintermonaten bleibt der Tierkörper noch in den Schalen und zersetzt sich nur langsam. So hat der Fang vom 19. März 1923 die im Winter 1922/23 gestorbenen Austern noch mit dem Weichkörper heraufgebracht, einige Wochen später hätte man nur noch die durch das Ligament noch zusammengehaltenen Schalen gefunden, die in jedem Fruhjahr und Sommer gefunden werden.

Daß die Abnahme des Austernbestandes nicht 1923 plötzlich erfolgte, zeigen spátere Fange. Zum Beispiel wurden nach dem Tagebuch des Fischereisachverständigen am 27. Mai 1924 in 10 Zügen mit dem Austernkratzer neben 68 Echinus 50 lebende Austern gefischt (1923 in 15 Austernkratzerfängen +2 Trawlzügen 78 Austern, was ungefăhr dasselbe Ergebnis bedeutet). Der Austernbestand der Helgoländer Bank hat dann in den folgenden Jahren regelmäBig langsam abgenommen, da kein neuer Ansatz erfolgte. Die Erzeugung von Austernlarven seheint in der südlichen Nordsee gegenüber früher stark abgenommen zu haben. Auch auf dem ,Austerngrund" sind die alten Austern nach dem Weltkrieg stark zurückgegangen. Während bei den Forschungsfahrten des "Poseidon" vor dem Weltkrieg in einem Fang der großen Kurre mindestens ein großer Fischkorb voll lebender Austern enthalten war, fingen wir im Marz. 1926 in mehreren Kurrenzügen zusammen nur 46 Stück Austern (vergl. Hagmerer und KändLer, 1927, S. 70 Anm.)."

Seitdem ist die Bank ohne wirtschaftlichen Nutzen. 1938 wurden in 2 Kurren- und 6 Austernkratzerzügen zusammen 10 Austern gefischt. Seit 1925 sind bei 135 Kurren- und 38 Austernkratzerfängen von den Anstaltsschiffen 175 Austern gefangen worden, also rund eine bei jedem Zug; die Höchstzahl bildeten 9 in einem Kurrenzug. Im Jahre 1932 versuchten drei Helgolander Boote wieder die Austernfischerei auf der Bank. Sie fischten von 9-14 Uhr und fingen $5+5+30=40$ Austern. An einem anderen Tage bekam ein Boot 30 Austern. Die 70 Austern wurden für 21 RM verkauft, der Ertrag hatte also kaum die Brennstoffkosten gedeckt').

\section{Die Tierbesiedlung der Ansternbank und ihrer Umgebung.}

\section{Das vorhandene Material.}

a) Das Fangmaterial.

Die Grundlage der vorliegenden Bearbeitung bilden die Bodengreiferfänge von 44 Stationen (vergl. S. 121 und Karte Abb. 1). Hinzu kamen drei bereits bestimmte Bodengreiferfänge von Prof. HAGMeIer aus früheren Jahren. Dieses Material wurde erganzt durch eine Reibe von Fängen mit der Zungenkurre und dem Austernkratzer; letzterer ist hierfür besonders geeignet and wurde früher von den Helgoländern (wie heute noch auf den nordfriesischen Bänken) zum Fang der Austern benutzt. Hierdurch konnten die größeren Epibiose-Tiere erfaßt werden. Insgesamt wurden 19382 Kurren- und 8 Austernkratzerfänge untersucht.

In die Faunenliste wurden ferner die seltenen, früher hier gefangenen Tiere mit aufgenommen. Von diesen kann nicht angenommen werden, daß sie heute gänzlich verschwunden sind, jedoch gelangen sie wegen ihrer Seltenheit nur gelegentlich ins Netz. Von besonderem Wert war hierbei wieder das Fangjournal des Fischmeisters über die Fahrten der Anstaltsschiffe seit 1923, aus denen die Angaben von 190 Kurren- und 16 Austernkratzerfängen herausgezogen wurden. Auch Herrn Oberpräparator HiNRIchs verdanke ich eine Liste seiner bis 1894 zurückgehenden Notizen über Funde von der Bank. Durch die Berücksichtigung dieses Materials war es auch möglich, einige Fluktuationen zu erkennen.

Wie bei der Bearbeitung der Rinne wurde ferner der Siebrest von den Bodengreiferfängen untersucht und die nur als Schalen vorhandenen Tierreste gesammelt. Auch hierdurch war es möglich, eine Reihe von Arten als hier früher vorkommend zu kennzeichnen.

1) SpÄrcK (1924) hat darauf hingewiesen, dal der starkere Stoffumsatz bei hoher Temperatur ein Verhungern der Austern bei nicht genugender Nahrungsmenge verursacht. Es tritt dabei zuerst eine Láhmung des Schließmuskels ein (vergl. auch OrroN, 1937). Es besteht jedoch keine Veranlassung, diese Erscheinung auch nur als Teilursache des Absterbens der Helgoländer Austern anzunehmen. 
b) Ïltere Angaben.

Zuzüglich der Berücksichtigung älterer Fangnotizen und der tierischen Reste im Sediment wurden auch Literaturangaben verwendet. Für die Fauna der Austernbank ist weder wie für die Rinne die Arbeit von Herncke (1894) ,Die Mollusken Helgolands" von Bedeutung, da sie auf einwandfreien Bestimmungen und langjähriger Sammeltätigkeit beruht. Einige Pantopoden gibt Schlotтtie (1932) an. Die Arbeit von K. Möbrus (1893) ist besonders in Hinblick auf die biocönotischen Ausführungen von Wert (vergl. Abschn. D V). Auf die Angaben über die Austern der Helgoländer Bank ist bereits eingegangen worden (S. 130). MöвIUs fing in einigen Zügen mit dem Austernkratzer auch 60 wirbellose Tiere, die er in seiner Arbeit anführt. Die meisten sind in späteren Fängen bestätigt worden, die übrigen werden in der Faunenliste nur als Anhang zu jeder Gruppe angegeben, da die Artbestimmung wohl nicht immer gesichert ist. Der Bericht von Henking (1900) ist bereits in Abschnitt C I behandelt worden.

\section{Faunenliste mit antökologischen Angaben.}

Die $\mathrm{n}$ i $\mathrm{e} \mathrm{h} \mathrm{t}$ in Bodengreiferfängen gefundenen Arten sind vor dem Namen durch einen $\mathrm{S}$ t e r $\mathrm{n}\left({ }^{*}\right)$ gekenn. zeirhnet. Es handelt sich hierbei um Tiere, die in Dretschfängen des Verfassers 1938 festgestellt wurden. Ältere Fänge der Biologischen Anstalt und Literaturangaben sind durch ein Kreuz (†) bezeichnet. Ferner wurden in die Liste die Arten aufgenommen, von denen sich im Bodengreifer nur Schalenreste als Zeichen ihres Vorkommens fanden. Bei diesen ist der Artname mit einer eckigen $\mathrm{K}$ l a $\mathrm{m} \mathrm{m}$ er versehen.

Herr Dr. H. Herrting-Helgoland übernahm wieder die Nachbestimmung einiger Muscheln und Schnecken. Ebenso sandte ich Herrn Dr. H. Frredrich-Kiel einige Polychaeten zur Bearbeitung. Die übrigen Angaben beruhen auf Bestimmungen des Verfassers. Es werden insgesamt 208 Arten aufgefüht.

Endobiose-Art:

\section{Foraminifera.}

Astrorhiza limicola Sandahl. Die Verbreitung zeigt Abb.9. Das so häufige Vorkommen im Umkreis der Austernbank war bisher unbekannt, obgleich die Ortsdichte stellenweise außerordentlich hoch ist: Bei Stat. 18 konnten 67 Stück aus einem Greiferfang ausgesucht werden (s. Abb. 15). Dar Boden entspricht hier ungefähr dem des Siedlungsgebietes in der Rinne (C., S. 34); es kann aber nicht wie dort ein so geschlossenes Verbreitungsgebiet festgelegt werden. In geringerer Zahl tritt die Foraminifere hier auch zusammen mit Nucula nucleus auf.

Endobiose-Art:

Spongiaria.

Clion a ce la ta Grant. Der Bohrschwamm ist im Gebiet der Austernbank häufig und muB als ein Hauptfeind der heute hier noch lebenden Austern angesehen worden, von denen etwa ein Drittel befallen ist. Alle jüngeren im Sediment liegenden Austernschalen sind mit dem lebenden Schwamm durchsetzt, die älteren weisen noch die Bohrgänge auf. So enthielten von 530 Schalen 50 den Schwamm. Ein ähnliches Bild zeigt sich bei anderen größeren Muschelarten.

E pibiose-Arten:

*H a lichondria panicea (Pallas). Ein Ring von $10 \mathrm{~cm}$ Durchmesser von der Austernbink im Dretschfang (1938).

†H a liclona oc ulata (Pallas). 1923 in einem Kurrenfang von der Austernbank.

Endobiose-Art:

\section{Coelenterata.}

Cevianthus lloyd $i$ i Gosse. Im Gebiet der Austernbank und deren nächsten Umgebung auf sandig-schlickigem Boden mit Schillbeimischung häufig. Bis fün in einem Greifer. Die Verbreitung deckt sich mit der von Nucula nucleus. In den übrigen Gebieten fehlend, nur bei Stat. 37, deren Boden und Fauna Ähnlichkeit mit der Austernbank besitzt, 2 Stück in einem Fang.

Epibiose-Arten:

$T u$ с ularia indivisa L. Vereinzelt. Zusammen mit folgender Art.

$T u b u l a r i a d u m$ ortier $i$ van Beneden. Im Gebiet bei 5 Stationen auf Muschelschalcn gefunden. Ferner in Dretschfängen von der Austernbank.

Perigonimus repens Allman. Seltener als in der Rinne; auf Nucula nucleus.

$E u d e n d r i u m$ rame $u m$ (Pallas). Ein kleiner Stock auf lebender Auster.

$E u d e n d r i u m$ ramosum (L.). Auf lebender Auster. 
Hydrallmania falcata (L.). Zum Teil große Kolonien auf Muschelschalen; seltener als in der Rinne.

Sertularia cupressina L. Auf der Austernbank und bei Stat. 6.

$C$ a $m p a n$ ul ar $i a j$ ohn s to $n i$ Alder. Nicht selten. Vielfach auf anderen Hydroiden dichte Überzüge bildend.

* Campanularia raridentata Alder. Im Dretschfang von der Austernbank. Auf Kirchenpaneria.

Campanulina hincksi Hartl. Selten. Auf lebenden Corbula.

* Kirchenpa ue ria pinnata (L.). Im Dretschfang von der Austernbank.

Laomedea gelatinosa (Pallas). Auf der Austernbank und deren engeren Umkreis. Die von Hartcaub aufgostellte Art $L$. helgolandica faßt Möвros (1893) nur als Varietät des tieferen Wassers von $L$. gelatinosa auf. Er fand sie in vielen groBen Stöckchen auf Ascidiella aspersa.

L a omedea longissima (Pallas). Bei Stat. 38 und 41 mittelgroße Stöcke. Einzelne Laomedea sp. auch auf lebenden Corbula angesiedelt.

Nach Notizen von Hinrichs sind auf der Austernbank noch folgende Hydrozoen gefunden worden:

$\uparrow$ Perigonimus vestita Allm. 1896 und 1930 im August auf Austernschalen.

$\dagger$ Halecium halecinum (L.).

$\dagger$ Bougainvillia ramosa (v. Beneden).

†Sertularella polyzonias (L.). Mehrmals.

†Campanularia verticillata (L.).

†Cuspidella grandis Hincks. 1901 auf Austernschale. MöвıUs gibt ferner an:

$\uparrow$ Hydractinia echinata (Flem.).

†Halecium tenellum (Hincks.).

†Calicella syringa (L.).

A lc yon $i$ um digitatum $\mathrm{L}$. Große Kolonien fast auf allen Austernschalen der Bank, so daß sie neben dem Schill den grỏßten Massenanteil in Dretschfängen haben. In allen übrigen Gebieten - wohl wegen des Mangels größerer Ansetzungspunkte - fehlend. Von 170 Kolonien waren 86 weiß und 84 rot.

*M e tridium dianthus Ell. Nicht selten große Tiere auf lebenden Austern, wo sie bei einigen die ganze Klappe bedecken. Auf einer Auster fanden sich 4 große und 20 kleine Seenelken. Ferner auf Austernschalen und Steinen.

*Urticina felina L. Gelegentlich in Kurrenfängen von der Austernbank.

A ct in ot ho e ang ü $\operatorname{c}$ o ma (Price). Auf der Austernbank in sehr großer Zahl auf Muschelschalen; bis 70 auf $1 / 10 \mathrm{qm}$ ! Auch auf lebenden Austern, ferner eine auf lebender Nucula nucleus. - Dagegen ist die Art in der Rinne nur ganz gelegentlich zu finden. Außerhalb der nächsten Umgebung der Austernbank wurden nur noch 2 Exemplare bei Stat. 26 festgestellt.

\section{Entoprocta.}

Nur von Möвıus (1893) wird $\dagger$ Pcdicellina cernua Pall. angegeben.

\section{Planaria.}

Cryptocelides loveni Bergendal. Polyclade, von der Nordsee bekannt (s. Bock, 1913, S. 100). det. J. MeIXner, höchstwahrscheinlich diese Art.

Der Erhaltungszustand der in den übrigen Bodengreiferfängen enthaltenen Planarien

erlaubte keine Bestimmung mehr. - Mösıus gibt noch an: $\dagger$ Eurylepta cornuta (Müll.).

\section{Nemertini.}

Line us biline at us (Ren.). Bei Stat. 3 in einem Fang 6 Stück. Ferner je 1 Exemplar von Stat. 9, 10,41, 42. Die meisten Würmer wurden in leeren Sabellaria-Röhren gefunden. Die übrigen $14 \mathrm{im}$ Bodengreifer gafangenen Nemertinen gehören zu verschiedenen anderen Arten, doch waren sie zu beschädigt für eine Bestimmung.

†Cerebratulus marginatus Ren. Wurde in früheren Jahren in Drutschfängen von der Austernbank erbeutet.

Endobiose-Arten:

Polychacta.

Aphroditidae.

a) Errantia.

* Aphrodite acule at a (L.). Im waichen Schlick südöstlich der Austernbank (Dretschfänge). 
Lepidonotus squamatus (L.). 4 Tiere von Stat. 41 und 42; wohl auf die eigentliche Austernbank beschränkt. In Dretschfängen häufig, sitzt zwischen den Sabellaria-Röhren.

Gat ty an a cirrosa (Pall.). 5 Stück von Stat. 3-4-37-41. Ferner in Dretschfängen von der Austernbank.

Harmothö̈ $i m p$ ar Johnst. Stat. 6-41-42. Je 1 in einem Fang, ferner in Dretschproben von der Austernbank.

Ha los y $n$ a gelatinos a M. Sars. Nur 2 Stück von Stat. 41.

$P$ h o lö̈ m in $u$ t a Fabr. Häufig im Gebiet der Austernbank und deren Umkreis, wo $S a-$ bellaria-Kolonien vorhanden sind, zwischen denen der Wurm lebt. Auf der Austernbank bis fünf auf $1 / 10 \mathrm{qm}$.

Phyllodocidae.

Phyllodocegroenlandic a Oersted. 5 Stück von Stat. 8-9-10-42. In Dretschfängen von der Austernbank. Der Wurm findet sich meist zusammen mit Lep donotus und Pholoë in Sabellaria-Röhren.

Eteone longa (Fabr.). I Expl. von Stat. 26, also vom Übergangsgebiet zur Rinne.

Neroidae.

Nereis longissima (Johnston). Überall verbreitet, bis 3 Stück in 1 Fang, insgesamt 17 Expl. von 11 Stationen.

Nephthydidae. Einige Exemplare von Dr. Frredrch-Kiel nachbestimmt.

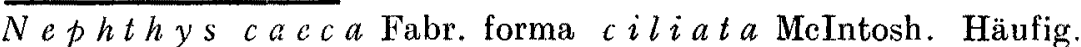

$N e p h t h$ ys hombergi $i$ Audouin u. M.-Edwards. Uberall häufig, z. T. sehr große Stückc.

Nephthys cirrosa Ehlers. Häufig.

$N e p h t h$ ys rubella Michaelsen. I Stück von Stat. 6.

Nephthys longosetos a Oersted. 1 Expl. von Stat. 14.

Sphaerodoridae.

Ephesia gracilis Rathke. 1 Expl. von Stat. 28. Ferner in Dretschfängen von der Austernbank.

G] yoeridae.

Glyceraconvoluta Keferstein. Von dieser für die Nordsee zuerst in der Rinne festgestellten Art (C., S. 38) wurden 12 Stück im engeren Umkreis der Austernbank und bei Stat. 25 gefunden.

Glycera a $l$ b a Rathke. Insgesamt 12 Stück.

Glycera capitat a Oersted. Im engeren Umkreis der Austernbank 6 Stück.

Goniada maculata Oersted. 7 Expl. von Stat. $1-3-9-15-31-42$.

Eunicidae.

Lumbriconereis impatiens (Claparède). Im Vergleich zur Rinne nicht selten. 9 Stück vom engeren Umkreis der Austernbank (5 Stationen).

A r i c i i d a e.

b) Sedentaria

A riciacuvicri Andouin u. M.-Edwards. 1 Expl. von Stat. 42

Scoloplos armiger (O. F. Müller). Überall vorkommend, meist 1 Wurm auf $1 / 10 \mathrm{qm}$, nur bei Stat. 35 in 1 Fang 7 Stück.

Spionidae.

$S p i o p h a n \varepsilon s$ bomb y $x$ (Claparède). In einem eng begrenzten Raum um Stat. $30-31-$ $32-44$ gefunden; bis 4 in einem Fang.

Polydora pulchra Carazi. 6 Stück von 4 Stationen.

Polyd or a coeca (Oersted). In den beiden benachbarten Stationen 4 und 43 in 2 Fängen 5 Stück (det. Friedrich).

Polydora n. sp. 1 Stück von Stat. 42 (3.9.1938). Die Artbeschreibung wird durch Dr. K. Friedrich erfolgen zusammen mit Exemplaren der gleichen Art aus der Kieler Bucht.

$N$ erine ciliatus (Keferstein). Bei Stat. 29 und 40 in 2 Fängen 10 Expl. (det. Friedrich). Scolecolepis (Nerine) bonnieri Mesnil. 6 Expl. von 5 Stationen.

Magelonidae.

Mage lona papillicornis F. Müller. 2 Expl. von Stat. 28 und 35, also vom sandigen Boden am Rande der Loreleybank. 
Dis o midae.

Poecilochaetus serpens Allen. Im ganzen Gebiet fleckenweise vorkommend. Rei Stat. 25, also beim Ubergang zur Rinne, 16 Stück auf 1/10 qm.

Cirratulidae.

Cirratulus filiformis Keferstein. Nur 1 Stück von Stat. 11. Neu für die Nordsee; nächster Fundort nach FriEdricr (1938) W.-Norwegen.

Thar y $x$ marioni (Saint-Joseph). 1 Expl. von Stat. 41, det. Frredricr. Bestimmung mit Vorbehalt.

Chloraemidae.

Stylarioides plumosus (O. F. Müller). Nur 1 Stück von der Austernbank (Stat. 3).

Diplocirrus gla $u$ c us Haase. 3 Stuck vom weichen Schlick (Stat. 1 - 7 - 8), ferner 1 von Stat. 42 .

Scalibreg midae.

$S$ c a libregma inflatum Rathke. Wie in der Rinne findet sich der Wurm in schlickigen Böden im ganzen Umkreis der Austernbank. Die sommerliche Massenentwicklung (C., S. 39) nahm aber 1938 hier nicht die Ausmaße an wie 1936 und 1937 in der Rinne. Es ist wahrscheinlich, daß dies auf. Jahresunterschiede zurückzuführen ist. Die höchste Zahl betrug 40 auf $1 / 10 \mathrm{qm}$.

Opheli idae.

Ophelia limacina (Rathke). Diese für die Loreleybank charakteristische Art (s. Abschn. D III 4 d) tritt einzeln auch im ganzen Umkreis der Austernbank in Böden mit einer größeren Sandbeimengung auf, besonders natürlich in den reinen Sandgebieten um Stat. 33. Die Höchstzahl von 3 auf $1 / 10$ qm fand sich bei Stat. 27, also am Südhang der Loreleybank.

A m motrypane a ulogaster Rathke. 3 Würmer von Stat. $1-2-9$, also dem weichen Schlickgebiet südöstlich der Austernbank.

Capite 11 id a e.

Notomastus latericeus M. Sars. In schlickigen Gebieten, besonders südöstlich der Austernbank (10 Stück von 6 Stationen).

Oweniidae.

Owenia fusiformis d. Chiaje. Im ganzen Gebiet verbreitet. Entsprechend der Bodenzusammensetzung zeigten die Röhren wieder typische Baunterschiede; wie sie bereits in der Rinne festgestellt wurden (C., S.64). Die Höchstzahl für ${ }^{1 / 10} \mathrm{qm}$ betrug 12 und fand sich bei Stat. 26, also im Übergangsgebiet zur Rinne. Auf der Austernbank und ihrer Umgebung sind meist 2-3 in einem Fang zu finden.

Amphictenidae.

Pectinaria koreni Malmgr. Im Umkreis der Austernbank nicht selten in schlickigen Böden; auf dieser selbst aber fehlend. Bis 11 auf $1 / 10 \mathrm{qm}$ (Stat. 7).

Pectinaria a uricoma (0. F. Müller). Nur 2 Stück von Stat. 10 (also von der Austernbank) und Stat. 29.

Ampharetidae.

Ampharete $g r u b$ e $i$ Malmgr. Uberall auftretend, aber fleckenweise, meist 1 Expl. auf $1 / 10 \mathrm{qm}$.

Terebellidae.

Lanice conchileg a (Pall.). Auf die Austernbank und deren engste Umgebung beschränkt, ferner im Übergangsgebiet zur Rinne (Stat. 26); stets 1 Stück auf 1/10 qm.

Polycirrus medusa Grube. Nur bei Stat. 21 und in 2 Fängen von Stat. 41 je 1 Expl.

Sabellidae.

Das ychone sp. Die Gattung ist von Hagmeier früher öfters gefunden worden. Möbius gibt die Art D. dalyelli (Köll.)? an. 
Epibiose-Arten:

Sabellariidae.

Sabellaria spinulos a Leuck. In großer Zahl auf der Austernbank, wo die Röhrenkolonien große Klumpen auf lebenden Austern, Muschelschalen usw. bilden. Bis 63 Würmer wurden hier auf $1 / 10 \mathrm{qm}$ gezählt. Zusammen mit den großen Schillmassen erzeugen diese Kolonien das charakteristische Erscheinungsbild des Austernbank-Sediments. Wenige Sabellaria wurden auch im Umkreis auf Schalen festgestellt. Abb.5 zeigt die Verbreitung der Röhrenbruchstücke (PüuP), die auf den Umkreis der Austernbank beschränkt sind; einige ferner im Übergangsgebiet zur Rinne.

Serpulidae.

* Pomatoceros triqueter L. Einige bewohnte Röhren auf lebenden Austern.

Von Möвıus werden an Polychaeten nock angegeben:

$\uparrow$ Eulalia viridis (L.); †Phyllodoce maculata (L.); †Dodecaceria concharum Oersted; †Thelepus cincinnatus (Fabr.); †Thelepodopsis flava Sars?; †Nicolea venustula (Mont.).

Sipunculidae.

Sipunculoidea.

Phascolosoma sp. 2 Tiere von der Austernbank (Stat. 3 und 41).

†Phascolosoma minutum Keferstein. Wurde nach Aufzeichnungen von Hinsichs in mehreren Stücken im Juli 1935 auf der Austernbank gefunder'.

Crustacea.

Epibiose-Arten:

Cirripedia.

$B$ a lanus crenat us Brug. Im Verhältnis zur großen Zahl der Plattenreste im Sediment der Austernbank (s. Tab. 8: Stat. 10) lebend recht selten. Einige auch auf lebenden Austern.

$B$ a la $n$ us b a l a $n$ us (L.) Da Costa. Seltener als die vorige Art, bei Stat. 7 aber ca. 70 Expl. auf einem Kohlestück, $2-3 \mathrm{~mm}$.

* S a c u $\operatorname{lin}$ a car $\operatorname{con} i$. Thompson. Einmal im Dretschfang an Portunus holsatus.

Schizopoda: Mysidacea.

Gastrosaccus spini/er Goës. 6 Stück von den Stationen 4-6-13-33, also einem verhältnismäßig kleinen Gebiet, was bei diesen sonst halbplanktisch lebenden Krebsen doch auf einen abgegrenzten Lebensraum schließen läßt. Im Oktober fanden sich Junge im Brutraum.

Endobiose-Arten:

Decapoda.

Upogebia delta ura (Leach). 1 Expl. von Stat. 21, fermer in allen 3 Fängen von Stat. 41 1-3 Stück. Während drei von den im Oktober 1938 gefangenen Krebsen 3,5,5 und 6,5 cm maßen, waren die drei ubrigen $0,8-0,9 \mathrm{~cm}$ lang, stellen also Jungtiere von diesem Sommer dar',

Callianassa subterranea Mont. 20 Krebse von der Austernbank, deren nächsten Umgebung und dem Übergangsgebiet zur Rinne. Bis 5 Stück in einem Fang (4 Stück: Stat. 25; 5 Stück: Stat. 43). Die Länge betrug im August bis Oktober 1,0-3,0 cm. (Befall mit Epicariden s. S. 138.)

Epibiose-Arten:

†Pandalus montagui Leach. In früheren Jahren regelmäßig und häufig in Kurrerfängen von der Austernbank. In 10 Zügen wurden hier 1923 etwa $8 \mathrm{~kg}$ gefangen! Seit einiger Zeit ist der Krebs aber - wie in der Rinne - selten (vgl. Tab. 7).

Cr ang on $\operatorname{cr}$ ang o $n$ (L.). 7 Expl. in 5 Bodengreiferfängen, ferner nicht selten in der Dretsche. Die für die Rinne charakteristische und dort häufige Art $C r$. allmani wurde im Umkreis der Austernbank nicht festgestellt.

Ga lat hea in termed $i$ a Lilljeborg. Im Bodengreifer nur 1 Stück von der Austernbank (Stat. 10). In Dretschfängen nicht selten, Länge bis $2,5 \mathrm{~cm}$. Im Juli Weibchen mit Eiern.

†G a l a the $a$ nex a Embleton. Von dieser im Gebiet der südlichen Nordsee vordem nur aus der Rinne bekannten Art wurde nach Mitteilung von Hinichs ein Exemplar im Julj 1923 auf der Austernbank gefangen. 
Porcellana longicornis (Pennant). Der in Dretschfängen von der Austernbank häufigste Decapode fand sich hier auch in den Bodengreiferproben (bis 4 Stück auf $1 / 10 \mathrm{qm}$ ), während er in allen umliegenden Gebieten fehlt. Der Krebs sitzt besonders zwischen den Austernschalen, an denen er oft schwer zu finder ist. Die Carapaxbreite beträgt bis $6,7 \mathrm{~mm}$, man findet aber auch eiertragende Weibchen (Juli bis September) mit $5 \mathrm{~mm}$ Carapaxbreite. Im Aquarium schlüpften Ende Juli Larven.

Dic Krebse zeigen auf der Oberseite des Carapax eine außerordentliche Vielfalt in Färbung und Zeichnungsmustern, von denen in Abb. 6 einige wiedergegeben sind. Als Grundfarbe ist meist olivgrün vertreten, doch finden sich auch häufig Tiere mit elfenbeinweißem Unterton, auf dem das Zeichnungsmuster dann in Form von rotbraunen Streifen, Flecken, Punktreihen usw. erscheint. Neben diesen treten mehr einfarbige grüngelbe Tiere mit nur feiner braunroter Sprenkelung auf. In den meisten Fällen ist eine - oft allerdings sehr undeutliche -- Symmetrie in der Zeichnung festzustellen. Eine Typisiening der Muster stößt bei der Mannig. faltigkeit auf Schwierigkeiten.

Eupagurus bernhardus (L.). In Dretschfängen häufig, im Bodengreifer nur gelegentlich auftretend, so dal. die Besiedlungsdichte recht gering sein muß. Die ausgewachsenen Krebse leben in $3-5 \mathrm{~cm}$ langen Buccinum-Gehäusen, jüngere Tiere wurden ferner in folgenden Gehäusen festgestellt:

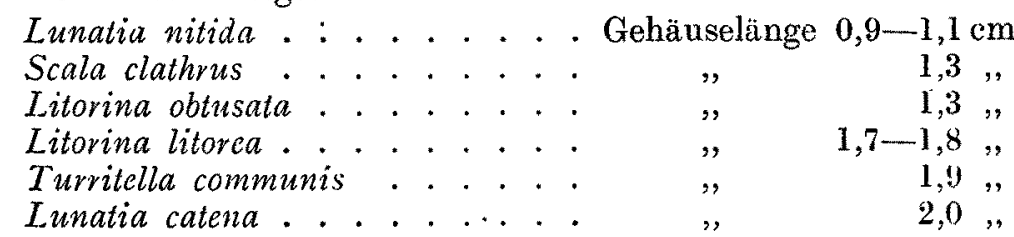

Üher diese Größe hinausgehend werden dann zunachst junge Buccinum-Gehäuse genowmen. Als kleinstes bewohntes Schneckengehause wurde in der Rinne Gibbula tu-
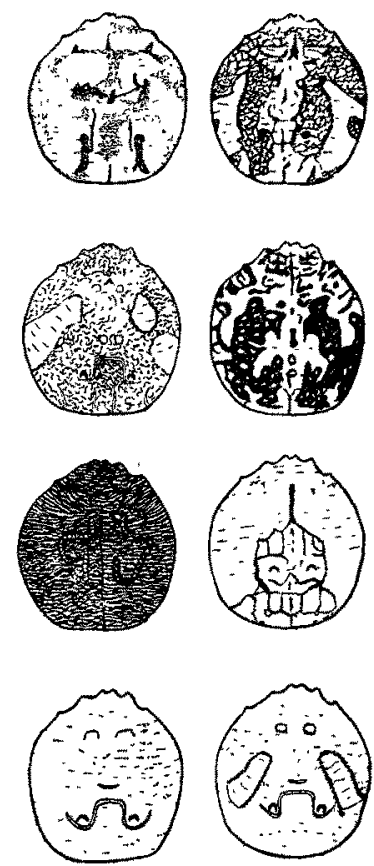

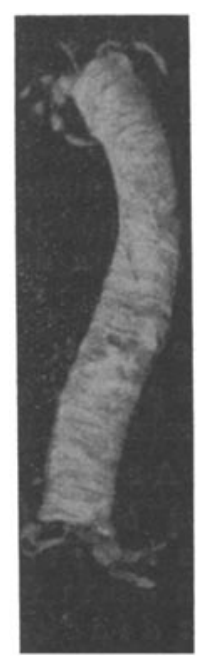

Abb. 7 Zwei Eupagurus in einer Polychaeten. röhre (Hydroides). Röhrenlange $1,7 \mathrm{~cm}$ Lebendaufnahme.

Abb. 6 Porcellana longicornis. Zeichnungsmuster auf dem Carapax.

mida (4-5 mm Länge) gefunden. Wie bereits in der Rinne festgestellt (C., S. 44), werden von jungen Eupagurus auch in Ermangelung von leeren Schneckengehäusen Röhrenbruchstücke von Sabellaria bewohnt. Abb. 7 zeigt 2 Einsiedlerkrebse, die sich beide in einer Röhre des Polychaeten Hydroides norvegicus niedergelassen haben, jeder an einem Ende. Die Fortbewegung der beiden Krebse' war natürlich sehr erschwert, da jeweils der stärkere den schwächeren mitzieht. So können sie auch unmittelbar an einem in eine Versuchsschale gegebenen Stück Muschelfleisch vorbeilaufen, wenn der stärkere im Augenblick die falsche Orientierung hat oder durch seinen Gegenspieler abgelenkt wird. 
Leichter als Schneckengehäuse verlassen die Krebse ihre Röhre und klettern an dieser herum, in die sie aber stets wieder zurückkehrten. Die Wohnung wurde jedoch bald gewechselt, als zwei leere Schneckengehäuse in das Becken gegoben wurden.

Eb a lia cra nchi Leach. 2 Expl, von der Austernbank (Stat. 3 und 41); auch in Dretschfängen nicht selten; in den umliegenden Gebieten fehlend.

$\uparrow M a c r o p a d i a$ rostrata (L.). Gelegentlich in Kurrenfängen von der Austernbank.

* H y a s arane us (L.). In Dretsch- und Kurrenfangen von der Austernbank häufig.

Corystes cassivela unus (Penn.). I Stück von Stat. 29; $1 \mathrm{~cm}$ Carapaxlänge.

Portunus pusillus Leach. Diese in der Rinne häufige, sonst in der südlichen Nordsee fehlende Art ist auch auf der Austernbank nicht selten - mit ein Beweis für die faunistische Zusammengehörigkeit der beiden Gebiete.

$P_{0}^{\circ}$ rt $u$ us holsatus Fabr. Im Bodengreifer 1 Expl. von Stat. 7 ; in Dretschfängen von der Austernbank große Krebse. I Stück von Sacculina befallen.

C a $n$ c $е r$ p a gurus L. Auf die Austernbank beschränkt, hier nicht selten. In Dretschfängen sehr große Exemplare. Im Juli sind junge Krebse von $0,5-2,3 \mathrm{~cm}$ zu finden.

†P $P l u m n$ is $h i r l e l l u s$ (L.). Von Hinricas früher einige von der Austernbank notiert.

†P $i$ n noteres pis $u$ m (L.). Von HenRrous mehrfach auf der Austernbank in Modiola festgestellt: $1894 ; 1898(\%) ; 1910(\hat{\sigma}+q)$. Wahrscheinlich ist der „Muschelwächter" häufiger, nur schwer aufzufinden.

Endobiose-Art:

inmaceae.

$D i a s t y l i s$ rathkci (Kröyer). 14 Stuck von 7 Stationen, bis 4 in einom Fang. Austernbank und nähere Umgebung, auch in dèn weichen Schlickbóden.

\section{Isopoda: Epicartda.}

Pse udione borealis Caspers (1939). Diese neue parasitische Epicariden-Art fand ich zuerst auf der Austernbank im Kiemenraum von Callianassa subterranca. Spater wurde die Art noch an Callianassa aus dei Tiefen Rinne und verschiedenen Töilen der südlichen Nordsec festgestellt. Ein Weibehen von der Austembank enthielt im Oktober 1938 weitentwickelte Eier, in denen schon Einzelheiten des Epicaridiums zu erkennen waren (s CaseErs, 1939, $\mathrm{S}$ 239). Der Befall von Callianassa ist gering (auf der Austernbank 3 von 20). Die Parasiten sind beim Wirtskrebs leicht an der starken Aufschwellung des Kiemenraumes zu erkennen. In diesem ist das 3-5 $\mathrm{mm}$ lange Weibchen, zwischen dessen Pleopoden das Mannchen sitzt, dicht an die Kiemen angeheftet. Bisher konnte an Callianassa nur cin einseitiger Befall testgestellt werden.

Endobiose-Art:

\section{Amphipoda.}

Phot is longicaudata (Sp. Bate). Nur 1 Expl. von Stat. 42, während die Art in der Rinne sehr häufig ist.

Epibiose-Arten:

*Corophium bonelli. In Dretschfängen.

Ampeliscabrevicorn $i$ s (Costa). In einem engbegrenzten Bezirk um Stat. $4-23-17$; bis 8 in einem Fang.

A mpelisca di ad e ma (Costa). Uberall der häufigste Amphipode, bis 15 Stuck auf $3 /{ }_{10} \mathrm{qm}$.

A mpelisca spinipes Boeck. 2 Expl. von Stat. 10.

* Podoceropsis excavat a Sp. Bate. In Dretschfang von der Austernbank. Mösius gibt für die Austernbank noch an: $\uparrow$ Caprella linearis $L$.

Epibiose-Arten:

Pantopoda.

Nymphon rubrum Hodge. 1 Expl. von Stat.4. Von Schlotтxe (1932) nicht auf der Austernbank gefunden, aber vermutet.

Schlotrke (1932) stellte auf der Austernbank noch folgende Arten test:

$\dagger A$ noplodactylus petiolatus (Kröyer). Häufigste Art.

†A m mothea echinata (Hodge). Einige.

Endobiose-Arten:

Lamellibranchia.

$N u c u l a$ n ucleus L. Die Art zeigt im Umkreis der Austernbank ein äuBerst scharf begrenztes Gebiet der Verbreitung, innerhalb dessen die Muschel aber in größerer Zahl zu finden ist (s. Abb. 8). Letzteres trifft besonders für den Osten des Verbreitungsgebietes 
zu, wo sich ein deutliches Kerngebiet erkennen läBt, dessen Grenze streckenweise unmittelbar mit der Grenze des Verbreitungsgebietes überhaupt zusammenfällt. Im Kerngebiet liegen die Stationen $3-10-41$, wo sich bis 26 Stück auf $1 / 10$ qm fanden. Das gesamte Verbreitungsgebiet weist eine weit nach Westen reichende Zunge auf, die sich über verschiedene Bodenformationen erstreckt und direkte Verbindung mit der Rinne besitzt. Die Gesamtfläche des von $N$. nucleus im Umkreis der Austernbank besiedelten Gebietes ist aber recht gering, bedingt durch die kleine Ausdehnung der Bank, mit der sich ja das Kerngebiet deckt, und deren Fauna durch das Vorkommen dieser Muschel als zur gleichen Lebensgemeinschaft wie die der Rinne gehörig gekennzeichnet ist. Über Nahrungsaufnahme und Darmverlauf s. CAspers (1939); vgl. ferner Abschn. D III 1 und 2.

Entsprechend den Verhältnissen in der Rinne im August 1936 (C. S. 55) war auf der Austernbank in diesem Monat neben den alten vorjährigen Muscheln Junggut von vorwiegend $3 \mathrm{~mm}$ (bis $5 \mathrm{~mm}$ ) Länge festzustellen, das im Oktober auf vorwiegend $5 \mathrm{~mm}$ (bis $6 \mathrm{~mm}$ ) herangewachsen war, während die ältesten Muscheln nun bis $11 \mathrm{~mm}$ maßen, wie aus folgender Aufstellung zu ersehen ist (Zahl der gemessenen Muscheln: 148).

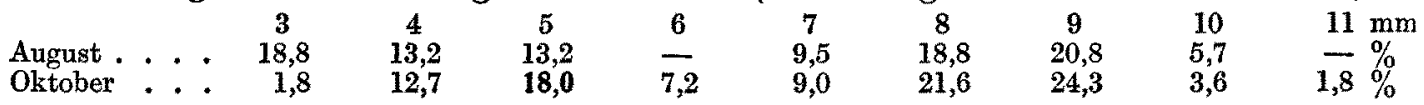

$N u c u l a$ nitida Sow. Das Gebiet dieser in ihrer Verbreitung stark von N. nucleus sich trennenden Art liegt in der Zone des weichen. Schlicks um Stat. 8 und 20 (bis 20 Stück auf $1 /{ }_{10} \mathrm{qm}$ ), wo es hart an das $N$. nucleus-Kerngebiet stöBt, ohne daß doch eine Vermischung eintritt (s. Abb. 8). Im Norden des $N$. nucleus-Verbreitungsgebietes fand sich N. nitida nur einmal bei Stat. 30. Verbreitung der Schalen im Sediment s. Abschn. D IV 3. Im Oktober waren bis $6 \mathrm{~mm}$ messende Tiere vorhanden, ferner einige Jungbrut.

T e ll im y a ferrug in o s a (Mont.). Nur 1 Stück bei Stat. 25. Hier zusammen mit 6 Monta cuta bidentata. Schalen im ganzen Umkreis der Austernbank, auf dieser selbst jedoch fehlend.

M o.n tacuta, bidentata (Mont.). Im Schlick besonders im Südosten der Austernbank, bis 17 Stück auf 1/10 qm (Stat. 8). Einige auch im Norden und Süden des Nucula nucleusGebietes, mit dem aber nur eine geringe Vermischung stattfindet. Größe 3-4 mm.

[Lepton squamosum (Mont.).] Nur 1 Schale von Stat. 10 (det. Herting).

$C a r d i u m$ fasciatum Mont. Nur 1 Muschel von Stat. 4. Auch von Herncke auf der Austernbank gefunden.

Cardium echinat $u$ m L Von Heincke auf der Austernbank festgestellt. Große Schalen auf dieser und im umliegenden Gebiet nicht selten (bis 4,6 cm). Oft vom Bohrschwamm angefallen.

$C a r d i u m$ ed $u l e \mathrm{~L}$. Lebendfunde von der Austernbank werden von Heincke angegeben. Auf dieser und im weiteren Umkreis finden sich recht regelmäßig, aber in nur geringer Zahl, Schalen, z. T. von großen Exemplaren.

[Cyprina islandica (L.).] Im Gebiet der Austernbank wenige Schalen.

Thyasiraflexuosa (Mont.). Je 1 Muschel von Stat. 29 und 38. Schalen auch bei Stat. 7.

Chi o ne o v a ta (Penn.). Nur wenige auf der Austernbank (l auf $1 / 10$ qm). 9 Stück bei Stat. 26, dem Übergangsgebiet zur Rinne. Hier auch die größte Menge von Schalen im Siebrest, während diese in den übrigen Stationen auch selten sind. Im Oktober ein stärkerer Anteil von Jungbrut $(4 \mathrm{~mm})$; die größte. Muschel maß $14 \mathrm{~mm}$.

$C h i o n e$ gallina (L.). Im ganzen Umkreis der Austernbank mit ziemlicher RegelmäBigkeit anzutreffen, jedoch meist nur 1 auf $1 / 10 \mathrm{qm}$, selten bis 3. Das Nucula nucleus-Gebiet aber wird gänzlich gemieden (vgl. Abb. 8). Im Oktober viele Jungmuscheln von 3-4 mm. Die Verbreitung der Schalen entspricht der der lebenden Tiere.

[Lucinopsis undata (Penn.).] I Schale von Stat. 33, also auf reinem Sandboden.

Tapes pullastra (Mont.). Im Bodengreifer fand sich bei Stat. 41 und 42 je 1 Exemplar $(1,5$ und $5 \mathrm{~cm})$. Auch in Dretschfängen von der Austernbank werden lebende Mus heln - allerdings nicht häufig - heraufgebracht. Schalen sind im Sediment in größerer Zahl vorhanden (vgl. Abschn. D IV 3). Auch Herncke gibt die Muschel bereits als typisch für die Austernbank an; dagegen fehlt sie in der Rinne!

[T a pes virgineus (L.)?] Ein kleines Gehäuse von Stat. 10 (det. Herturng, Bestimmung nicht ganz sicher).

T e ll ina pus ill a Philippi. 1 Stück (det. Hertuina) von Stat. 23. Bei dieser Station und ferner bei Stat. 40 auch Schalen im Sediment. 
$S$ y $n d$ os $m$ y a a $l b$ a (Wood). Im ganzen Gebiet verbreitet, aber sehr fleckenweise. 6 Stück bei Stat. 4 und bis 9 bei Stat. 41. Größe bis $13 \mathrm{~mm}$, im Oktober auch viele Jungmuscheln von $5 \mathrm{~mm}$.

$S$ y ndosm y a prismaticà (Mont.). Nur bei Stat. 5 und 6 je 3 Stück in 1 Fang; 10-12 mm. Im Siebrest Schalen stellenweise nicht selten.

[Psammobia ferroensis (Chemn.).] Im Siebrest von Stat. 18 und 40 gefunden, ferner Schalen im Dretschfang von der Austernbank.

Cultellus pellucidus (Penn.). Die Art bewohnt die sandig-schlickigen Gebiete und wurde in geringerer Zahl auch auf der Austernbank festgestellt. In den übrigen Gebieten finden sich durchschnittlich $2-3$ auf $1 / 10 \mathrm{qm}$, als Höchstzahl 5. Das Vorkommen ist recht regelmäßig. Die reinen Sandgebiete (um Stat. 33 und im Norden) werden gemieden, ebenso das Gebiet des zähen Schlicks um Stat. 7-19-24. Die Muscheln hatten im Oktober eine Durchschnittslänge von $20 \mathrm{~mm}$; daneben treten im August $6 \mathrm{~mm}$ lange Stücke auf. Im Oktober ist die MindestgröBe $10 \mathrm{~mm}$, die längsten Muscheln messen $30 \mathrm{~mm}$.

Ensis siliqua (L.). Charaktermuschel der Loreleybank (s. Abschn. D III $4 \mathrm{~d}$ ). Eine $10 \mathrm{~cm}$ lange lebende Muschel aber auch bei Stat. 12. Schalen ferner vereinzelt bei den südlich an die Loreleybank grenzenden Stationen.

$S p i s$ ula solida (L.). Verbreitung ähnlich wie die von Corbula (s. unten), ohne daß jedoch ein eigentliches Zentralgebiet festzustellen ist. Die von Nucula nucleus besiedelten Zonen werden völlig gemieden: s. Abb. 8. Größe bis $9 \mathrm{~mm}$. Schalen überall häufig, wenige nur im Gebiet der Austernbank.

Spis ula subty un cata (da Costa). Nur 2 Stück bei Stat. 8. Größe bis 14 mm. Schalen ebenfalls selten.

[Mactra stultorum L.] 1 Schale von Stat. 6 (det. Hertuing).

$S$ a $x i c a v a$ rugosa (L.). Nur 1 Stück in einem Fang von Stat. 41. Schalen besonders im Übergangsgebiet zur Rinne, aber auch auf der Austernbank.

[Arcinella plicata (Mont.).] Je 1 Schale von Stat. 7, 24, 38 und 42.

M y a are naria L. Je 1 bei Stat. 2, 8 und 41. Es handelt sich um junge Stücke von 3,8 bis $19 \mathrm{~mm}$. Wahrscheinlich gehen die größeren Muscheln später ein.

M y a tr un c a ta (L.). Im Umkreis der Austernbank in 5 Stationen je 1 Stück, 16-30 mm. Auch größere Stücke werden wohl vorkommen. Schalen im Siebrest selten, vorwiegend von dieser Art.

Co r bula gibba (Olivi). Für die Art kann ein Gebiet der Hauptverbreitung in der Zone des weichen Schlicks um Stat. $19-20-24$ angegeben werden, wo sich bis 38 Stück auf $1 /{ }_{10} \mathrm{qm}$ fanden. Sonst ist die Muschel in allen Teilen verbreitet, wo der Boden Schlickbeimischung enthält, sie meidet jedoch die eigentliche Austernbank (vgl. Abb. 8). Ebenso sind die Schalen im Sediment überall im Umkreis der Bank anzutreffen, besonders gehäuft jedoch in der Zone der Hauptverbreitung der lebenden Muscheln.

Während die Jungbrut im August menganmäßig noch keine Rolle spielt, finden wir im Oktober einen größeren Anteil der Größenzusammensetzung bei $4 \mathrm{~mm}$, wie aus nachfolgender Aufstellung zu ersehen ist (Zahl der gemessenen Muscheln: 82):

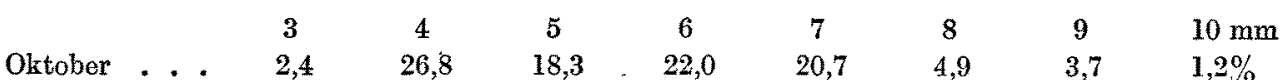

Wieweit die ebenfalls in größerer Menge vorhandenen 6-7 $\mathrm{mm}$ großen Muscheln bereits geschlechtsreif sind, ist nach dem vorliegenden Material nicht festzustellen.

[Thracia papyracea Poli.] 3 Schalen im Siebrest von Stat. 14 und 40.

Epibiose-Arten:

* Ostrea ed ulis L. 1938 wurden auf der Austernbank 10 lebende Austern gefangen. Die Schalen im Sediment sind auf der Bank außerordentlich häufig, im Umkreis jedoch nur gelegentlich anzutreffen. Über frühere Häufigkeit usw. vgl. Abschn. C; Bewuchs s. Abschn. D III 5 c $\beta$.

*Mytilus edulis $\mathcal{L}$. Eine $1 \mathrm{~cm}$ lange Muschel im Dretschfang von der Austernbank an Hydrallmania festgesponnen in $25 \mathrm{~m}$ Tiefe. HeINoxe (1894) gibt $M$ ytilus mit als typisch für die Austernbank an, was aber fraglich erscheint, da dann Schalen im Sediment häufiger sein müßten.

*Modiola modiol us (L.). Große Muscheln in Dretschfängen, Schalen im Siebrest nicht selten. Auch von Hexncke als typisch für die Austernbank angəgeben.

†Modiolaria marmorata (Forb.). Von Heincke auf der Austernbank festgestellt. 
$+C h l a m y s$ opercularis (L.). Nach Notizen von Hinrichs 1 lebende Muschel 1904 von der Austernbank. Schalen im Sediment der Bank selten (vgl. Abschn. D IV 3). Auch lebend werden heute wohl noch einige hier - wenigstens in einzelnen Jahren - vorkommen, wenn auch Funde aus der letzten Zeit nicht bekannt sind.

[Chlam ys y a $y i a$ (L.).] Schalen im Sediment der Austernbank etwas häufiger als von der vorigen Art (vgl. Abschn. D IV 3). Lebendfunde sind nicht bekannt; aber wohl möglich. Die Schalen sehen z. T. sehr frisch aus.

f[Chlamys tigerina (Müll.).] Nach Herturng vor 1900 einige Schalen auf der Austernbank gesammelt.

PA nomia patelliformis L. Von Herncke für die Austernbank angegeben, in deren Umkreis gelegentlich Schalen im Siebrest zu finden sind. Eine Häufung der Schalen auf der Bank.

†in omia ephippium L. Von Hencke auf der Austernbank gefunden. Möbrus gibt für die Austernbank noch an: †Macoma baltica (L.).

Epibiose-Art:

Placophora.

fLepidopleurus ásellus (C. Spengler). Von Hexncke für die Austernbank als begleitende Form angegeben. Von mir wohl nur durch Zufall nicht getunueu.

\section{Gastropoda.}

Endobiose-Arten:

\section{Prosobranchia.}

Turritella communis Lam. 1 lebende von Stat. 25. Gehäuse in geringerer Zahl im ganzen Umkreis der Austernbank.

Scal a clathrus (L.). Je I von Stat. 42 und 43 ; ferner in Dretschfängen. Ist von Herncke bereits auf der Austernbank festgestellt und für diese als typisch angegeben worden (sonstige Verbreitung vgl. C., S. 48).

[S cala clathrula (Kanm.).] Von dieser sonst isoliert in der Rinne vorkommenden Art (s. C., S. 91) fand sich bei Stat. 6 und 10 je 1 Gehäuse.

Epibiose-Arten:

[Gibbula $t$ umida (Mont.).] Gehäuse dieser für die Rinne charakteristischen, sonst in der Deutschen Bucht fehlenden Schnecke wurden auch bei den meisten Stationen in der Umgebung der Austernbank wie auf dieser selbst gefunden, jedoch meist nur 1-3 auf

$1 / 10 \mathrm{qm}$. Auch lebende Tiere werden hier wohl noch gelegentlich auftreten.

[Ma nzonia costata (J. Adams).] 1 Gehäuse von Stat. 40 (det. Herteing).

H y a lavitrea (Mont.). Die 1936 in der Rinne gefundene Muschel stellte zusammen mit einer $1932 \mathrm{NW}$ von Helgoland gefangenen den ersten Lebendfund in der südlichen Nordsee dar. Meine Vermutung (C., S. 49), daß die Art in der Rinne häufiger ist, nur meist wegen ihrer Kleinheit übersehen wird, gewinnt an Wahrscheinlichkeit durch den Fang von 20 lebenden $H$ yala in einer Bodengreiferprobe von der Austernbank (Stat. 3); ferner wurde 1 lebende noch bei Stat. 24 festgestellt. Die Länge der Schnecken war durchweg $3 \mathrm{~mm}$ (Oktober 1938).

[Lacuna divaricata (Fabr.).] Gehäuse im Siebrest von Stat. 10 (det Hertuing).

[L itorina litorea (L.).] Gehäuse in Dretschfängen, selten. Von Eupagurus bewohnt.

[Litorina obtusata (L.).] Ein von Eupagurus bewohntes Gehäuse.

[Bittium reticulatum (da Costa).] Gehäuse bei Stat. 25 und 26, also vom Übergang zur Rinne, ferner von Stat. 40.

I unatia nitida (Don.). Diese in der Rinne häufige Raubschnecke wurde nur einmal bei Stat. 25, also am Abfall zur Rinne, lebend gefunden. Gehäuse finden sich - jedoch nur in geringer Zahl - bei fast allen Stationen, ferner weisen die im Sediment der Austernbank liegenden Muschel- und Schneckenschalen häufig Bohrlöcher auf, so daß Lunatia in anderen Jahren hier wohl auch häufiger lebend anzutreffen sein wird.

$B u c c i n u m u n d a t u m \mathrm{~L}$. In Dretsch- und Kurrenfängen große Stücke. Die Besiedlungsdichte ist aber gering; in einem Kurrenzug von 20 Minuten werden etwa 25 Stück gefangen. Sehr häufig sind die - meist von Eupagurus bewohnten - Gehäuse. Besonders in den Wintermonaten viele Laichballen.

[Nassa incrassata (Ström).] Einige Schalen auf und im Umkreis der Austernbank. 
Lora turqicula (Mont.) Schon von Heincke für die Austernbank angegeben. In den Bodengreiferfängen fanden sich 8 lebende Schnecken yon den Stationen 4-9-28$29-32-36$, also vom Gebiet zwischen Austern- und Loreleybank. Aus dieser Zone auch einige Gehäuse im Siebrest, ferner von Stat. 25.

tPhilbertia li nearis (Mont.). Im Siebrest der Austernbank nicht selten. Dagegen wurden auch wie in der Rinne keine lebenden Tiere gefangen. Es ist daher anzunehmen, daß die Art in den letzten Jahren ausgestorben ist. Von Herncke wird sie als typisch für Rinne und Austernbank angegeben.

\section{Opisthobranchia.}

Endobiose-Art (Tectibranchia):

Cylichna $c y l i n d r a_{\alpha} c$ e a Penn. Findet sich im ganzen Umkreis der Austernbank in schlickigen Böden, bis 3 in einem Fang. Im Gebiet der Nucula nucleus-Verbreitung gänzlich fehlend.

E pibiose-Arten $(N u d i b r a n c h i a)$ : det. Hertulang.

*Tritonia plebeja Johnston. In Dretschfängen von der Austernbank die häufigste Art. In der Rinne noch nicht gefunden.

†T ritonia hombergi Cuvier. Ist nach Mitteilung von Hinrichs im August 1921 auf der Austernbank gefunden worden.

* La me llid oris bila me ll a ta L. Auf der Austernbank nicht selten; auch von HEINCKE: für diese angegeben und in früheren Jahren bei Dretschfängen oft gefunden.

Coryphella andsburgi (Alder u. Hancock). I Expl. im Dretschfang, ferner 1 junges Tier von Stat. 41.

A e o lidi el l a n. sp.? Heincke. 1 Expl. Stat. 41. Diese schon früher auf der Austernbank gefundene Nacktschnecke hält Herturvg für die von Heincke 1897 beschriebene Aeoli. diella n. sp.? Das bisherige Material reichte aber nicht aus, um die Sicherstellung der Art zu ermöglichen.

Hervcke (1894 und 1897) gibt noch folgende Arten für die Austernbank an:

$\dagger$ Lamellidoris muricata Müller.

+Polycera quadrilineata Müller.

Amphorina coerulea Mont. Bisher einziger Fundplatz in der Nordsee.

† Cratena longicaudata Heincke.

Endobiose-Arten:

Phoronidea.

Phoronis mülleri de Selys-Longchamps. Die Verbreitung und Ortsdichte ist in Abb. 9 dargestellt. Beim Vergleich mit der Bodenkarte (Abb. 3) ist deutlich die Beschränkung auf die schlickigen Gebiete zu erkennen, wo die Ortsdichte proportional zur Höhe der Schlickbeimischung ist. Das Hauptgebiet im Südosten fällt mit dem Kerngebiet der Amphiura-Verbreitung (Abb. 8) zusammen. Gänzlich von der Art unbesiedelt bleiben die sandigen Gebiete; auch die Austernbank weist nur an ihrem südöstlichen Rand eine geringe Beimischung auf.

$\dagger P$ horonis gracil $i s$ v. Beneden. Nach Mitteilung von Hinrichs im Juli 1935 in 2 Austemschalen von der Austernbank.

Epibiose-Arten:

Bryozoa.

Cris $i$ a eburnea (L.). Verschiedene kleine Stöcke auf Muschelschalen und Hydroiden. $\dagger B u g u l a$ plumosa (Pall.). Angabe von Hinrichs.

Mcmbranipora pil.osa (L.). Kleine Uberzüge auf Sertularia und Muschelschalen.

Mcmbraniporareticulam (L.) (M. lacroixii[Aud.]). Auf Muschelschalen und Steinen. Aspidclectra ne lo lontha (Busk.). Bei Stat. 40 kleine Überzüge auf Muschelschalen.

* Fl ustra foliacea (L.). GroB॰ Büschel in Dretschfängen von der Austernbank.

Eucratea loricata (L.). Eine kleine Kolonie von Stat. 3.

* A l c y o nidiumparasiticum (Flem.). Überzüge an Hydrallmania von der Austernbank. Möвıus (1893) gibt ferner an: †Bicellaria ciliata (L.) und †Scrupocellaria scrupea Bsk.

Endobiose-Arten:

\section{Echinodermata.}

* A stropecten irregularis (Penn.). Nicht häufig, aber regelmäßig in Dretschfängen von der Austernbank; bis 25 in einem Zug ron 20 Minuten Dauer (Kurre) über die Bank weg. 
A mphiura filiformis (O. F. Müller). Wio Abb. 8 zeigt, ist ein deutliches Kerngebiet um die Stationen $1-2-8-9 \mathrm{zu}$ erkennen, wo bis 34 Stück auf $1 / 10 \mathrm{qm}$ vorkommen (Stat. 2 und 9). Zahlen über 10 sind dann nur noch inselartig anzutreffen, so bei Stat. 11, wo 13 Amphiura zusammen mit 2 Nucula nucleus auftraten. Auch die übrigen Stationen im Nucula nucleus-Kerngebiet weisen noch 3-5 Amphiura in einem Fang auf. Das Amphiura-Kerngebiet schließt unmittelbar an das $N$. nucleus-Kerngebiet an, und zwischen beiden besteht eine schroffe Grenze. Auch im Norden finden sich dicht neben der $N$. nucleus-Zone bei Stat. 16 noch 10 Amphiura zusammen mit 2 Nucula nitida in einer Bodengreiferprobe. Sonst sind nur noch bei Stat. 25 über 10 Amphiura (13 Stück) in einer Probe zu finden. Für den Schlangenstern kann ein Randgebiet angegeben werden, das sich über das Nucula nucleus-Zentralgebiet und dessen Umgebung hinzieht, wie in $\mathrm{Abb} .8$ dargestellt ist. Im Westen wird jedoch das Sandgebiet völlig gemieden. Charakteristisch sind 2 weite Ausbuchtungen: 1. nach Norden bis zur Stat. 36. Diese Zone fällt mit einem Gebiet etwas sandärmeren Schlicks zusammen, das sich über die $30 \mathrm{~m}$ tiefe Zone hinzieht (vgl. Abb. 3), jedoch nicht deren ganze Sohle einnimmt. Der Mittelpunkt ist bei Stat. 37. - 2. eine Zunge nach Sudwesten, die ungefähr mit de: gleichen Ausbuchtung des $N$. nucleus-Gebietes zusammenfällt, jedoch auch hier die östlichen sandigeren Zonen meidet.

Außerhalb dieses Amphiura-Verbreitungsgebietes findet man den Schlangenstern nur gelegentlich und dann auch nur selten über 1 Stück auf 1/10 $\mathrm{qm}$.

Die in nachfolgender Aufstellung angegebenen Hundertsätze der einzelnen Größen für August und Oktober 1938 (Zahl der gemessenen Tiere: 207) zeigt, daß bereits im August ein Anteil von ganz jungen Bodenstadien vorhanden ist (1 $\mathrm{mm}$ Scheibendurchmesser), der auch noch im Oktober zusammen mit den bereits auf $2 \mathrm{~mm}$ herangewachsenen Tieren deutlich erkennbar ist. Wie in der Rinne (C., S. 58) sind von den vorjährigen Schlangensternen im August solche mit einem Scheibendurchmesser von $5-6 \mathrm{~mm}$ am reichsten vertreten, wie auch noch im Oktober. Der neue Brutfall hatte aber in den 1938 unter. suchten Gebieten nicht die Stärke wie 1936 in der Rinne.

$\begin{array}{lccccccc}\text { Scheibendurchmesser: } & 1 & 2 & 3 & 4 & 5 & 6 & 7 \mathrm{~mm} \\ \text { August }: \therefore & 4,0 & - & 0,8 & 14,4 & 36,0 & 36,0 & 8,8 \% \\ \text { Oktober }: \cdots & 3,7 & 6,1 & - & 171 & 48,7 & 22,0 & 2,4 \%\end{array}$

$\uparrow$ tAphipholis squamata (D. Chiaje). Ist von Hagrerer im Dezember 1925 bei Boden. greiferfängen von der Austernbank (vgl. Abschn. D IV 2) gefunden worden. Auch von Mösius angegeben.

Ophi ura a $l b i d$ a Forbes. Wie in der Rinne kann dieser Schlangenstem im Umkreis der Austernbank keiner Gemeinschaft gesondert zugeschrieben werden; er ist fast in allen Stationen vertreten, bis 19 Stück auf $1 / 10 \mathrm{qm}$.

In der Rinne war im September 1936 ein Gipfelpunkt der Größenkurve (Scheibendurchmesser) bei $1 \mathrm{~mm}$ als Zeichen des stattgefundenen Brutfalls festzustellen (s. C., S. 57). Wie aus folgender Aufstellung zu ersehen ist (Zahl der gemessenen Tiere: 117), hatte auch im Umkreis der Austernbank im Oktober 1938 über die Hälfte der Tiere einen Scheibendurchmesser von $1-2 \mathrm{~mm}$, wie es ebenso die Größenkurve vom Januar und April aus der Rinne zeigt. Während im August noch Tiere mit $12 \mathrm{~mm}$ gemessen wurden, fehlen diese im Oktober bereits ganz, und auch die übrigen älteren Ophiura sind stark im $\mathbf{A b}$ nehmen begriffen.

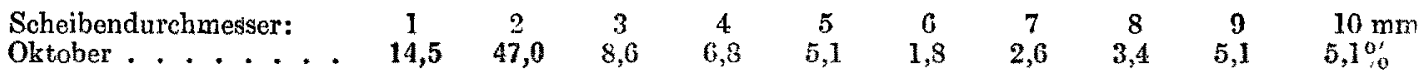

Spatang us purpureus O. F. Müller. Selten. In Kurren- und Dretschfängen von der Austernbank.

Echinocardium cordatum (Penn.). Am regelmäBigsten ist das weiche Schlickgebie, im Südosten der Austernbank besiedelt (Amphiura filiformis-Kerngebiet), wo sich je: doch meist nur 1 Stück auf $1 / 10 \mathrm{qm}$ findet. Ferner ist der Seeigel in den übrigen Teilen mit schlickiger Beimischung vertreten, meidet jedoch gänzlich das von Nucula nucleus besiedelte Gebiet (s. Abb. 8).

Im August findet man die jungen Bodenstadien, die im Olstober auf $0,8-1,1 \mathrm{~cm}$ herangewachsen sind. Zwei Drittel der in dieser Zeit im Greifer enthaltenen Echinocardium werden von diesen jungen Tieren gebildet. 
Epibiose-Arten:

* Solaster papposus (L.). Der sonst in der Deutschen Bucht seltene Sonnenstern zeigt auf der Austernbank eine große Häufigkeit, was seine Ursache in dem harten Bodengrund der Bank haben mag, den die Art bevorzugt. Die größten haben einen Scheibendurchmesser von $8,5 \mathrm{~cm}$.

As $t c r i a s \gamma t b c u s \mathrm{~L}$. In Bodengreiferfängen 4 Stück von der Austernbank und deren nächsten Umgebung; auf der Bark in Dretschfängen große Exemplare. In allen übrigen Gebieten fehlend. Von Juli bis Oktober junge Tiere von 1,7-7 mm Scheibendurchmesser.

Ophiothrix fragilis (Abbildg.). In großen Mengen zwischen dem Schill der Austernbank, während die Art in der Rinne seltener ist.

Psammechinus miliaris (Gmel.). Dieser am Nordhang der Rinne häufige Seeigel wurde auch in 6 Bodengreiferfängen von der Austernbank und deren nächsten Umgebung gefunden: Höchstzahl in einem Fang 3. Diese Art ist ferner in großer Zahl in Dretschproben von der Bank zu fangen; der Durchmesser beträgt höchstens $11 \mathrm{~mm}$.

* E chinus esculentus (L.). RegelmäBig und in sehr groBer Zahl in Dretsch-und Kurrenfängen von der Austernbank. Die Häufigkeit überwiegt hier bei weitem die der Tiefen Rinne: In einem Kurrenzug von 20 Minuten quer über die Bank weg wurden bis 150 Stück gefangen! Bis $10 \mathrm{~cm}$ Durchmesser.

Echinocyamus pusillus (O. F. Müller). Im Gegensatz zur Rinne ist die Art wohl in einem großen Gebiet, aber doch nicht in allen Stationen und nur in sehr geringer Stückzahl anzutreffen. Die gröBte Zahl von 7 auf $1 / 10 \mathrm{qm}$ fand sich bei Stat. 26, die im Übergangsgebiet zur Rinne liegt.

Auch 1938 war kein begrenztes Auftreten von Jungtieren festzustellen, so daß die für die Rinne geäuBerte Vermutung eines während des ganzen Sommers stattfindenden geringen Brutfalls (s. C., S. 60) an Wahrscheinlichkeit gewinnt.

Epibiose-Art:

\section{Tethyodea (Ascidiacea)}

*A s c id i ell l a a spers a (O. F. Müller). Früher auf der Austernbank regelmäBig.in Schleppnetzfängen, seit einigen Jahren aber - entsprechend wie in der Rinne - sehr silten. Die in der Rinne sehr häufige Dendrodoa grossularia wurde auf der Austernbank nie festgestellt!

Móвı́s gibt noch †Molgula sp. für die Austernbank an.

\section{Synökologie.}

1. Die Siedlungsgebiete.

Als kleinste Glieder einer Tiergemeinschaft sind die Siedlungen anzusehen. Diese ergeben sich durch die Verbreitung einzelner Tierarten (Leitfolmen), worauf aufbauend dann ein synthetisches Bild der Bodenbesiedlung gewonncn wird, das zur Aufstellung und Zuordnung von Biocönosen führt (vergl. auch C., S. 65-67 und Caspers, 1950).

In $\mathrm{Abb} .8$ ist die Verbreitung einzelner Arten, auf welche die Aufstellung von Siedlungen beruht, angegeben: Die Muscheln Nucula nucleus (S. 138), Nucula nitida (S. 139), Corbula gibba (S. 140), Spisula solida (S. 140) und Echinocardium cordatum (S. 143). Abb.9 zeigt noch die Verbreitung von Phoronis mülleri und der Foraminifere Astrorhiza limicola. werden:

Nach folgenden Arten können hiernach geschlossene Siedlungsgebiete gekennzeichnot

a) Die Nucula nucleus-Siedlung. Diese weist ein Kerngebiet auf der Austernbank und einen weiten Ausläufer nach Südwesten auf, der in Verbindung mit der Rinne steht.

b) Die Amphinra filiformis-Siedlung. Deutlich ist ein Kerngebiet südöstlich der Austernbank ausgebildet, an die es eng angrenzt. Ferner werden aber größere Teile der umliegenden Böden von Amphiztra eingenommen; ein weiter südwestlicher Ausläufer deckt sich stellenweise mit dem gleichgerichteten N. nucleus-Ausläufer und steht ebenfalls in Verbindung mit der Tiefen Rinne. Auch auf der Austernbank finden sich einige Amphitra in jedem Fang.

c) Die Nucula nitida-Siedlung. Diese zeigt eine große Häufigkeit südöstlich der Austernbank, wo die Siedlung sich stellenweise mit dem Amphiura-Kerngebiet deckt, während aber dei Hauptverbreitung südlich an dieses angrenzt.

d) Die Phor nis-Siedlung. Das deutlich ausgebildete Kerngebiet deckt sich mit dem von Amphiura. Für die sonstige Verbreitung ist aber keine deutliche Grenze anzugeben; stellenweise wird auch die Nucula nucleus-Siedlung mit erfaßt. 
Auch Corbula gibba zeigt eine Anreicherung im Gebiet südöstlich der Austernbank, ist jedoch zusammen mit Spisula solida, Chione gallina und Echinocardium im ganzen Gebiet um die Austernbank vertreten, während diese selbst von diesen Arten unbesiedelt bleibt.

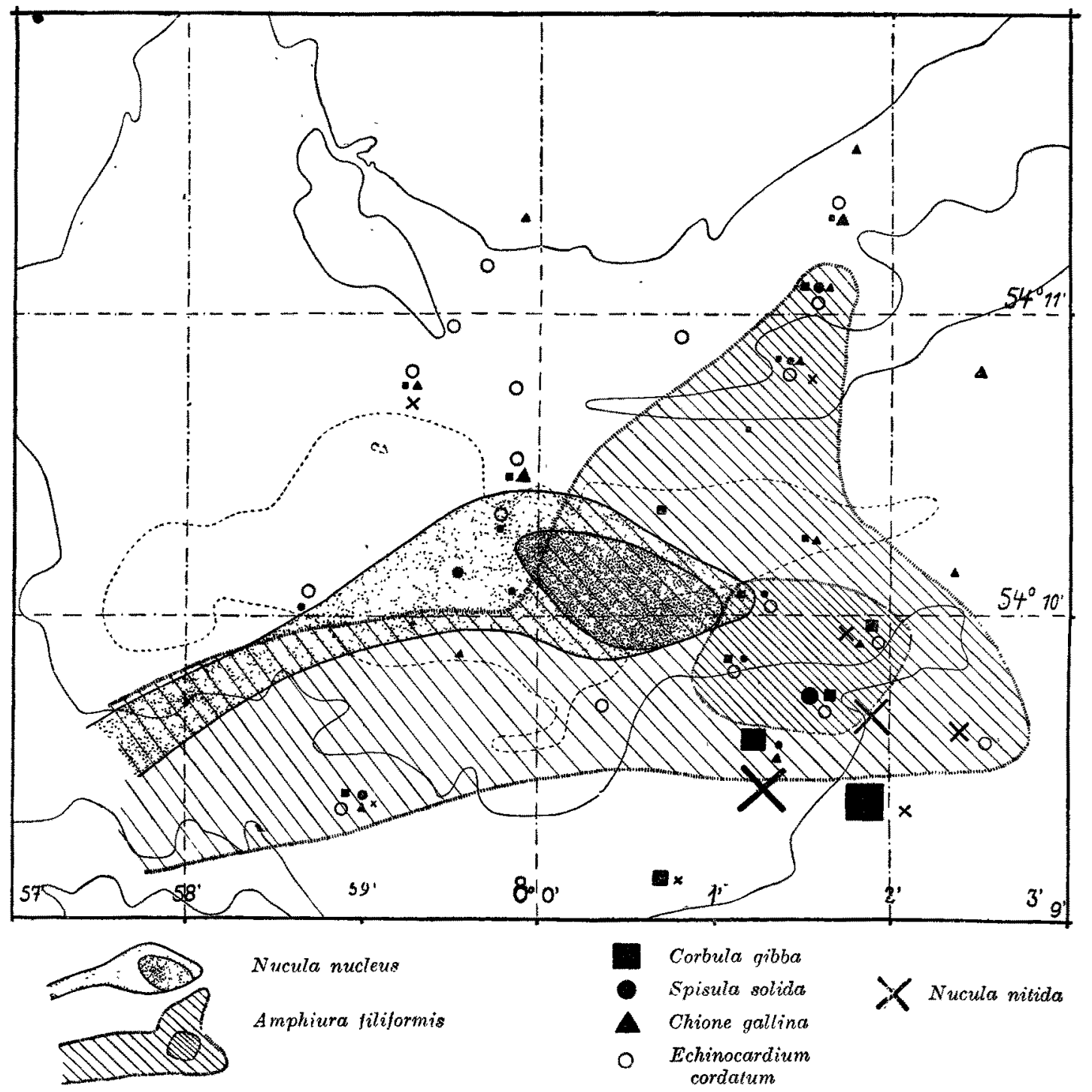

Abb. 8. Siedlungsgebiet von Nucula nucleus (mit Kerngebiet), Nucula nitida, Corbula gibba, Spisula solida. Chions gallina, Amphiura filiformis (mit Kerngebiet) und Echinocardium cordatum.

Aus der Verbreitung der genannten Arten sind bereits die Grundlinien der Faunenverteilung zu erkennen: Es hebt sich die Endobiose des Nucula nucleus-Kerngebietes hervor, die sich mit der Epibiose der Austernbank deckt, so daß diese also auch deutlich durch die Endobiose gekennzeichnet ist.

Eine Vermischung mit der Austernbank gehen von den oben besprochenen Arten nur Amphiura und Phoronis - beide aber nur in geringem Maße - ein. Die übrigen zeigen im Umkreis der Bank ein ungleichmäßiges Siedlungsgebiet, ohne daß hier jedoch scharf abgegrenzte Gebiete vorhanden wären, die die Aufteilung in mehrere Biocönosen notwendig machen würden. Wir könnendaher in dem untersuchten Meeresgebiet die Biocönose der A ustern ba $\mathrm{n}$ - auf Grund des Siedlungsbildes durch die Nucula nucleus-Endobiose charakterisiert, ferner besonders durch die Epibiose kenntlich - u n d die u m i i e ge n de

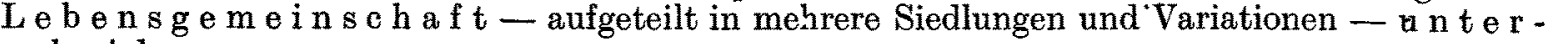
s cheiden.

Ehe die Lebensgemeinschaften als ganzes besprochen werden, sollen zunächst einige Endobiosen behandelt werden, die sich auf Grund der Siedlungs-Einteilung ergeben. 


\section{Die Xucula nudeus-Endobiose.}

Es wurde schon bemerkt, daß das Siedlungsgebiet dieser Muschel ein deutliches Kerngebiet aufweist, das mit der Epibiose der Austernbank zusammenfällt, wie auch Abb. 12 zeigt (die Austernbank ist durch die Schillanreicherung in dem Querschnitt kenntlich). Von den oben besprochenen Siedlungen zeigt nur die von Amphiura eine Überschneidung mit der von $N$. nucleus, wobei aber die Kerngebiete voneinander getrennt bleiben. Ferner weist der südliche Teil des N. nucleus-Gebietes eine geringe Beimischung von Phoronis auf.

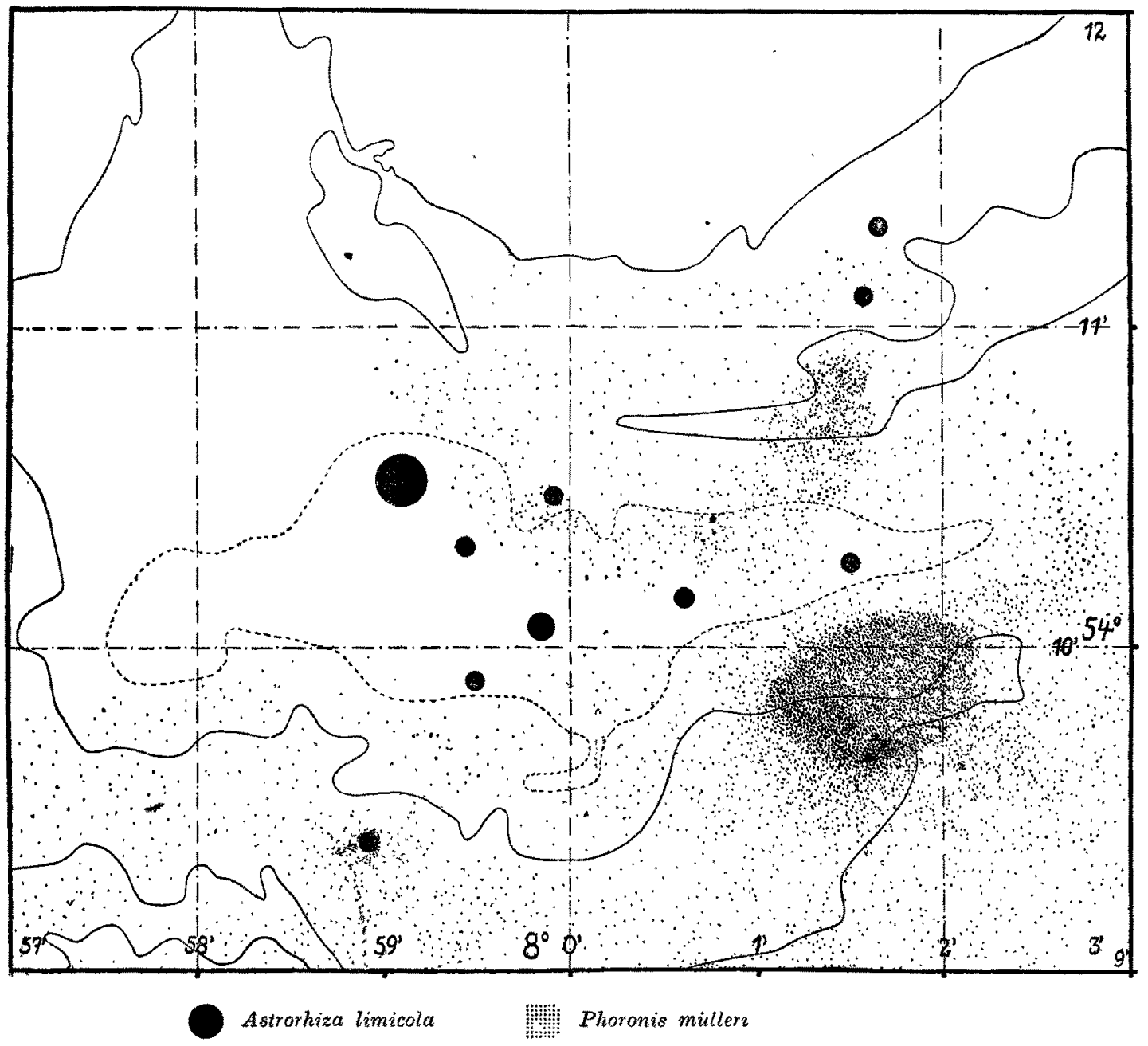

Abb. 9. Siedlungsgebiete ron Phoronis mulleri und Astromiza limicola.

a) Das Kerngebiet.

Innerhalb dieses Gebietes liegen die Stationen $3-4-10-41$. Tabelle 3 zeigt die Zusammensetzung dreier Fänge von Stat. 41, ferner je ein Fang von Stat, 3 und 4. Der Fang von Stat. 3 ist in $\mathrm{Abb} .10$ dargestellt ${ }^{1}$ ). Außer den in der Tabelle angegebenen Arten wurden in anderen Bodengreiferfängen aus dem Gebiet noch Galathea intermedea, Ampelisca spinipes, Corophium bonellii und Phyllodoce groenlandica gefunden.

Die Fänge überraschen durch ihren Arten- und Individuenreichtum (bis 210 Tiere in einem Fang, insgesamt 75 Arten), wobei sogar die Rinne übertroffen wird. Unter den Muscheln ist Nucula nucleus weitaus vorherrschend, während auch Chione ovata und Cardium fasciatum selten sind. Charakteristisch ist Tapes, die man vorwiegend in Dretschfängen findet. Als Eindringlinge von den benachbarten Gebieten müssen Montacuta bidentata, Syndosmya alba und Cultellus aufgefaßt werden. Schnecken waren in den Bodengreiferfängen nur durch Nudibranchier

1) Die Tiere sind in natürlicher Größe eingezeichnet, beim Druck verkleinert. 
vertreten. Die Polychaeten zeigen eine sehr grcße Artenzahl, besonders unter den Aphroditiden. Scalibregma ist im Sommer bis Herbst nicht selten, ferner Owenia und Lanice, deren Röhren den gleichen Aufbau wie in der Rinne zeigen. Von besonderer Häufigkeit ist Sabellaria, deren

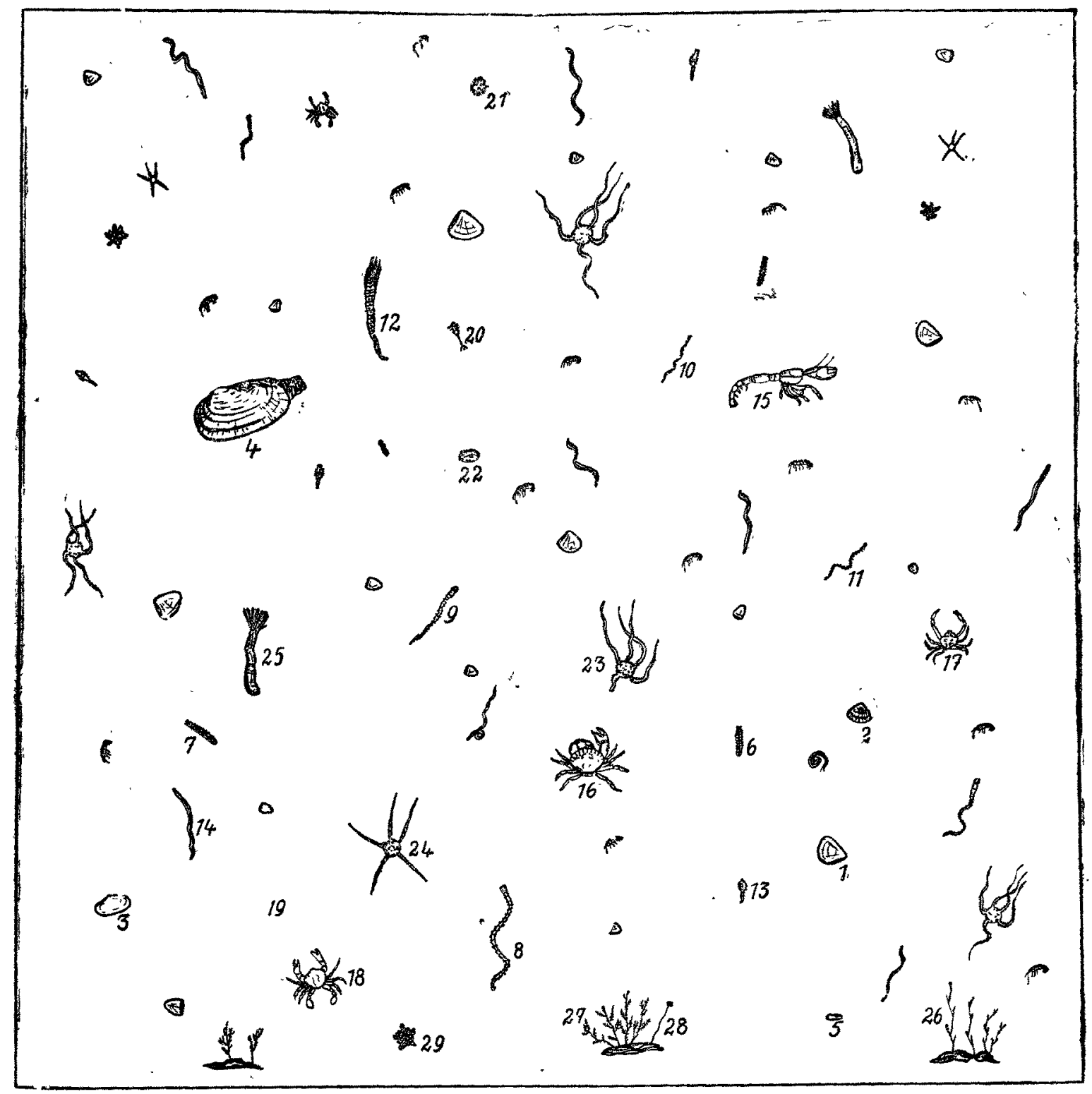

$1=$ Nucula nucleus, $2=$ Chione ovata, $3=$ Syndosmya alba, $4=M y a$ truncata, $5=$ Saxicava rugosa, $6=$ Gattyana cirrosa, $7=$ Pholoe minuta, $8=$ Nephthys cirrosa, $9=$ Glycera alba, $10=$ Goniada maculata, $11=$ Lumbriconereis impatiens, $12=$ Stylarioides plumosus, $13=$ Scatibregma inflatum, $14=$ Lineus biliniatus; $15=$ Callianassa subterranea, $16=$ Cancer pagurus, $17=$ Ebalia cranchi, $18=$ Portunus pusillus, niatus; $15=$ Callianassa subterranea, $16=$ Cancer pagurus, $17=$ Ebalia cranchi, $18=$ Portunus pusilus, $\mathbf{2 3}=$ Amphiura filiformis, $24=$ Ophiura albida, $25=$ Cerianthus lloydi, $26=H_{y}$ ydrallmania falcata, $27=$ Sertularia cupressina [Laomedea gelatinosa], $28=$ Tubularia dumortieri, $29=$ Astrorhiza limicola.

Abb. 10. Nucula nucleus-Endobiose. Kerngebiet. Tierbestand eines Bodengreifer-Fanges ( $1 / 10$ qm) von der Austernbank: Stat. 3 (12. Aug, 1938). Vergl. Tabelle 3. Ni cht e in geze i e h net sind: 70 Stück Actinothoe anguicoma, 63 Stitek Sabellaria spinulosa und 11 Kolonien Clione celata.

Röhren - wie besprochen - kennzeichnend für die Austernbank sind. Im ganzen zeigt die Polychaeten-Zusammensetzung das gleiche Bild wie in der Rinne. Ebenso ist die Krebsfauna sehr artenreich; auch eine Reihe in den sonstigen Gebieten fehlende Arten hat ein gemeinsames Vorkommen auf der Austernbank und in der Rinne (vergl. die Faunenliste). 
$\mathrm{T}$ abelle 3 .

$N u c u l a$ nucleus. Fndobiose. Kerngebiet.

3 Bodengreiferfänge von Stat. 41 (25. Okt. 1938); 1 Fang von Stat. 3 (12. Aug. 1938); 1 Fang von Stat. 4 (18. Okt. 1938), jeweils $0,1 \mathrm{qm}$.

\begin{tabular}{|c|c|c|c|c|c|c|c|c|c|c|c|}
\hline & \multicolumn{6}{|c|}{ Station 41} & \multicolumn{2}{|c|}{ Stat. $\left.3^{1}\right)$} & \multicolumn{2}{|c|}{ Stat. 4} & \\
\hline & Zabl & $\mathrm{g}$ & Zahl & $g$ & Zahl & $g$ & Zahl & $\mathrm{g}$ & Zahl & $\mathrm{g}$ & \\
\hline 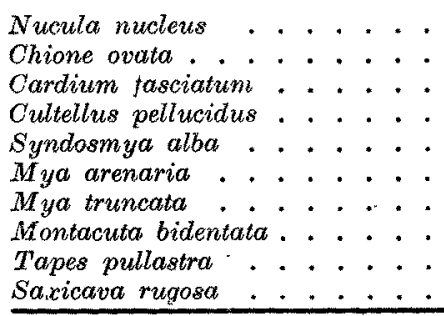 & 20 & $\begin{array}{r}21,50 \\
0,01 \\
\end{array}$ & $\begin{array}{r}36 \\
1 \\
2 \\
2 \\
9\end{array}$ & $\begin{array}{l}3,30 \\
0,29 \\
0,46 \\
0,30\end{array}$ & $\begin{array}{l}5 \\
1 \\
1\end{array}$ & $\begin{array}{l}0,27 \\
0,60 \\
0,01\end{array}$ & $\begin{array}{l}1 \\
1 \\
1\end{array}$ & $\begin{array}{l}1,80 \\
0,08 \\
0,10 \\
2,47 \\
0,01 \\
\end{array}$ & $\begin{array}{r}36 \\
1 \\
9\end{array}$ & $\begin{array}{l}4,78 \\
0,01 \\
0,06 \\
0,02\end{array}$ & \\
\hline $\begin{array}{l}\text { Coryphella landsburgi. . . : } \\
\text { Aeolidiella sp. }\end{array}$ & $\begin{array}{r}28 \\
1\end{array}$ & $\begin{array}{r}24,93 \\
0,01\end{array}$ & 48 & 4,34 & $\begin{array}{r}19 \\
1 \\
1 \\
\end{array}$ & $\begin{array}{l}2,48 \\
0,01 \\
0,01 \\
\end{array}$ & 21 & 4,46 & 4.8 & 4,87 & 10 Arte \\
\hline 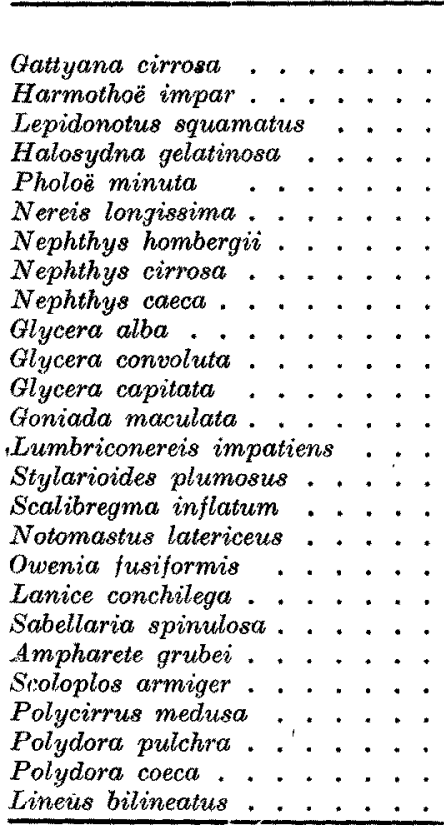 & $\begin{array}{r}2 \\
24 \\
1 \\
3 \\
1 \\
-\quad 21 \\
4\end{array}$ & $\begin{array}{l}0,01 \\
0,02 \\
0,02 \\
0,12 \\
0,02 \\
0,01 \\
0,18 \\
0,42 \\
0,20\end{array}$ & $\begin{array}{l}12 \\
2 \\
1 \\
4 \\
2 \\
1\end{array}$ & $\begin{array}{l}0,12 \\
0,01 \\
\\
0,25 \\
0,40 \\
0,43 \\
0,02 \\
0,18\end{array}$ & $\begin{array}{l}8 \\
3\end{array}$ & $\begin{array}{l}0,08 \\
0,75\end{array}$ & $\begin{array}{l}1 \\
2 \\
1 \\
4\end{array}$ & $\begin{array}{l}0,01 \\
0,05 \\
0,05 \\
\\
0,01 \\
0,02 \\
0,06 \\
0,02\end{array}$ & $\begin{array}{r}10 \\
2 \\
45 \\
11 \\
1 \\
1 \\
1\end{array}$ & \begin{tabular}{l|}
0,03 \\
0,23 \\
0,36 \\
0,06 \\
0,01 \\
0,01
\end{tabular} & 2 Arten \\
\hline & 73 & 2,05 & 32 & 1,69 & 19 & 1,74 & 84 & 1,32 & 86 & 1,17 & 26 Arten \\
\hline 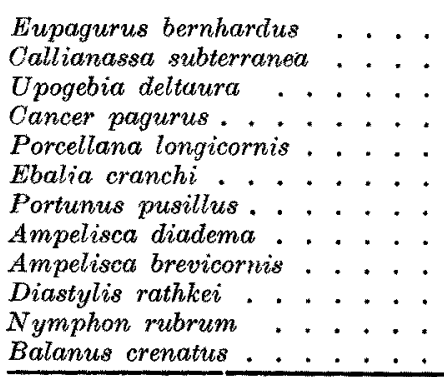 & $\begin{array}{r}1 \\
3 \\
4 \\
4 \\
1 \\
13\end{array}$ & $\begin{array}{l}0,05 \\
6,37 \\
\\
0,04 \\
0,20 \\
0,29\end{array}$ & $\begin{array}{l}1 \\
1\end{array}$ & $\begin{array}{l}0,01 \\
0,02\end{array}$ & 11 & $\begin{array}{l}0,07 \\
0,23\end{array}$ & $\begin{array}{r}1 \\
1 \\
1 \\
2 \\
15 \\
1\end{array}$ & $\begin{array}{c}0,28 \\
0,16 \\
\\
0,02 \\
0,07 \\
0,02 \\
0,01\end{array}$ & $\begin{array}{l}1 \\
3 \\
8 \\
1 \\
1 \\
1 \\
\end{array}$ & $\begin{array}{l}0,01 \\
0,10 \\
0,13 \\
0,01 \\
0,01\end{array}$ & \\
\hline & 22 & 6,95 & 11 & 0,22 & 16 & 0,32 & 21 & 0.56 & 15 & 0.27 & 12 Arten \\
\hline $\begin{array}{l}\text { Psammechinus miliaris } . . . \\
\text { Echinocyamus pusillus } \\
\text { Amphiura filiformis } . . . \\
\text { Ophiura albida } . . \\
\text { Asterias rubens }\end{array}$ & $\begin{array}{l}5 \\
9\end{array}$ & $\begin{array}{l}0,10 \\
0,01\end{array}$ & $\begin{array}{r}8 \\
19\end{array}$ & $\begin{array}{l}0,35 \\
0,60\end{array}$ & $\begin{array}{l}3 \\
7 \\
2 \\
\end{array}$ & $\begin{array}{l}0,12 \\
0,13 \\
1,70 \\
\end{array}$ & $\begin{array}{l}1 \\
1 \\
4 \\
3\end{array}$ & $\begin{array}{l}0,04 \\
0,04 \\
0,30 \\
0,10\end{array}$ & $\begin{array}{l}1 \\
3\end{array}$ & $\begin{array}{l}0,01 \\
0,09\end{array}$ & \\
\hline & 14 & 0,11 & 27 & 0,95 & 12 & 1,95 & 9 & 0,48 & 4 & 0,11 & 5 Arter \\
\hline
\end{tabular}

1) Stat. 3 s. die Darstellung des Fanges in Abb. 10. 


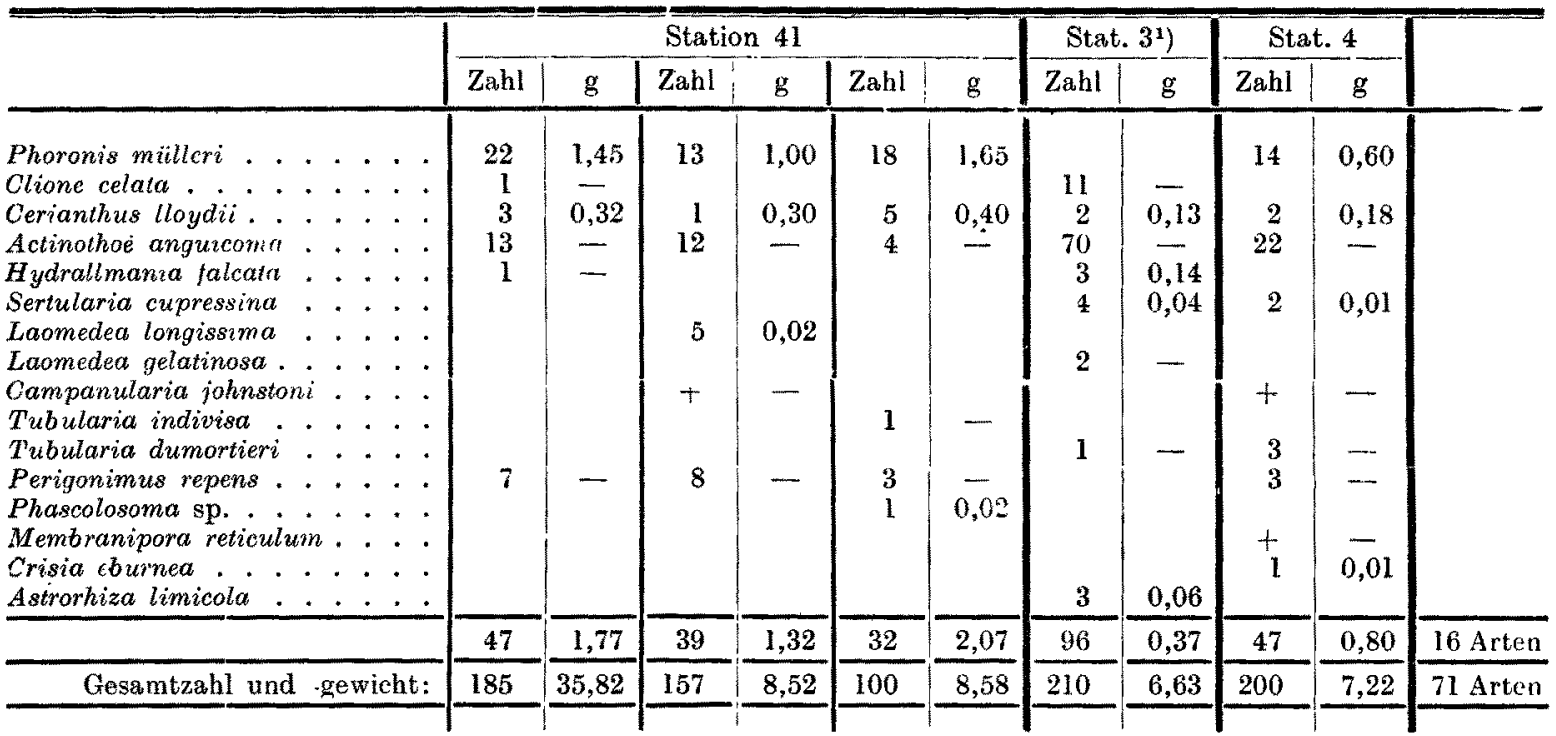

Unter den Echinodermen ist die Seltenheit von Echinocyamus bemerkenswert. Amphiura ist in geringerer $\mathrm{Zahl}$ regelmäBig vertreten, die Häufigkeit von Ophiura entspricht der in der Rinne. Ein sehr kennzeichnendes faunistisches Element ist die Aktinie Actinothoë anguicoma, die auch als Epifauna-Art in sehr großer Zahl in den Bodengreiferfängen zu finden ist. Die schillreiche Böden bevorzugende Aktinie Cerianthus findet hier wie in der Rinne einen geeigneten Lebensraum. Auf Nucula fanden sich - allerdings seltener als in der Rinne - Ubberzüge von Perigonimus. Bemerkenswert ist schließlich das Vorkommen von Astrorhiza in einem Fang (Stat. 3), wo die Foraminiferen zwischen dem Pümp saßen (vergl. weiter Abschn. D III 5 $\mathrm{b}$ und $\mathrm{c}$ ).

\section{b) Der A usläufer zur Rinne.}

Das $N$, nucleus-Kerngebiet weist ein größeres Randgebiet nur im Westen auf, wo es sich als ein langer schmaler Ausläufer bis zur Rinne hinzieht. Im Südosten bildet die Grenze des Kerngebietes die der Endobiose überhaupt, im Norden und Süden ist sonst nur ein sehr schmales Randgebiet vorhanden (s. Abb. 8). Tiefe und Bodenbeschaffenheit sind in den einzelnen Teilen des südwestlichen Ausläufers verschieden. Aus diesem Grunde weisen auch die in diesem Gebiet liegenden Stationen größere Unterschiede auf, wie die vier in Tabelle 4 aufgeführten Stationen zeigen. Stat. 5 liegt im Bereich des groben Sandes. Das Auftreten von zwei $N$. nucleus beweist aber die Zugehörigkeit zu dieser Endobiose. Ophelia als kennzeichnender Polychaet der Sandböden (s. S. 135 u. 157), ferner Cochlodesma und Syndosmya prismatica sind Vertreter der benachbarten Siedlung. Kennzeichnend ist die geringe Besiedlungsdichte: 17 Tiere teilen sich in 11 Arten auf. Dieses Bild zeigen auch Stat. 6 und 23 . Stat. 6 liegt ebenfalls in einem Gebiet groben Sandes, aber mit einer kleinen Schlickbeimischung; die Individuenzahl betràgt daher 22 bei 12 Arten. Hier tritt auch Corbula als fremdes Element der Endobiose auf, ferner ist Ophelia wieder vertreten. Auf die Schlickbeimischung muß auch die für dieses Gebiet verhältnismäßig hohe Zahl von fünf $N$. nucleus zurückgeführt werden, während in dem fast reinen Sand von Stat. 23 wieder nur eine auf $1 / 10$ qm zu finden war; entsprechend sinkt hier auch die Individuenzahl auf 10 mit 9 Arten. Bemerkenswert ist, daß hier 1 Echinocardium (16 mm) lebte.

Ein völlig geändertes Bild zeigt Stat. 26. Hier, unmittelbar am Abfall zur Rinne, findet sich grauer sandiger Schlick, der stark mit feinem Bruchschill vermischt ist, so daß wir ihn im ganzen zum Sedimenttypus der Rinne rechnen müssen. Entsprechend zeigt die Fauna viele Parallelen: Zunächst ist die hohe Ortsdichte und Artenzahl hervorzuheben. Der auf der Austernbank und den umliegenden Gebieten sehr seltene Seeigel Echinocyamus tritt hier in größerer Zahl ( 7 auf 1/10 $\mathrm{qm}$ ) auf, ferner ist besonders die Muschel Chione ovata hervorzuheben, deren Häufigkeit ja in der Rinne als im umgekehrten Verhältnis zu der von $N$. nucleus stehend festgestellt wurde (s. C., S. 55 und Caspers, 1940); während sie wie Echinocyamus auf der Austernbank selten ist, waren bei Stat. 269 Stück enthalten. In der Tiefen Rinne war von der reichen N. nucleus-Siedlung die „Nucula-arme Echinocyamus-Siedlung am Nordhang" abgetrennt worden (s. C., S. 69). Zu dieser Siedlung muß auch das Gebiet um Stat. 26 gerechnet werden, so daß also durch Stat. 26 der unmittelbare Zusammenhang der $N u$ - 
Tabelle 4

$N u c u \iota a n u c l e u s$. Endobiose. Ausläuferzur Rinne.

Je 1 Bodengreiferfang $0,1 \mathrm{qm}$ von Stat. 5 und 6 (12. Aug. 1938), 23 und 26 .(21. Okt. 1938).

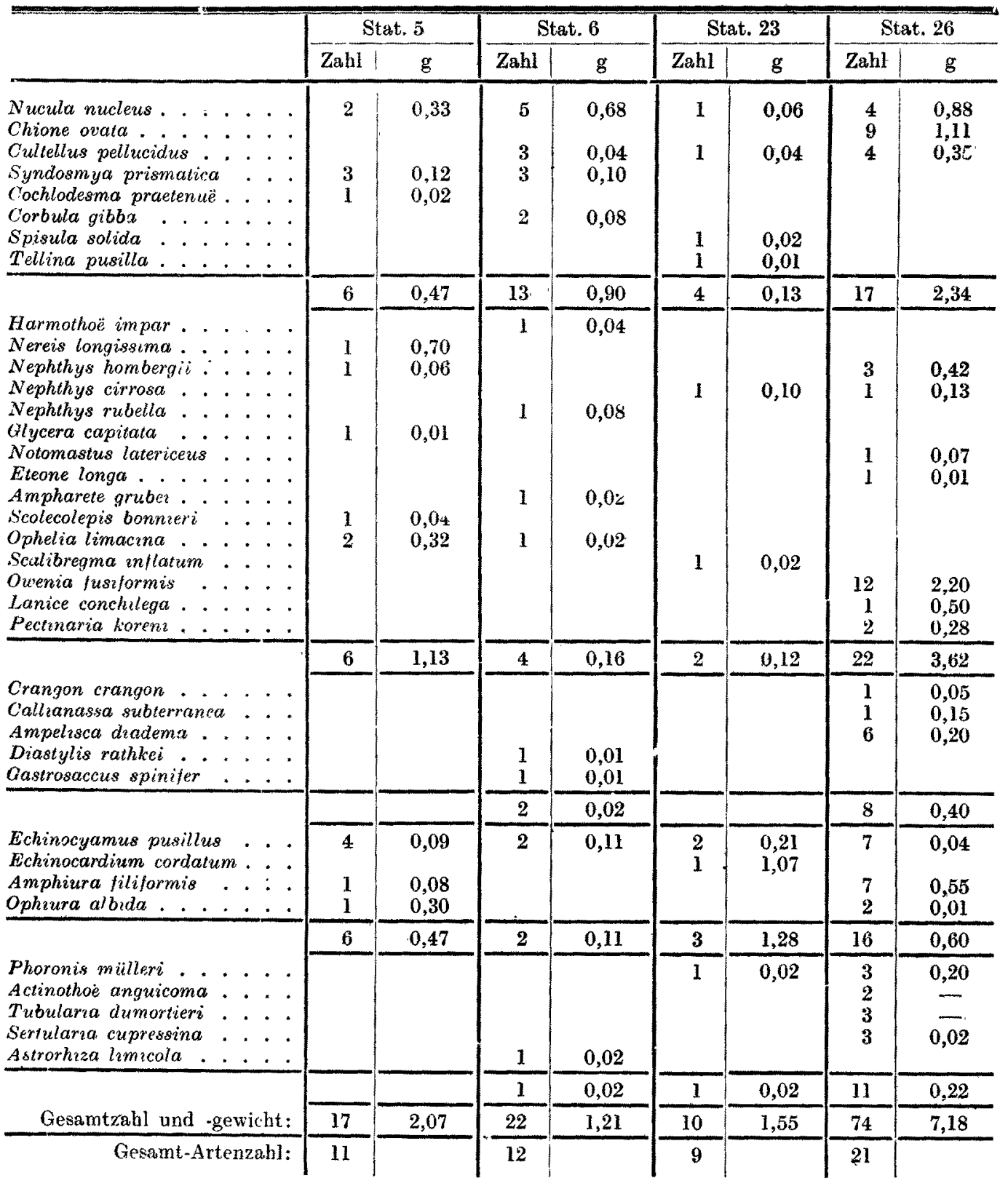

culanucleus-Endobiose der Austernbank mit der Biocönose der Rinne b e s t e h t. Auch die das Sediment zum Aufbau der Röhre benutzenden Polychaeten, besonders Owenia, ferner Lanice und Pectinaria, zeigen hier entsprechend wie in der Rinne eine Anreicherung. Bedingt durch das Fehlen von Sabellaria-Röhren fehlen aber die Aphroditiden, die meist zwischen den Röhren leben, ebenso die Nemertine Lineus bilineatus.

\section{Die Amphiura flliformis - Endobiose.}

Die oben angegebenen Siedlungsgebiete von Amphiura, Nucula nitida und Phoronis zeigen vielfältige Überschneidungen, wie aus $\mathrm{Abb} .8$ und $9 \mathrm{zu}$ ersehen ist. Es wurde schon bemerkt, daB Amphiura ein deutliches Kerngebiet enthält, das sich mit dem von Phoronis deckt und einen. Teil des weichen Schlickes südöstlich der Austernbank einnimmt. Die Randgebiete von Amphiura erstrecken sich über einen sehr großen Raum und erfassen z. T. auch die Austern- 
bank und den südwestlichen Ausläufer der $N$. nucleus-Endobiose. Diese zeigt auch in der Rinne eine Beimischung von Amphiura, wo ebenfalls durch den Schlangenstern eine Endobiose gebildet wird, die sich besonders im Südosten der Rinne im weichen Schlick erstreckt (s. C., S. 69 u. 78). Entsprechend kann auch in der Umgebung der Austernbank eine Amphiura-Endobiose aufgestellt werden, die allerdings eine größere Zahl von $\mathrm{V}$ a $\mathrm{r}$ i a t i o n e n aufweist.

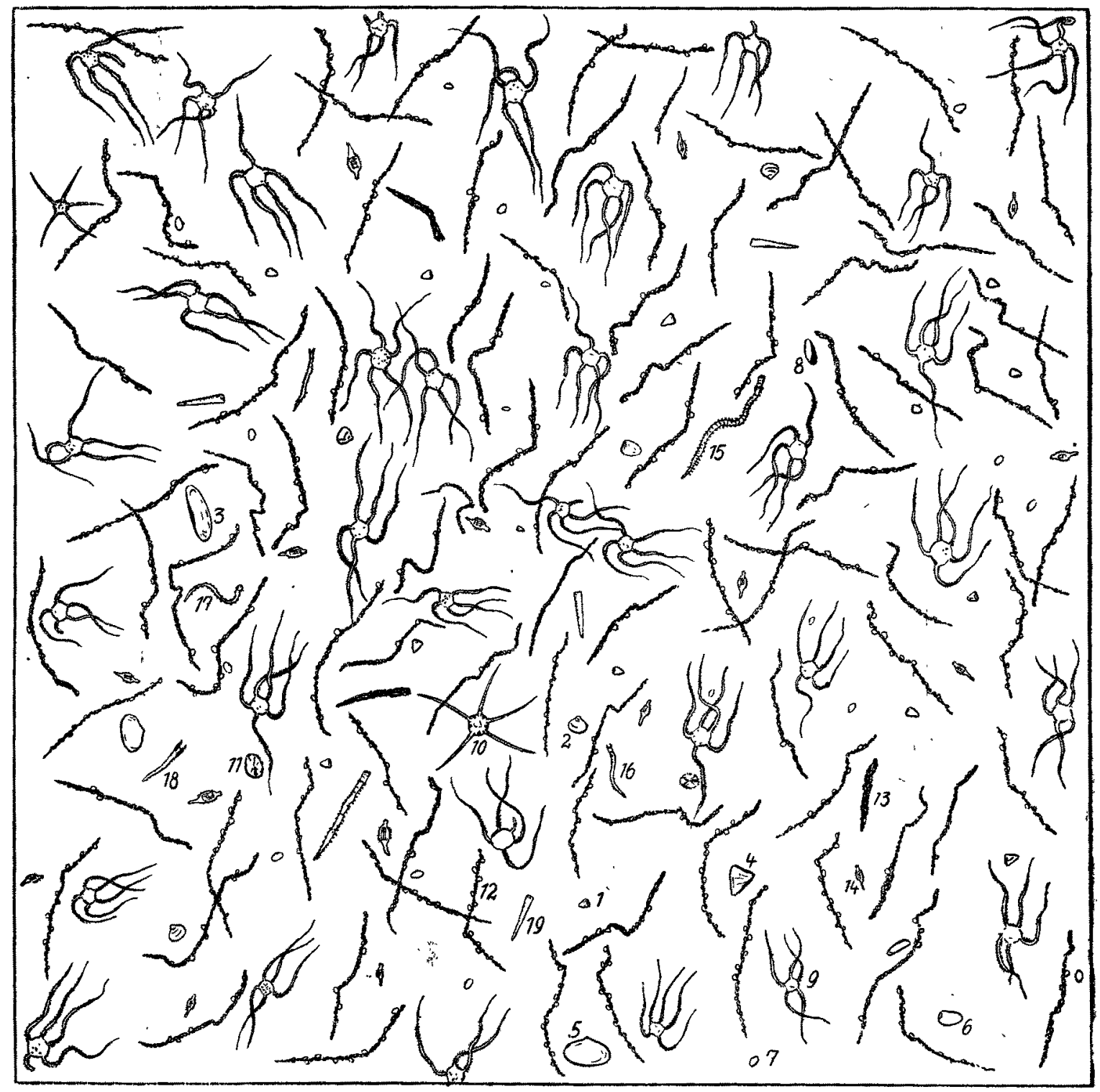

$1=$ Nucula nitida, $2=$ Corbula gibba, $3=$ Cultellus pellucidus, $4=$ Spisula solida, $5=$ Spisula subiruncata, $6=$ Mya arenaria, $7=$ Montacuta bidentata, $8=$ Cylichna cylindracea, $9=$ Amphiura fliformis, $10=0$ phiura albida, $11=$ Echinocardium cordatum, $12=$ Phoronis milller, $13=$ Owenia fusiformis, $14=$ Scalibregma inflatum, $15=$ Nephthys hombergii, $16=$ alycera convoluta, $17=$ Phyllodoce groenlandica, $18=D_{k p l o c i r r}$ is glaucus, $19=$ Pectinaria koreni.

Abb. 11. Amphiura filiformis.Endobiose. Kerngebiet. Tierbestand eines Bodengreiferfanges $(0,1 \mathrm{qm})$ von Stat. 8 (12. Aug. 1938). Vergl. Tabelle 5.

a) Das Kerngebiet.

Wie bereits ausgeführt, grenzt dieses unmittelbar an das Kerngebiet von Nucula nucleus an (s. Abb. 8) und deckt sich mit dem Kerngebiet von Phoronis (Abb.9), Abb. 3.zeigt hier eine Schlickanreicherung, so daß die Beziehung zum Sediment klar zu ersehen ist. Innerhalb dieses Gebietes liegen die Stationen 1-2-8-9, deren Tierbestand in Tabelle 5 aufgeführt ist. Der Fang von Stat. 8 ist in Abb. 11 dargestellt. Die Stationen zeigen viele gemeinsame Züge. Zunächst ist 
die große Ortsdichte von Amphiura (bis 34 auf $1 / 10 \mathrm{qm}$ ) und Phoronis (bis 90) hervorzuheben, die die Individuenzahl des Gesamtfanges bestimmen. Die Artenzahl ist recht hoch, erreicht allerdings nur etwa ein Drittel von der der Austernbank. Nucula nitida ist nur am Südrand des Kerngebietes (Stat. 8) stärker vertreten. Stat. 2 ist die einzige Stelle, wo sich dais Kerngebiet mit der Nucula nucleus-Endobiose schneidet, allerdings fand sich in dem Fang nur 1 Nucula. Cor-

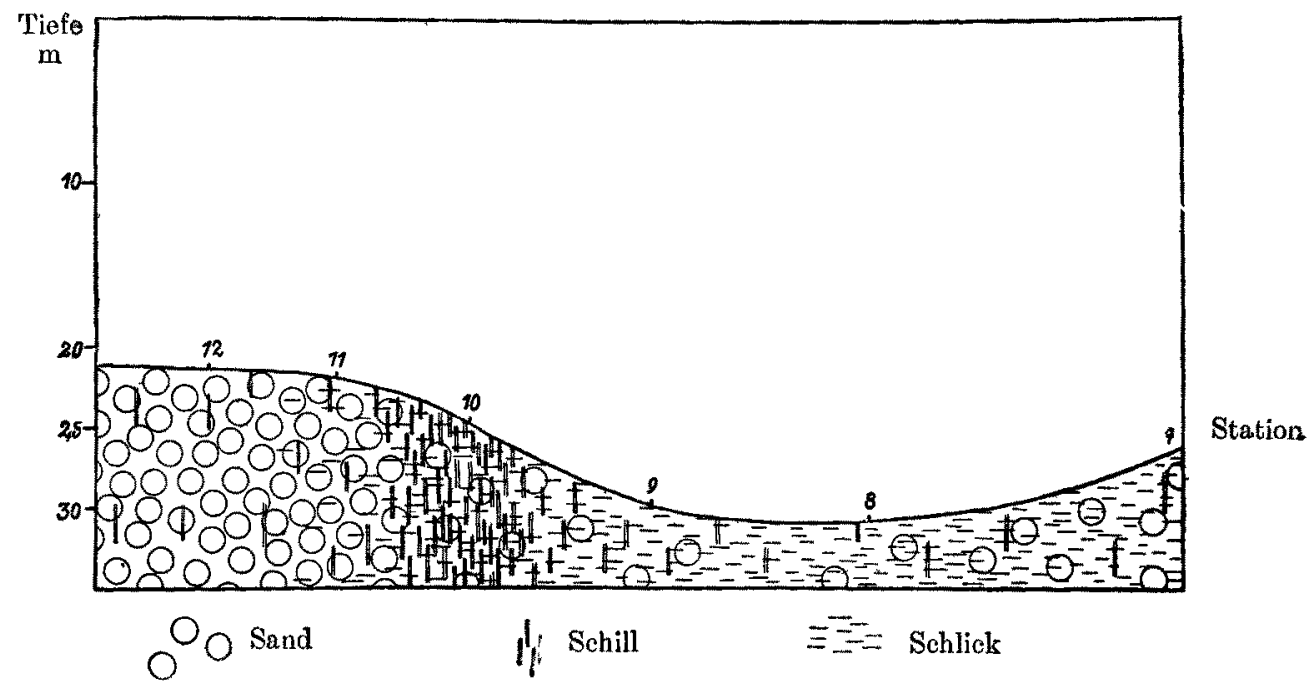

Abb. 12 a. Querschnitt durch das Amphiura-Kerngebiet und die Austernbank vort Stat. 7-13 mit Angabe der Bodenart (vergl. Abb. 3). $50 \times$ überhöht.

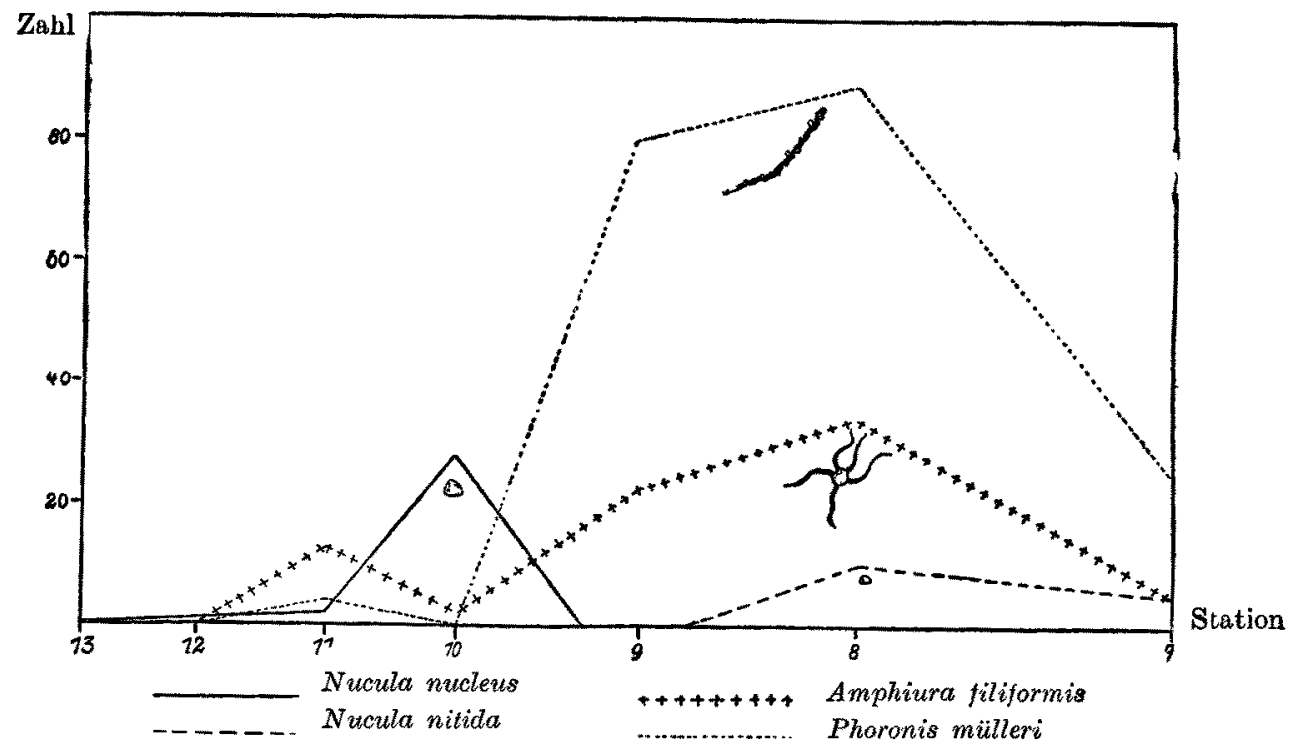

Abb. 12 b. Stückzahl auf $1 / 10$ qm von Nucula nucleus, N. nitida, Amphiura filiformis und Phoronis mülleri im Querschnitt durch das Amphiura-Kerngebiet und die Austernbank von Stat. 7-13.

bula gibba, Montacuta bidentata, Spisula, Syndosmya, Cultellus pellucidus, Lora turricula und Cylichna sind weitere Leitformen (2. Ordnung), die diese Endobiose im Gegensatz zu der der Austernbank kennzeichnen. Bemerkenswert ist der Mangel an Crustaceen und Hydrozoen (bei letzteren durch den Mangel an Ansatzmöglichkeiten und Verschlickungsgefahr bedingt). Die Röhren von Orevia sind hier. wegen des Fehlens an feinen Muschelbruchstücken vorzugsweise us Sand aufgebaut. Echinocardium tritt regelmäßig auf; Polychaeten sind recht artenreich vertreten.

Der in Abb. 12 dargestellte Querschnitt von Stat. 7-13 schneidet das Amphiura-Kerngebiet und die Austernbank, die durch die Schillanreicherung am Hang (Stat. 10) kenntlich ist. Unter diesem Querschnitt ist die Stückzahl auf $1 / 10 \mathrm{qm}$ von Amphiura, Phoronis, Nucula nucleus und $N$. nitida graphisch angegeben. Zunächst ist die scharfe Trennung der beiden Nucula-Arten 
Tabelle 5 .

Amphiura filiformis. Endobiose. Kerngebiet.

Je 1 Bodengreiferfang $0,1 \mathrm{qm}$ von Stat. 1, 2, 8 und 9 (12. Aug. 1938).

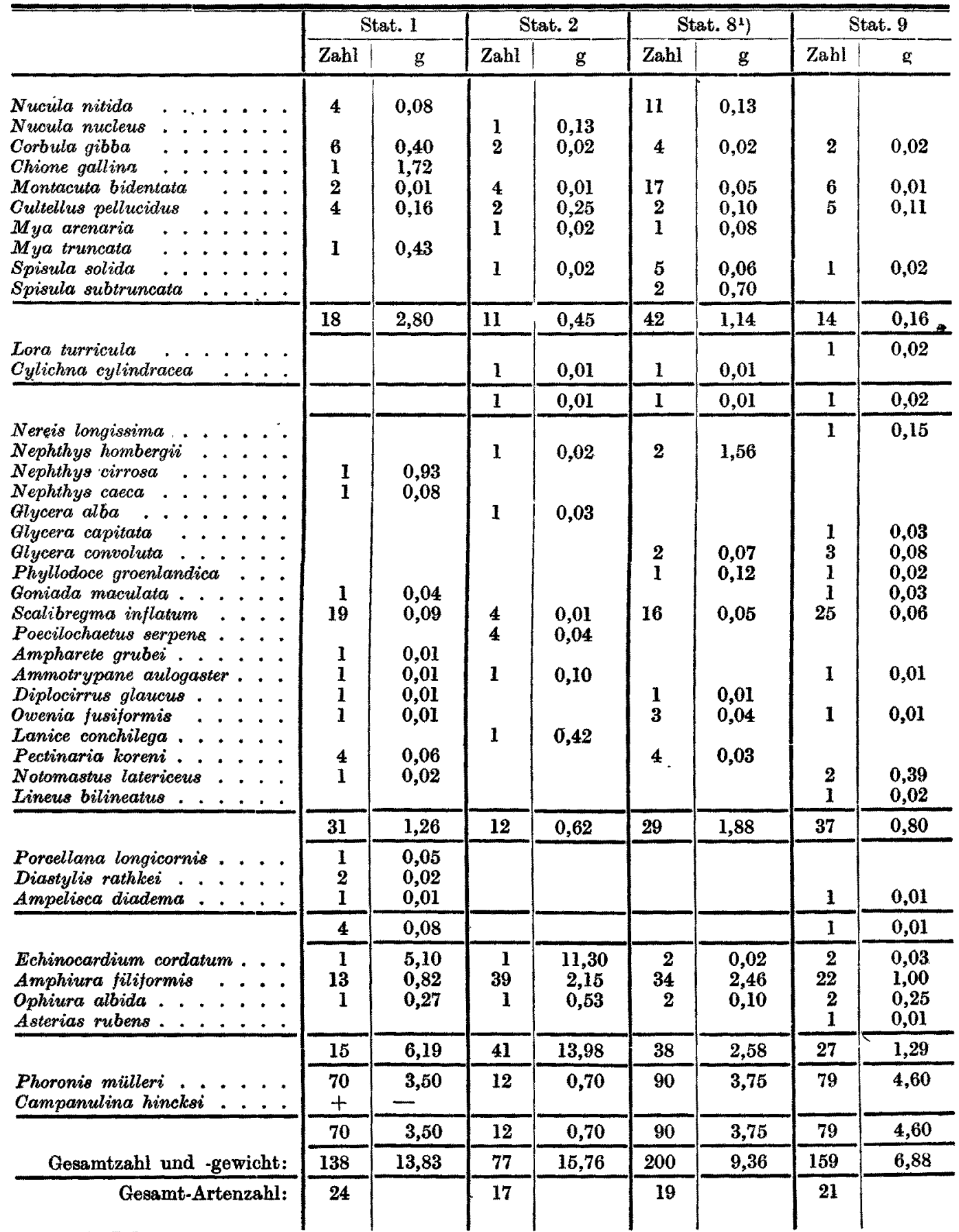

1) Stat. 8 s. die Darstellung des Fanges in Abb. 11.

zu erkennen, wobei bei $N$. nucleus die scharfe Beziehung zum Schillgebiet der Austernbank hervortritt, während $N$. nitida auf die reinen Schlickgebiete beschränkt ist. Hier tritt auch das Kerngebiet von Amphiwra und Phoronis durch einen hohen Gipfelpunkt der beiden Arten hervor. Bemerkt muß werden, daß diese starken faunistischen Unterschiede innerhalb einer sehr kleinen Fläche bestehen: Stat. 7 und 13 sind nur $3,4 \mathrm{~km}$ voneinander entfernt, die Trennung der beiden Nucula-Arten findet innerhalb eines Grenzsaumes von etwa $600 \mathrm{~m}$ statt. Die Mittelpunkte der beiden gänzlich verschiedenen Endobiosen liegen $1000 \mathrm{~m}$ voneinander entfernt. 
Tabelle 6.

A mphiura filiformis-Endobiose. Südiches und nördliches Randgebiet.

Südliches Randgebiet: Je 1 Bodengreiferfang 0,1 qm von Stat. 19, 20 und 24 (21. Okt. 1938).

Nördliches Randgebiet: Je 1 Bodengreiferfang 0,1 qm, von Stat. 16 (18. Okt. 1938), 36 und 37 (25. Okt. 1938).

\begin{tabular}{|c|c|c|c|c|c|c|c|c|c|c|c|c|}
\hline & \multicolumn{6}{|c|}{ Sudliches Randgebiet } & \multicolumn{6}{|c|}{ Nördliches Randgebiet } \\
\hline & \multicolumn{2}{|c|}{ Stat. 19} & \multicolumn{2}{|c|}{ Stat. 20} & \multicolumn{2}{|c|}{ Stat. 24} & \multicolumn{2}{|c|}{ Stat. 16} & \multicolumn{2}{|c|}{ Stat. 36} & \multicolumn{2}{|c|}{ Stat. 37} \\
\hline & Zahl & $\mathrm{g}$ & Zahl & $\mathrm{g}$ & Zahl & $\mathrm{g}$ & Zahl & $\mathrm{g}$ & Zahl & $\mathrm{g}$ & Zahl & $\mathrm{g}$ \\
\hline 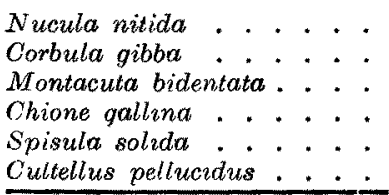 & $\begin{array}{r}3 \\
38\end{array}$ & $\begin{array}{l}0,08 \\
1,98\end{array}$ & $\begin{array}{r}20 \\
20 \\
\\
1 \\
1\end{array}$ & $\begin{array}{l}0,58 \\
0,70 \\
0,05 \\
0,01\end{array}$ & $\begin{array}{r}1 \\
10 \\
1\end{array}$ & $\begin{array}{l}0,01 \\
0,27 \\
0,01\end{array}$ & $\begin{array}{l}2 \\
4\end{array}$ & $\begin{array}{l}0,03 \\
0,02 \\
\\
0,24 \\
\end{array}$ & $\begin{array}{l}2 \\
1 \\
1 \\
\end{array}$ & $\begin{array}{l}0,02 \\
0,02 \\
0,34 \\
\end{array}$ & $\begin{array}{l}1 \\
1 \\
1\end{array}$ & $\begin{array}{l}0,04 \\
0,05 \\
0,01\end{array}$ \\
\hline & 41 & 2,06 & 44 & 1,34 & 12 & 0,29 & 7 & 0,29 & 4 & 0,38 & 3 & 0,10 \\
\hline 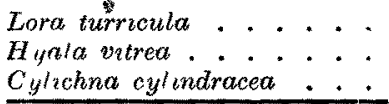 & & & & & 1 & 0,01 & 1 & 0,02 & $\begin{array}{l}2 \\
1 \\
\end{array}$ & $\begin{array}{l}0,05 \\
0,02 \\
\end{array}$ & 1 & 0,01 \\
\hline & & & & & 1 & 0,01 & 1 & 0,02 & 3 & 0,07 & 1 & 0,01 \\
\hline 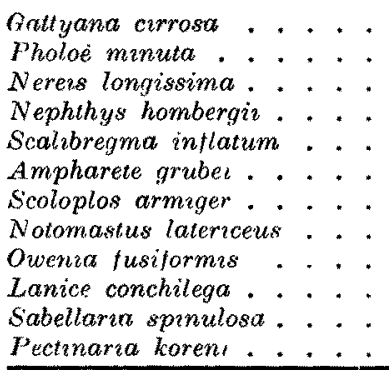 & $\begin{array}{l}2 \\
1\end{array}$ & $\begin{array}{l}0,07 \\
0,34 \\
0,02 \\
0,08\end{array}$ & 2 & 0,01 & 1 & 0,01 & $\begin{array}{r}1 \\
1 \\
30\end{array}$ & $\begin{array}{l}0,01 \\
0,08 \\
0,20 \\
0,15 \\
0,01\end{array}$ & 1 & $\begin{array}{l}0,15 \\
0,12\end{array}$ & $\begin{array}{l}2 \\
2 \\
1 \\
1 \\
5 \\
\\
\\
1\end{array}$ & $\begin{array}{l}0,03 \\
\\
0,30 \\
0,01 \\
0,01 \\
0,01 \\
0,30 \\
0,14 \\
\end{array}$ \\
\hline & 10 & 0,51 & 3 & 0,02 & 2 & 0.02 & 34 & 0,45 & 5 & 0,59 & 13 & 0,80 \\
\hline $\begin{array}{l}\text { Crangan crangon . . . } \\
\text { Ampelesca deadema } . . .\end{array}$ & 2 & 0,47 & & & 1 & 0,01 & 1 & 0,01 & & & 1 & 0,03 \\
\hline & 2 & 0,47 & & & 1 & 0,01 & 1 & 0,01 & & & 1 & 0,03 \\
\hline $\begin{array}{l}\text { Echinocardium cordatum. } \\
\text { Amphrura filiformis } . . \\
\text { Ophoura albida. }\end{array}$ & 2 & 0,24 & $\begin{array}{l}\mathbf{3} \\
\mathbf{3} \\
\end{array}$ & $\begin{array}{l}0,10 \\
0,02 \\
\end{array}$ & & & $\begin{array}{r}10 \\
2 \\
\end{array}$ & $\begin{array}{l}0,40 \\
0,01 \\
\end{array}$ & $\begin{array}{l}1 \\
4 \\
7 \\
\end{array}$ & $\begin{array}{l}9,10 \\
0,40 \\
0,25 \\
\end{array}$ & $\begin{array}{r}1 \\
7 \\
10 \\
\end{array}$ & $\begin{array}{r}14,30 \\
0,20 \\
0,70 \\
\end{array}$ \\
\hline & 2 & 0,24 & 6 & 0.12 & & & 12 & 0,41 & 12 & 9,75 & 18 & 15,20 \\
\hline 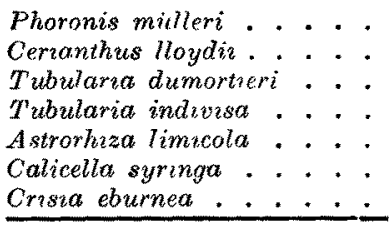 & $\begin{array}{r}29 \\
2 \\
1\end{array}$ & $\begin{array}{c}0,75 \\
- \\
-\end{array}$ & 23 & 1,10 & 18 & 0,90 & $\begin{array}{r}19 \\
1\end{array}$ & $\begin{array}{l}1,20 \\
0,15\end{array}$ & $\begin{array}{l}2 \\
1 \\
\end{array}$ & $\begin{array}{l}0,02 \\
0,01 \\
\end{array}$ & $\begin{array}{r}43 \\
2 \\
2 \\
3\end{array}$ & $\begin{array}{l}1,60 \\
0,14 \\
-\end{array}$ \\
\hline & 32 & 0,75 & 23 & 1,10 & 18 & 0,90 & 21 & 1,37 & 17 & 1,13 & 51 & 1,74 \\
\hline Gesamtzahl und -gewicht: & 87 & 4,03 & 76 & 2,58 & 34 & 1,23 & 76 & 2,55 & 41 & 11,92 & 86 & 17,88 \\
\hline Gesamt-Artenzahl: & 11 & & 10 & & 8 & & 15 & & 13 & & 19 & \\
\hline
\end{tabular}

b) Das südliche Randgebiet.

Vom Amphiura-Kerngebiet nach Süden zu nimmt die Zahl von Amphiura und Phoronis ab. Der Charakter der Stationen kennzeichnet dieses Gebiet als zur Amphiura-Endobiose gehörig, wenn auch in der übrigen Fauna Änderungen eintreten, wie aus dem Beispiel der Stationen 19, 20 und 24 in Tabelle $6 \mathrm{zu}$ ersehen ist. Bezeichnend für das Gebiet ist die Artenarmut, die fast alle Gruppen betrifft. Trotzdem darf diese Zone nicht einfach als ,arme Siedlung" mit allgemeinem Rückgang der Fauna aufgefaßt werden, da einzelne Arten hier eine besondere Ortsdichte zeigen, so Corbula gibba und bei Stat. 20 auch Nucula nitida. Wieweit dieses Siedlungsbild nur für die Untersuchungszeit zutrifft, also nur eine vorïbergehende „Fleckung“" der Endobiose darstellt, kann nicht entschieden werden. Im Sediment sind keine Unterschiede zum Kerngebiet festzustellen. Sicher werden sich die Grenzen der Siedlungen rerschieben, doch bleibt 
die Lage der Variationen innerhalb der Endobiose erhalten, wie nach den Siebrestbestimmungen festgestellt wurde (vergl. Abschn. D IV 3). Wahrscheinlich wird in anderen Jahren auch im ganzen südlichen Gebiet Amphiura in geringerer Zahl zu finden sein, so daß diese ganze Zone zu der Endobiose gerechnet werden kann. Hierauf weist auch die Verteilung der übrigen Leitformen hin. Bei Stat. 7 und 25 ist o ne größere Artenfülle bei starkem Rückgang von Amphiura zu bemerken; Stat. 25 zeigt Anklänge an die Fauna der Tiefen Rinne, zu der sie ja ähnlich wie Stat. 26 (s. S. 149) liegt.

$$
\text { c) Das nördliche Randgebiet. }
$$

Nördlich des Kerngebietes erstreckt sich Amphiura in Form einer breiten Zunge bis zum Rand der. Loreleybank. In Abb. 13 b ist ein Querschnitt (50 mal überhöht) durch dieses
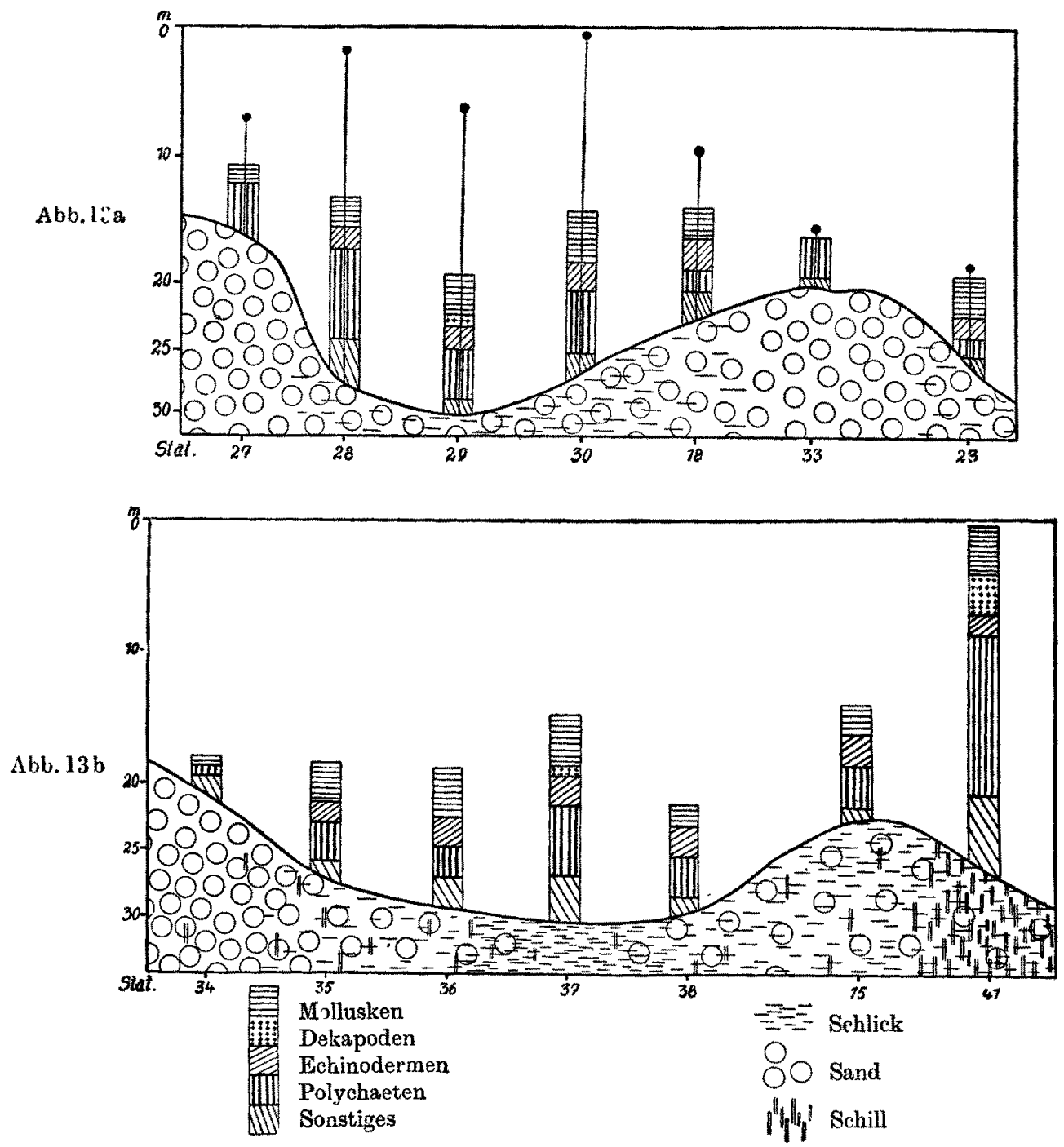

Abb. 13: Zwei Querschnitte von der Loreleybank nach Süden. 50× überhöht. Bodenart (vergl. Abb. 3) und Artenzahl der einzelnen Tiergruppen in den Bodengreifer-Fängen.

Abb. 13a: Schnitt bis zum Sandgebiet westlich der Austernbank. Stat. 27 bis $30-18-33-23$. Ferner Angabe der Gesamtstückzahl der Tiere in einem Fang (bei Stat. 18 sind die 67 Astrorhiza nicht mitgerechnet). Abb. 13 b: Schnitt bis zur Austernbank. Stat. 34 bis $38-15-41$.

Gebiet vom Rand der Loreleybank bis zur Austernbank (Stat. 23-38, 15 und 41) dargestellt, in den auch das Sediment eingezeichnet ist. Die Entfernung von Stat. 23-41 beträgt $3 \mathrm{~km}$. Bei den Stationen ist die Artenzahl für die einzelnen Gruppen graphisch angegeben. Zunächst ist für das ganze Gebiet die Abnahme der Gesamt-Artenzahl bemerkenswert, wobei Stat. 34 
und 35 zunächst unberücksichtigt bleiben sollen. Nur bei Stat. 37 ist eine geringe Zunahme festzustellen, was besonders auf eine Vermehrung der Polychaeten-Arten zurückzuführen ist, die ja auch zum gröBten Teil die hohe Artenzahl auf der Austernbank (Stat. 41) bewirken. Aus dem Querschnitt ist zu ersehen, daß bei Stat. 37 eine Schlickanreicherung besteht, auf die wohl die Artenvermehrung zurückzuführen ist. Der Fang von dieser Station ist in Tabelle 6 wiedergegeben zusammen mit je 1 Fang von Stat. 16 und 36.

Ziemlich regelmäBig im ganzen Gebiet finden sich Corbula gibba, Spisula solida und Chione gallina; doch bleibt die Ortsdichte gering; Nucula nitida ist selten. Phoronis (vergl. Abb. 9) ist fast im ganzen Gebiet verbreitet (5-25 in einem Fang, nur bei Stat. 37 eine Anreicherung). Stellenweise ist auch Astrorhiza vertreten (Abb. 9).

Gegenüber dem Kerngebiet der Endobiose ist sisso ein Artenrückgang festzustellen, wenn auch die Gesamt-Artenzahl die des südlichen Randgebietes übertrifft. Das letztere Gebiet weist dagegen eine groBe Ortsdichte einiger Muscheln auf, die im Norden selten sind (Nucula nitida) oder hier regelmaßig, aber in geringerer Zahl vorkommen (Corbula gibba).

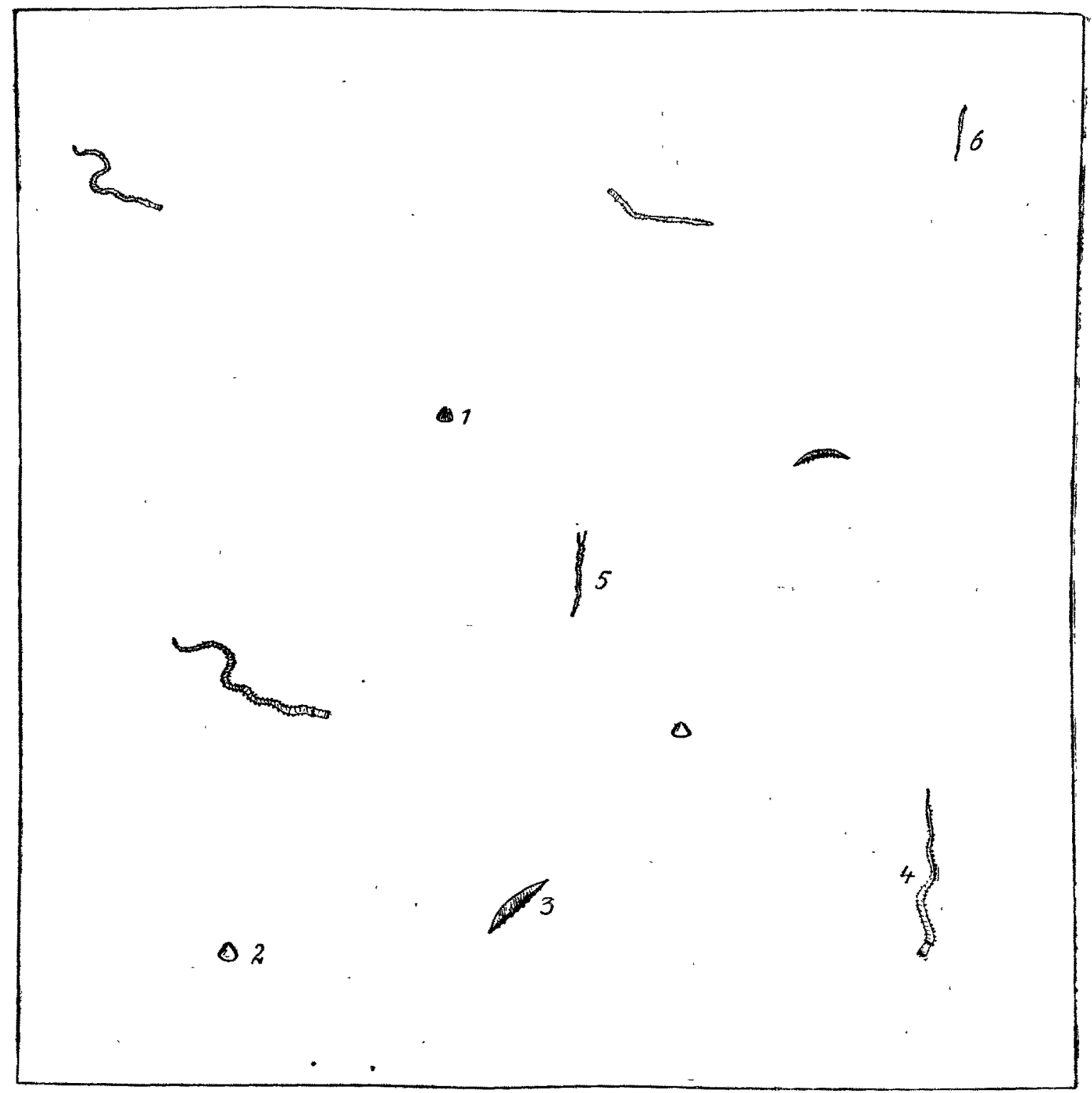

Abb. 14. Besiedlung des Südrandes der Loreleybonk. 1 Bodengreifer-Fang (0.1 qm) von Stat. 27 (2l. Okt. 1938), $1=$ Chione gallina, $2=$ Spisula solida, $\mathbf{3}=$ Ophelia limacina, $4=$ Nephthys spec., $5=$ Scolecolepis bonnieri, $6=$ Scoloplos armiger. 
4. Vie Sandgebiete.

a) Der Südrand der Lorele ybank.

Wie überall ist in den reinen Sandgebieten ein arten- und mengenmäBiger Rückgang der Makrofauna festzustellen. Die Loreleybank schlieBt das Untersuchungsgebiet im Norden ab, weiter nördlich ziehen sich die feinen Sande bis zu dem sehr grobkörnigen Sandgebiet des , $A m$ phioxus-Grundes" hin. Der Rand der eigentlichen Loreleybank wird von den Stationen 27 und 34 berührt; die südlicheren Stationen weisen bereits eine Schlickbeimischung auf. Entsprechend erhöht sich bei diesen die Arten- und Stückzahl, wie aus den beiden Schnitten Abb. 13 a und b zu erkennen ist. Bei Stat. 34 (Abb. 13 b) fanden sich in einem Fang sogar nur 1 Muschel, 1 Polychaet, 3 Hydrozoen und Bryozoen.

Ein Fang von Stat. 27, unmittelbar neben der Tonne „Loreleybank-Süd", ist in Abb. 14 dargestellt: 6 Arten, 12 Tiere (s. auch Abb. 13 a). Dieser Fang enthält 3 Ophelia limacina, eine Polychaetenart, die für die Sandböden charakteristisch ist. Die übrigen hier vorkommenden Tiere leben auch in den benachbarten reicher besiedelten Gebieten und müssen als Restbestandteile einer verarmten Fauna aufgefaßt werden. Regelmäßig tritt Chione gallina auf.

b) Das grobe Sandgebiet im Westen der Austernbank.

Hier finden sich viele faunistische Übereinstimmungen mit der Loreleybank, wenn auch die Korngröße des Sandes verschieden ist (vergl. S. 124). Zunächst ist ebenfalls ein starker Rückgang der Arten- und Individuenzahl festzustellen, wie aus Abb. 13 a zu ersehen ist. Eine Zunahme ist aber sofort bemerkbar, wenn in den Randgebieten eine geringe Schlickbeimischung besteht. Von dem Sand wird der höchste Teil der Erhebung zwischen der Loreleybank und der Tiefen Rinne eingenommen (s. Abb. 3). Wie auf der Loreleybank ist Ophelia limacina kernzeichnend, ferner sind Cultellus pellucidus, Syndosmya prismatica, Gastrosaccus spinifer, Echinocyamus, Nereis longissima und Nephthys als fast regelmäBig vorkommend zu nennen.

c) Ü bergangsgebiete.

Zwischen den Sandgebieten westlich der Austernbank, der Loreleybank und den Gebieten der Nucula nucleus- und Amphiura-Endobiose erstreckt sich eine Zone, deren faunistische Zuordnung wegen des Fehlens der Leitformen 1. Ordnung auf Schwierigkeiten stößt. Das Sediment besteht hier aus Sand mit einer geringen Schlickbeimischung (s. Abb. 3), und entsprechend hat auch die Fauna einen Übergangscharakter. Die Arten- und Individuenzahl ist dabei recht hoch - wenigstens im Vergleich zu den reinen Sandgebieten (vergl. Abb. 13 a). Im ganzen kann gesagt werden, daß wir es hier mit einem durch die benachbarte Amphiura-Endobiose gekennzeichneten Außengebiet zu tun haben, in welchem aber die Leitform 1. Ordnung $A n$.phiura wegen des zu geringen Schlickgehalts des Bodens keinen Lebensraum hat (von einigen gelegentlich auftretenden Stücken abgesehen, bis zwei in 1 Fang). Die Zusammengehörigkeit wird durch das regelmäBige Auftreten von Cylichna cylindracea, Lora turricula, Montacuta bidentata und stellenweise Corbula gibba bestätigt. Ferner ist in geringerer Zahl fast überall Phoronis vertreten (Abb. 9).

Innerhalb des Gebietes fand sich die gröBte Fleckbildung von Astrorhiza limicola bei Stat. 18. Für die Gesamtverbreitung dieser Foraminifere kann angegeben werden, daß sie die harten sandig-schlickigen Böden besiedelt, ohne daß eine weitere Beziehung zu einer Endobiose zu ermitteln wäre. Der Fang von Stat. 18 ist in Abb. 15 dargestellt. Die 67 hier auf 1/10 qm enthaltenen Astrorhiza beherrschen das Siedlungsbild völlig (wahrscheinlich ist die Ortsdichte der Foraminifere noch größer, da bei dem Aussieben mit einem gewissen Ausfall zerbrochenè Stücke zu rechnen ist).

\section{d) Anhang: Die Fauna der Loreleybank.}

Wenn auch keine systematischen Untersuchungen über dieses Gebiet gemacht wurden, so ist doch ein kurzer Überblick auf Grund einiger Fangergebnisse möglich, durch den das Bild der die Austernbank umgebenden Siedlungen abgerundet werden kann.

Wie besprochen, ist schon in den am Südrand der Loreleybank gelegenen Stationen ein starker faunistischer Rückgang festzustellen, wobei aber der Polychaet Ophelia limacina kennzeichnend für die Sand̈böden ist. Dieser findet sich auch in Dretschfängen von der ganzen Bank. Diese enthielten ferner an Muscheln vorwiegend Spisula solida (bis $27 \mathrm{~mm}$ ), weiter einige Donax vittatus und Chione gallina (bis $19 \mathrm{~mm}$ ). Als kennzeichnendste Muschel ist Solen siliqua anzugeben; daneben kommt seltener Ensis ensis vor. Die erstere Art erhielt ich in großer Zahl während den Farthen eines Saugbaggers, an denen teilzunehmen ich Gelegenheit hatte. Es fan- 
den sich Exemplare bis $18 \mathrm{~cm}$ Länge (Gewicht $103 \mathrm{~g}$ ). Sie müssen sehr tief sitzen, da das Saugrohr des Baggers 2-3 $\mathrm{m}$ in den Boden geht, und andere Muscheln, die an der Bodenoberfläche leben, hier sehr selten erhalten werden. Nur einige Eupagurus in Buccinum, Echinocardium

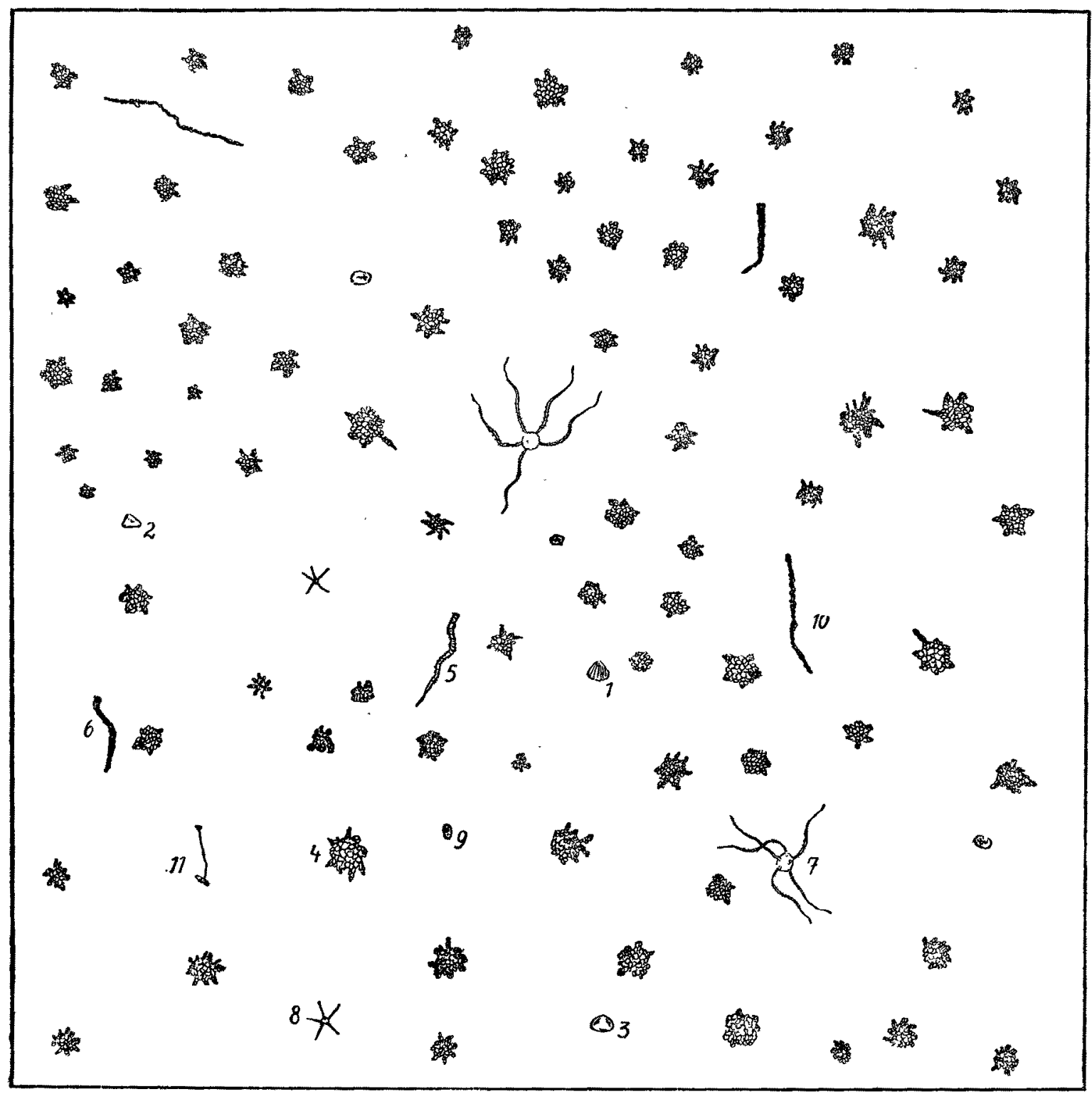

Abb. 15. Fleck der Foraminifere Astrorhiza limicola. 1 Bodengreifer-Fang $(0.1 \mathrm{qm})$ von Stat. 18 (18. Okt. 1938). $1=$ Chione gallina, $2=$ Sprsula solida, $3=$ Cochlodesma praetenue, $4=$ Astrorhiza limicola, $5=$ Nephthys spec., $6=$ Owenia fusitormis, $7=$ Amphiura fillformis, $8=$ Ophinara albida, $9=$ Echinocyamus pusillus, $10=$ Phorons mülleri, $11=$ Tubularia indivisa.

cordatum und Spatangus purpureus werden ferner gelegentlich mit hochgebracht. In Dretschfängen ist der Decapode Thia polita nicht selten und für dieses Gebiet charakteristisch. Das Vorkommen der sonst Schlickböden bewohnenden Herzigel ist besonders bemerkenswert.

An Schalen wurden festgestellt: vorwiegend Spisula solida und Donax vittatus, ferner Chione gallina, Cardium edule, Cyprina islandica, Macoma baltica, Mytilus edulis, Mactra stultorum, Mya arenaria und von Schneckengehäusen Buccinum undatum, Lunatia nitida, Gibbula tumida und Litorina litorea. Auch Röhren von Lanice conchilega sind gelegentlich zu finden. Vom Saugbagger werden auch regelmäßig Austernschalen mit heraufgebracht. - Unter den Fischen sind besonders die beiden Trachinus-Arten anzugeben, die hier regelmäßig zu finden sind; Tr. vipera scheint häufiger als $T r$. draco zu sein. 


\section{Die Biocönosen.}

a) Zusammenfassende Uै bersicht.

Wie bereits in dem Abschnitt über die Siedlungsgebiete behandelt, ist in dem untersuchten Gebiet die Biocönose der Austernbank in die umliegende Amphiura-Endobiose eingeschoben. Die Eigenarten der beiden Endobiosen, ihre Leitformen, Siedlungen und Variationsgebiete sind ebenfalls bereits besprochen, so daß abschließend nur noch ein zusammenfassender Uberblick notwendig ist. Die Biocönose der Austermbank bedarf dann noch einer eingehenderen vergleichenden Besprechung.

Für die $N u c u l a n u c l e u s-\mathbf{E} \mathrm{n} \mathbf{d}$ o b i o s e war ein mit der Epibiose der Austernbank zusammenfallendes Kerngebiet und ein bis zur Rinne reichender Ausläufer festgestellt worden: der am Rande den Charakter der Rinnenfauna zeigt, während die übrigen Gebiete eine starke Beimischung der Amphiura-Endobiose aufweisen; besonders Elemente des Sandgebietes sind - entsprechend dem stärkeren Sandanteil im Sediment - vertreten. Diese Beimischung ist auf der Austermbank nur in geringem Maße festzustellen, so daß diese eine g e s c h lo s s e $\mathrm{n}$ e $\mathrm{B}$ i o c ön o s e darstellt. Die auch hier enthaltenen Amphiura und Phoronis zeigen einen ähnlich kleinen Beimischungsgrad wie in der Rinne.

Die Amphiuratiliformis-Ge mein s chaft (Endobiose) hat als Leitform 1. Ordnung Amphiura. Die bei der Besprechung des Kerngebietes aufgeführten Leitformen 2. Ordnung sind die gleichen wie die in- der Rinne für diese Gemeinschaft gefundenen. Entsprechend dem größeren Gebiet, das diese im Umkreis der Austernbank auf sehr verschiedenen Böden einnimmt, vermehrt sich die Zahl der Variationsgebiete. Hinzu treten Flecken besonderer Massenentwicklung einzelner Arten. Die schlickigen Gebiete, auf denen Amphiura fehlt oder nur in geringer Ortsdichte vorkommt, müssen ebenfalls zu dieser Gemeinschaft gerechnet werden, da die Leitformen 2. Ordnung' vorhanden sind, und Amphiura in anderen Jahren wohl in den Gobieten mit einer Schlickbeimischung in größerer Zahl vorkommt.

Gesondert behandelt wurden die Sandgebiete, in denen Ophelia limacina als kennzeichnende Art lebt. Für eine Entscheidung darüber, ob diese - besonders die Loreleybank - noch als oine Sandvariation der Amphiura-Endobiose oder zu einer anderen Gemeinschaft gerechnet werden mussen, ist die Untersuchung eines größeren Meeresgebietes notwendig.

b) Dic Lebensgemeinschaft der Austernbank und ibrVerhältnis z $u$ der der Tiefen $R$ inne.

Nachdem erkannt wordon ist, daßB die Austernbank ebenso wie die Fauna der Tiefen Rinne zuir Nucula nuclcus-Gemeinschaft gehört, muß untersucht werden, wieweit Ubereinstimmungen zwischen den beiden Gebieten bestehen und worauf andererseits die Unterschiede beruhen Dies geschieht zunächst am besten durch einen Vergleich über die Leitformen (s C., S. 78).

Die Lejt form 1. Ordnu $\mathrm{r}$. Nucula nucleus tritt in etwa gleicher Ortsdichte in beiden Gebieten auf und ist damit auch auf der Austernbank die weitaus vorherrschende Muschelart.

Leitformen 2. Ordnung. Als Muscheln waren in der Rinne Chione ovata und Cardium las $c i$ at $u m$ genannt. Die erstere Art ist auf der Austernbank sehr selten. Bei der gleichen Anzahl von Nucula sind in der Rinne doch in jedem Fang etwa 2 Chione enthalten; in den Nucula-ärmeren Siedlungen vergrößert sich die Ortsdichte der Chione-Art wie in der Umgebung der Austernbank bei Stat. 26 (s. S. 149). Bei der Behandlung der Gemeinschaft in der Rinne war (nach Angaben von Heıncke) vermutet worden (C., S. 78), daB Nucula auf der Austernbank seltener und dafür die damit in Wechselbeziehung stehende Chione häufiger sei, so daß die Bank als Chione ovata. Variation gelten kann. Dies hat sich nicht bestätigt, sondern die Austernbank mu Biernach dem Kerngebiet der Gemeinschaft in der Rinne gleichgesetzt werden. Ebenso Ist die in der Rinne baufige Cardium fasciatum auf der Austernbank selten. - Lepidopleurus asellus ist in der Rinne recht häufig, während die Art für die Austernbank nur von HaINcke als begleitende Form angegeben wird. Die Gastropoden Gibbula tumida und Scala clathrus treten regelmảßig auf der Bank auf. Besonders die erstere Art ist wichtig, da sie in der Deutschen Bucht bisher nur hier und in der Rinne gefunden wurde. Das gleiche gilt für Portunus pusillus. Auch das isolierte Vorkommen dieses Krebses in der Rinne und der Austernbank zeigt die faunistische Zusammengehörigkeit der beiden Gebiete.

Leitformen 3. Ordnung waren Echinocyamus pusillus und Ophiura albida. Während der Schlangenstern die gleiche Häufigkeit hat, ist Echinocyamus auf der Austernbank ganz selten zu finden, im Gegensatz zur Rinne, wo die Ortsdichte bis. zu 52 Stück auf 1/10 qm beträgt. Dies muß a]s einer der charakteristischsten Unterschiede betrachtet werden. 
Von kennzeichnenden gemeins a m e $n$ Arten beider Gebiete seien hier noch genannt: Cerianthus lloydii, eine Altinien-Art, die schillreiche Böden bevorzugt und daher sonst in der Deutschen Bucht seltener ist; Ebalia cranchi, ein ebenfalls sonst in der Deutschen Bucht seltener Decapode; Pandalus montagui, eine Garneelenart, die früher auf der Austernbank sehr häufig war und ihr Vorkommen auf die Rinne ausdehnte (s. S. 136). Die feine Schillbestandteile zum Aufbau ihrer Röhren verwendenden Polychaeten Owenia und Lanice kommen auch auf der Austernbank in größerer Ortsdichte vor und zeigen den gleichen Röhrenaufbau wie in der Rinne. Von Polychaeten sind ferner die Aphroditiden zu nennen, die in beiden Gebieten sehr häufig sind, was besonders durch die Sabellaria-Röhren bedingt ist, zwischen denen sie leben. Gleiches gilt für die Nemertine Lineus bilineatus.

Un ters c h i e d e zwischen Austernbank und Rinne sind positive und negative. Fehlend auf der Austernbank ist Crangon allmanni, eine tiefere Meeresgebiete bevorzugende Art, deren inselartiges Vorkommen in der Rinne dadurch erklärlich ist. Die in der Rinne auf Muschelschalen in großer Ortsdichte regelmäBig zu findende Ascidie Dendrodoa grossularia fehlt auf der Austernbank gänzlich! Von dem in der Rinne häufigen Amphipoden Photis longicaudata wurde auf der Austernbank nur 1 Exemplar gefunden. Die auf lebenden Nucula Überzüge bildende Hydrozoe Perigonimus repens ist seltener. - Positive Züge zeigt die Austernbank besonders in dem Vorkommen der Muschel Tapes pullastra, für die sie Hencke schon als typisch angibt, während sie in der Rinne - auch in Schalenresten - völlig fehlt. Ferner ist die Aktinie Actinothö anguicoma zu nennen, die in riesiger Zahl auf den Schalen der Austernbank sitzt (bis 70 auf $1 / 10 \mathrm{qm}$ ), während sie in der Rinne sehr selten ist. Auf die Häufigkeit von Sabellaria, welche die der Rinne bei weitem übertrifft, wurde schon aufmerksam gemacht.

Durch die lebenden Austern bestehen heute keine wesentlichen Unterschiede mehr zwi. schen den beiden Gebieten.

Die auf der Austernbank fehlenden Arten werden in der Rinne wegen den dort herrschenden besonderen hydrographischen Verhältnissen bessere Lebensbedingungen haben. Für das auf die Austernbank beschränkte Vorkommen der in der Rinne seltenen oder fehlenden Arten kann schwer eine Erklärung gegeben werden. Historische Momente können bei der Nähe der beiden Gebiete und dem bei der Fortpflanzung eingeschalteten Larvenstadium keine Rolle spielen. Auch der Unterschied im Schill - mehr kleine Bruchstücke in der Rinne; größere Schalen auf der Austernbank - kann kaum zur Erklärung dienen. Wesentlicher werden hydrographische Faktoren sein (vergl. Abschn. B IV), besonders in Hinblick auf das Plankton. So findet sich Sabellaria in der Rinne vorwiegend am Nordhang, was wohl durch bessere Nahrungszufuhr bedingende Strömungsverhältnisse hervorgerufen ist, die vielleicht auf der Austernbank besonders optimal sind. Auch mögen die größeren Schalen bessere Ansatzmöglichkeiten bieten. Fü Actinothoë ist diese Erklärung aber kaum anwendbar, ebenso wie das isolierte Vorkommen von Tapes nicht erklärt werden kann.

Die Beimischung von Cultcllus und Syndosmya und anderer Arten der Amphiura-Endobiose zur Endobiose der Austernbank mag durch den stärkeren Anteil an schlickigen Bestand. teilen im Sediment - hervorgerufen durch das Vorwiegen großer Schalen' - bedingt sein, wodurch das Eindringen von Elementen der benachbarten Schlickböden erleichtert wird.

c) Die Epibiose der Austernbank.

a) Fang proben.

Zur Vervollständigung des Bildes der Austernbank-Biocönose wurden Fänge mit der Kurre und dem Austernkratzer ausgeführt (vergl. S. 131). Die Ergebnisse sind in der Faunenliste bereits mit verwertet worden, so daß hier nur noch eine Vorstellung über die Zusammensetzung dieser Fänge gegeben zu werden braucht. Hierzu sind in Tabelle 7 a Beifangauszählungen von 2 Kurrenzügen (Helgoländer Trawl) über die Bank (1938) zusammengestellt. Wie aus dem Unterschied zwischen den beiden Fängen zu erkennen ist, wechselt die Zusammensetzung stark, bedingt durch die Kleinheit der Bank, da bei einer etwas anderen Kursrichtung nur Teile der Bank erfaßt werden. So ist bei Fang 2 wahrscheinlich mehr im Schlick gezogen worden ( $A$ phrodite!). - Tabelle $7 \mathrm{~b}$ enthält einige Beifangproben von Zugen mit dem Helgoländer Trawl, der Granat- und Zungenkurre aus den letzten Jahren nach dem Journal des Fischmeisters. Hieraus ist besonders die hohe Zahl der gewöhnlich gefangenen Echinus esculentus ersichtlich (diese wurden stets genau gezählt), ferner sind regelmäßig Asterias, Solaster, Eupagurus, Hyas und Alcyonium in größeren Mengen erhältljch (kleinere Beifangtiere sind hier meist nicht notiert worden). Ebenso ist oft Methridium zu fangen.

Noch ergiebiger sind Austernkratzerfänge, bei denen allerdings eine quantitative Auszählung schwierig ist. In 6 Zügen fanden sich 193810 lebende Austern, ferner sehr viele Nucula nucleus, dagegen nur wenige andere Muscheln - entsprechend den Bodengreiferfängen. Unter den 
Tabelle 7

Beifanguntersuchungen ron der Austernbank.

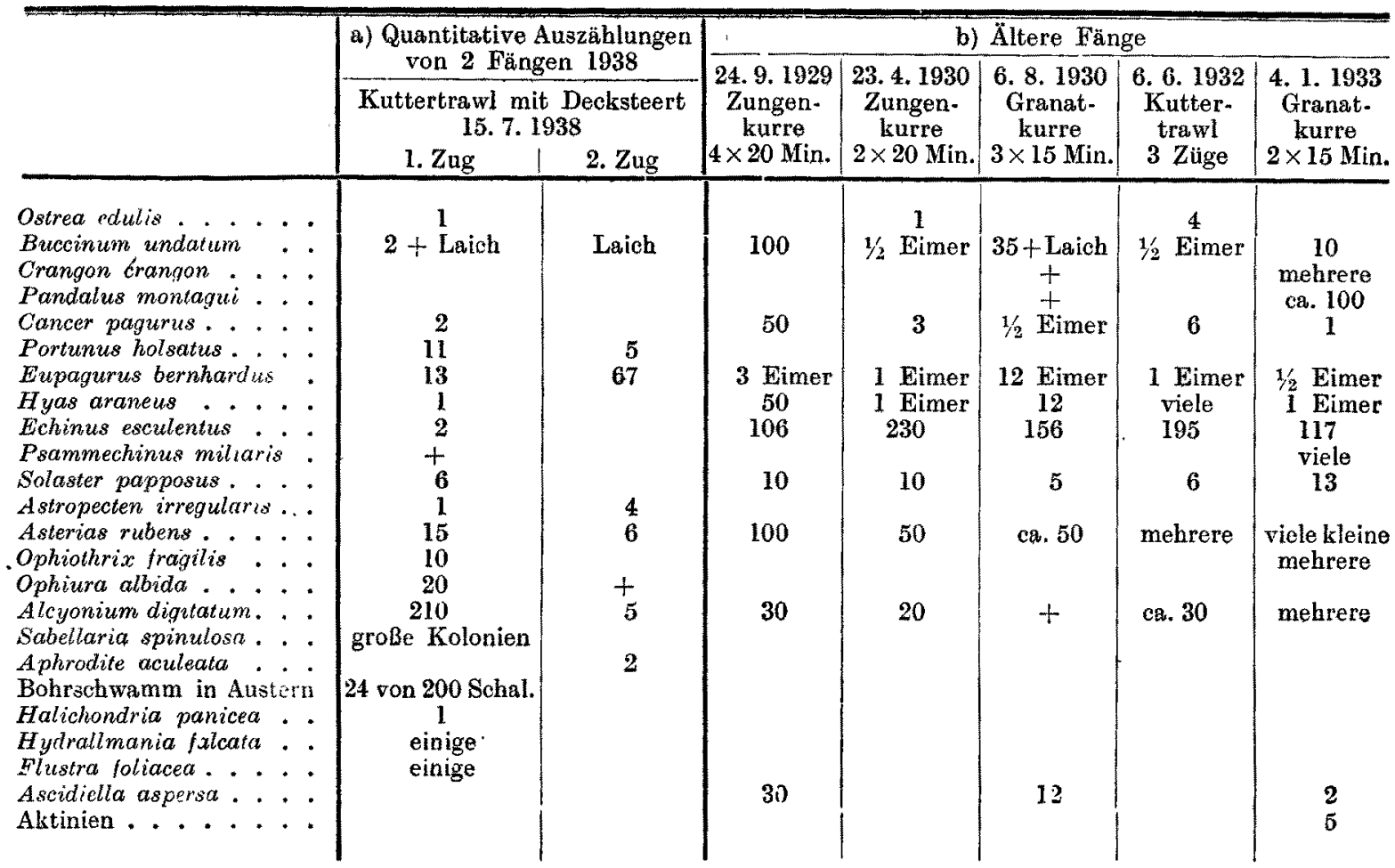

Krebsen ist Porcellana weitaus vorherrschend, ferner treten Cancer, Galathea und Ebalia auf. Die Hauptmasse der Echinodermen wird von Psammechinus miliaris eingenommen, ferner Asterias, große Solasler, Ophiura und viele Ophiothrix (die übrigen Gruppen vergl. die Faunenliste).

Die Epibiose der Austernbank ist danach als sehr reich zu bezeichnen, was bei den festsitzenden Tieren zunächst durch die Menge der Ansatzpunkte bedingt ist, ferner aber durch die reiche Planktonzufuhr, die ja primär auch für das Entstehen der Bank notwendig ist. Die Häufigkeit von Alcyonium und Sabellaria hat in diesen beiden günstigen Faktoren ihren Ursprung. Bei den beweglichen Tieren ist ebenfalls zunächst der harte Untergrund ein wichtiger Faktor; für kleinere Krebse bilden die Schalen gute Schlupfwinkel. Die reiche Endobiose bedingt auch eine große Zahl von räuberischen Tieren.

\section{B) Der Zustand derheutigen Austern.}

Die zehn 1938 gefangenen und von mir untersuchten Austern waren alte Tiere mit einer Länge von 8-11,2 cm; Junggut fehlte. Drei von ihnen zeigten einen Befall vom Bohrschwamm, zwei sehr stark. Der Bewuchs war unterschiedlich. Während eine Muschel fast völlig frei war (ein abgestorbener Balanus und Hydrozoenreste), waren die übrigen sehr stark besetzt; fünf wurden in verschiedenem Grade von Sabellaria-Kolonien überwuchert; auf einer Auster lebten ferner viele Actirothoë anguicoma und Pomatoceros triqueter, außerdem war sie vom Bohrschwamm stark befallen. Eine andere Auster wurde auf der Oberseite von vier großen Methridium dianthus fast völlig bedeckt, dazwischen fanden sich noch 20 kleine Seenelken. Die freien Stellen waren dicht mit Balaniden übersät, ferner Membranipora.

Ein derartig starker Bewuchs mit Epizoen ist durch das Alter der Austern gegeben und bedeutet eine sehr wesentliche Nahrungskonkurrenz. Es kann aber angenommen werden, daß dieser das Normale für die Helgoländer Bank darstellt, da auch die alten Berichte (besonders Henking) einen ähnlich starken Bewuchs mitteilen. Im ganzen ist dadurch aber eine Erholung Jer Bank durch Junggut sehr erschwert. - Für besondere Beobachtungen über die Form der Austern reicht mein Material nicht aus; die Helgoländer unterschieden früher mehrere Typen. die vom Standort abhängen sollen (nach Mitteilung von Fischmeister Holtuaxx). 


\section{Veränderungen der Austernbank-Biocönose. \\ 1. Allgemeine Gesichtspunkte.}

In der Einleitung wurde als eine Aufgabe der vorliegenden Arbeit die Untersuchung genannt, wieweit der starke Rückgang der Austern, eines der wichtigsten Glieder der Biocönose, eine Veränderung auch der übrigen Fauna der Austernbank zur Folge gehabt hat. In Abschnitt $\mathrm{C}$ ist der frühere Zustand der Bank nach den Literaturangaben behandelt worden, besonders in Hinsicht auf die Menge der Austern. Für den Rückgang der Austern wurden 1. Überfischung, 2. biologische Verhältnisse vermutet. Die Fischerei ist wohl kaum für die sonstige Fauna nachteilig gewesen, da der gesamte Beifang auf der Bank selbst noch wieder über Bord geworfen wurde. Die Änderung der biologischen Verhältnisse muß, falls es sich um geänderte Außenfaktoren handelt, eine Änderung der Gesamt-Biocönose bewirken. Es wäre hierbei z, B. an eine längere Kälteepoche zu denken, die für den Ansatz von Junggut der Austern, dann aber auch für einen Teil der übrigen Fauna nachteilig sein mußte. Fassen wir die Möglichkeit einer Austernkrankheit ins Auge (vergl. S. 130-131), so brauchten hiervon dann nur die Austern betroffen zu sein, so daß die Änderung der übrigen Fauna erst mittelbar durch den Rückgang eines Gliedes der Biocönose bedingt ist.

\section{Vergleich der alten Angaben (außer Austèrn).}

Die älteren Fangergebnisse sind bereits behandelt (S. 131-132) und in der Faunenliste mit verwertet worden. Die 60 Arten umfassende Liste von Möbrus (s. S. 132) entspricht im ganzen der heutigen Fauna; leider fehlen Bemerkungen über die Häufigkeit. Auch Nucula nucleus und Tapes pullastra werden angeführt. Von Bedeutung ist besonders die Mollusken-Liste von Heincke (1894), in der er ebenfalls Tapes als typische Erscheinung meldet. Dagegen gibt er Nucula nucleus nur als ,weniger häufig als begleitende Form" zusammen mit Chione ovata und Cardium fasciatum an. Bei der sorgfältigen Sammeltätigkeit Hernckes - auch wenn sie sich nur auf Netzfänge stützt - kann dies nur so erklärtwerden, da $B N u c u l a$ damals tatsächlich seltener war, während sie heute ja die häufigste Art darstellt.

Sabellaria war in früherer Zeit in gleicher Menge vorhanden und bildete ein wichtiges Erkennungszeichen der Bank. Ein besonderer Feind der Austern war schon damals der Bohrschwamm (vergl. S. 130). Leider fehlen Angaben über die Menge von Asterias. Hankıng (s. S. 130) teilt mit, da B Bohrschwamm und Seepocken in Sabellaria einen Widersacher hatten, indem diese sie überwucherten und zum Absterben brachten. Für die Austern war dies allerdings ohne Nutzen, da sie nun durch die Ablagerung von Sandkörnern in der Nahrungsaufnahme gestört wurden.

Prof. Hacueıer stellte mir die Liste zweier Bodengreiferfänge von der Austernbank, Dezember 1925, zur Verfügung, die in ihrer Zusammensetzung keine grundlegenden Unterschiede zu der heutigen Besiedlung erkennen lassen. Es wurden 3 junge Tapes pullastra zwischen Sabellaria gefangen; die weitaus häufigste Muschel war Nucula nucleus, während Chione ovata und Cardium fasciatum ebenso selten wie Echinocyamus waren.

Auf den starken Rückgang von Pandalus montagui und Ascidiella aspersa wurde bereits hingewiesen. Dieser hat ebenfalls in der Rinne stattgefunden und hängt nicht mit einer Änderung der Biocönose, bedingt durch den Rückgang der Austern, zusammen.

\section{Die erhaltenen Reste im Sediment (Siebrest-Untersuchungen).}

Eine Untersuchung über die Änderung der Biocönose nach dem Absterben der Austern kann sich nicht auf die spärlichen alten Fangmitteilungen beschränken, sondern es mußte festgestellt werden, wieweit die Menge und Verbreitung der im Sediment lagernden Muschelschalen und Schneckengehäuse als Reste der früheren Fauna eine Aussage hierüber ermöglichen (vergl. C., S. 86).

Um die Verbreitung der Arten festzulegen, wurde von sämtlichen Stationen der Siebrest qualitativ untersucht. In Tabelle 8 sind ferner vier quantitative Auszählungen von den Stationen 7, 10, 33 und 40 aufgeführt (über Methodik, verschiedene Haltbarkeit der Schalen usw. s. C., S. 87 u. 92). Es ist ohne Bedeutung, für jede Art die Verbreitung hier zu erörtern und danach Siedlungsgebiete - entsprechend wie bei der lebenden Fauna - aufzustellen. Die Grenzen sind natürlich auch nicht so scharf wie bei dieser. So kann die Angabe genügen, daß d i e E n d obiosen und Variationen der lebenden Fauna sich im Siebrestgenau widerspiegeln, so daß man lediglich auf Grund der Siebrest-Untersuchungen - wie in der Rinne - zu der gleichen Biocönosen- und Variationen-Aufteilung käme. Natürlich machen sich die Vermischungen stärker bemerkbar, auch ist es selbstverständlich, daß das Verbreitungsbild jeder Art das auf Grund der lebenden Tiere aufgestellte übertrifft; es muß ja auch immer mit Fluktuationen, „Flecken dichtester Besiedlung" während eines Jahres usw. gerechnet werden. 
Tabelle 8 .

Quantitative Siebrestbestimmungen.

4 Auszählungen von Station $7,10,33$ und 40 .

Gewichte der lufttrockenen Bestandteile in Gramm von je einer 0,1-qm-Bodengreiferprobe.

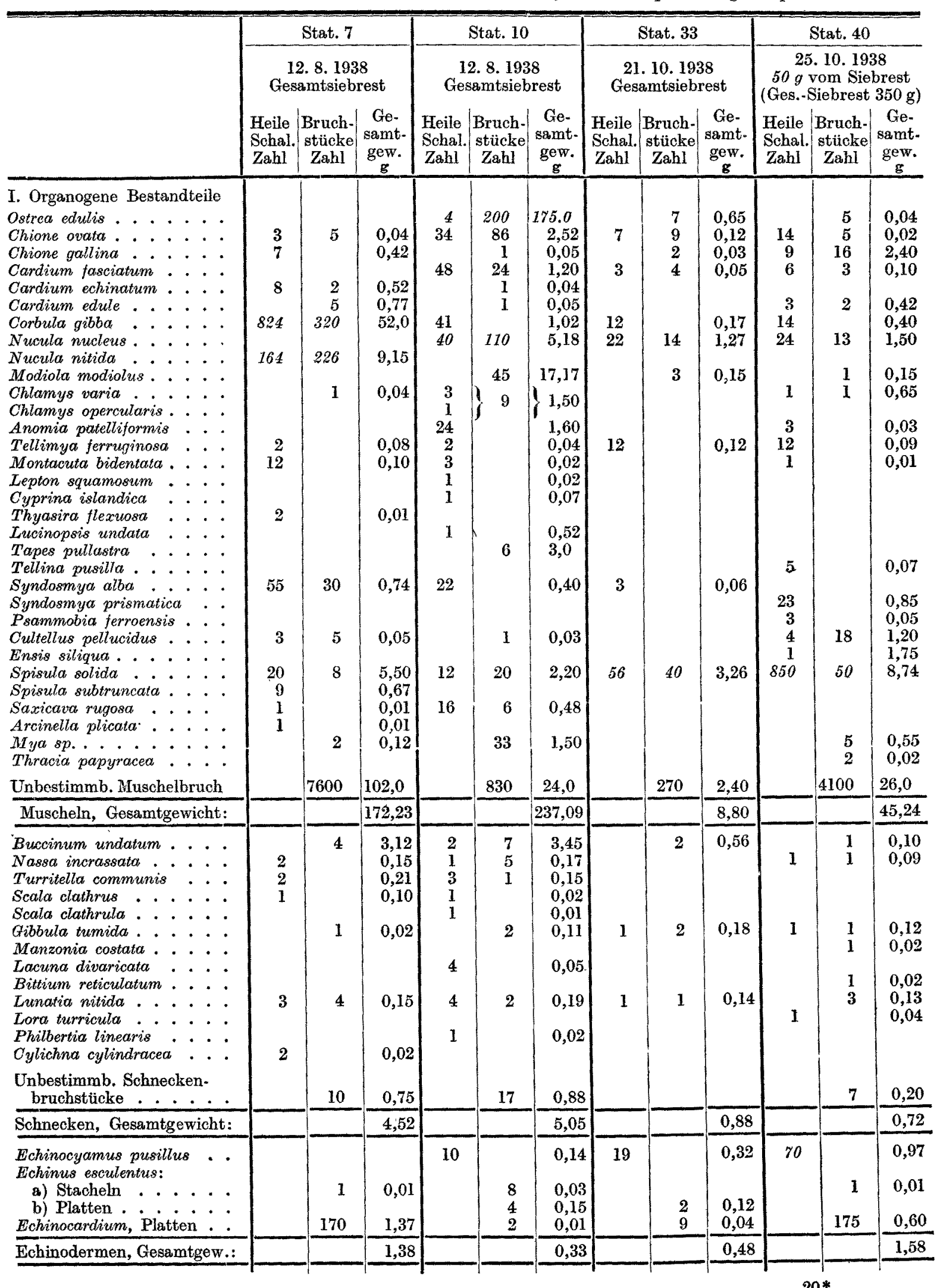




\begin{tabular}{|c|c|c|c|c|c|c|c|c|c|c|c|c|}
\hline & \multicolumn{3}{|c|}{ Stat. 7} & \multicolumn{3}{|c|}{ Stat. 10} & \multicolumn{3}{|c|}{ Stat. 33} & \multicolumn{3}{|c|}{ Stat. 40} \\
\hline & \multicolumn{3}{|c|}{$\begin{array}{c}\text { 12. } 8.1938 \\
\text { Gesamtsiebrest }\end{array}$} & \multicolumn{3}{|c|}{$\begin{array}{l}\text { 12. } 8.1938 \\
\text { Gesamtsiebrest }\end{array}$} & \multicolumn{3}{|c|}{$\begin{array}{l}21.10 .1938 \\
\text { Gesamtsiebrest }\end{array}$} & \multicolumn{3}{|c|}{$\begin{array}{c}25.10 .1938 \\
50 \mathrm{~g} \text { vom Siebrest } \\
\text { (Ges.-Siebrest } 350 \mathrm{~g} \text { ) }\end{array}$} \\
\hline & $\begin{array}{c}\text { Heile } \\
\text { Sehal. } \\
\text { Zahl }\end{array}$ & $\left|\begin{array}{c}\text { Bruch- } \\
\text { stücke } \\
\text { Zahl }\end{array}\right|$ & $\begin{array}{c}\text { Ge- } \\
\text { samt- } \\
\text { gew. } \\
\mathrm{g}\end{array}$ & $\begin{array}{l}\text { Heile } \\
\text { Schal. } \\
\text { Zahl }\end{array}$ & $\begin{array}{c}\text { Bruch- } \\
\text { stuicke } \\
\text { Zahl }\end{array}$ & $\begin{array}{c}\mathrm{Ge}- \\
\text { samt- } \\
\text { gew. } \\
\mathbf{g}\end{array}$ & $\begin{array}{l}\text { Heile } \\
\text { Schal. } \\
\text { Zahl }\end{array}$ & $\begin{array}{c}\text { Bruch } \\
\text { stücke } \\
\text { Zahl }\end{array}$ & $\begin{array}{c}\text { Ge- } \\
\text { samt- } \\
\text { gew. } \\
\mathbf{g}\end{array}$ & $\begin{array}{c}\text { Heile } \\
\text { Schal. } \\
\text { Zahl }\end{array}$ & $\mid \begin{array}{c}\text { Bruch- } \\
\text { stücke } \\
\text { Zah1 }\end{array}$ & $\begin{array}{c}\text { Ge- } \\
\text { samt- } \\
\text { gew. } \\
\mathrm{g}\end{array}$ \\
\hline $\begin{array}{l}\text { Balanus-Platten } \\
\text { Pomatoceros triqueter-Röhren } \\
\text { Krebsglieder } . . .\end{array}$ & & $\begin{array}{r}175 \\
2 \\
\end{array}$ & $\begin{array}{l}5,55 \\
0,01 \\
\end{array}$ & & $\begin{array}{r}570 \\
4 \\
5 \\
\end{array}$ & $\begin{array}{c}48,0 \\
0,07 \\
0,10 \\
\end{array}$ & & 15 & 0,35 & & $\begin{array}{r}25 \\
3 \\
\end{array}$ & $\begin{array}{l}0,53 \\
0,30 \\
\end{array}$ \\
\hline Gesamtgewicht: & & & 5,56 & & & 48,17 & & & 0,35 & & & 0,63 \\
\hline 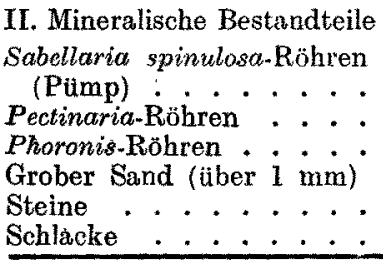 & & 30 & 0,28 & & $\begin{array}{c}800 \mathrm{com} \\
3 \\
\\
\\
2 \\
2 \\
\end{array}$ & $\begin{array}{c}590,0 \\
0,02 \\
\\
0,12 \\
0,35 \\
\end{array}$ & & $40 \mathrm{ccm}$ & 51,50 & & $\begin{array}{r}6 \\
10 \\
1 \\
\\
28 \\
\end{array}$ & $\begin{array}{l}0,47 \\
0,03 \\
0,01 \\
\\
1,32 \\
\end{array}$ \\
\hline $\begin{array}{c}\text { Mineralische Bestandteile, } \\
\text { Gesamtgewicht: }\end{array}$ & & & 0,28 & & & 590,49 & & & 51,50 & & & 1,83 \\
\hline Gesamtgew. des Siebrestes: & & & 183,96 & & & 881,13 & & & 63,01 & & & 50,00 \\
\hline
\end{tabular}

Nuculla mucleus zeigt den größten Schillanteil im Kerngebiet der lebenden Tiere. Ferner finden sich aber Schalen über die Grenze der nach der lebenden Fauna aufgestellten Endobiose hinausgehend zwischen dieser und der Loreleybank, ebenso auf den reinen Sandgebieten im Westen und Norden. - Nucula nitida ist auf den Umkreis des Amphiura-Kerngebietes beschränkt; nur einige wurden stellenweise nördlich der Austernbank festgestellt. Austernschalen finden sich in größerer Menge nur in dem kleinen Bezirk der Austernbank. In den übrigen Gebieten sind nur gelegentlich Bruchstücke zu finden, gehäuft bei Stat. 26 am Abfall zur Rinne, ferner regelmäßig in den Sandgebieten, besonders auch auf der Loreleybank.

Die in Tabelle 8 aufgeführten Auszählungen geben ein Bild von der artlichen Zusammensetzung des Schills aus verschiedenen Gegenden:

$\mathrm{S}$ t a t. 7 liegt innerhalb des $A m p h i u r a-\mathrm{K}$ ernge b i e t e s. Dies ist an der großen Zahl von Corbula gibba als vorherrschende Muschelart und Nucula nitida zu erkennen. Syndosmya alba, Spisula solida und subtruncata, Chione gallina, Cardium echinatum und Montacuta bidentata sind weiter kennzeichnende Arten. Unter den Schnecken ist besonders Cylichna zu nennen. Auch die große Zahl der Echinocardium-Platten war hier zu erwarten.

$\mathrm{S} t$ a t. 10 ist als Beispiel für die $\mathrm{A} u$ s t e r $n \mathrm{~b}$ a $\mathrm{nk}$ gewählt, die sofort durch die grolie Zahl von Austernschalen gekennzeichnet ist. Daneben ist auch im Siebrest Nucula nucleus die häufigste Art. Von charakteristischen Bestandteilen seien noch Chione ovata, Chlamys, Saxicava rugosa, Scala und Lacuna divaricata genannt, ferner die vielen Balanus-Platten und der Pümp. Letzterer macht $67 \%$ des Siebrest-Gesamtgewichtes aus, die Austernschalen rund $20 \%$. Ferner sind größere Stückzahlen von Corbula, Syndosmya und Spisula als Eindringlinge der AmphiuraEndobiose zu erwähnen. - Die Gesamtzusammensetzung entspricht also durchaus den Verhältnissen der heutigen Fauna. Es muß jedoch bemerkt werden, daß Nucula-Schalen im Verhältnis zu den lebenden Tieren zu gering vorhanden sind, was auch den Verhältuissen in der Rinne entspricht (s. C., S. 101). Im Gegensatz zum Sediment der Rinne, mit dem sonst viele Ähnlichkeiten bestehen, ist die Zahl von Chione und Chlamys bedeutend geringer, ebenso sind die Schnecken, besonders Gibbula tumida und Lunatia nitida, seltener.

Stat. 33 liegt im Mittelpunkt des Sandgebieteswestlich der A usternb a n k. Der grobe Sand herrscht weitaus vor, die organogenen Bestandteile machen nur $17 \%$ des an sich nur sehr geringen Siebrestgewichtes aus. Von der Gesamtzahl der Schalen und Bruchstücke (außer den unbestimmbaren) nimmt Spisula solida $40 \%$ ein. Daneben kommt Nucula nucleus, Corbula, Tellimya ferruginosa und Echinocyamus in größerer Menge vor.

Bei Stat. $40 \mathrm{nördlich}$ der Austernbank ist die Mischung der verschiedenen Siedlungen zu erkennen. Zunächst einmal ist auch Nucula nucleus in größerer Zahl vorhanden, vorherrschend unter den Muscheln ist jedoch Spisula solida entsprechend der Näho des Sandgebietes der Loreleybank. Montacuta bidentata, Corbula gibba, Chione gallina und Telli- 
mya ferruginosa sind Elemente der Amphiura-Endobiose. Hervorzuheben ist die große Zahl von Echinocyamus; auch Chione ovata ist stärker vertreten. Im ganzen gleicht die Zusammen. setzung der von Stat. 33, doch ist, wie bei der lebenden Fauna, durch die Schlickbeimischung eine größere Artenfülle gegeben.

Nach den Siebrest-Untersuchungen sind folgende Aussagen möglich:

1. Die im Schill vorhandenen Schalen spiegeln die Besiedlung einer längeren $\mathrm{Z}$ e it wi eder (abzusehen ist natürlich von der unterschiedlichen Zerstörbarkeit).

2. In der Bodenbeschaffenheit finden sich heutekeine wesentlichen Unterschiedezu den Beschreibungen von Mörsos und Henking a us der Zeit, als die Bank noch mitvielen lebenden Austern besetzt war; auf Grund allein des Sedimenteskönnteheutealso nicht auf die Unproduktivität der Bank geschlossen werden.

3. Die Grenzender heutigen Endobiosen sind - abgesehen von Grenzsäumen - k on st a n t. Auch die Variationsgebiete spiegeln sich in den Schalenablagerungen wieder. Dadurch ist für das Gebiet ein nennenswerter Transport von Bodenmaterial abzulehnen. Nur Nucula nucleus scheint zeitweise eine weitere Ausdehnung besonders nach Norden zu haben.

4. Die Mengedor $N u c u l a-S c h a l e n$ a d der Austernbank ist geringer als nach dor Ortsdichtederlebenden Muschelnzuerwarten war.

5. Die artliche Zusammonsetzung des Austernbankschills erweist vielegemeinsame $\mathrm{Zug}$ u mit dem der Tiefen Rinne. Unterschicde sind gegeben Bruchstücke;

a) durch die gröl3ere Menge von ganzen Austernschalen und dem Zurückgehen der kleinen

b) durch den wesentlich größeren Anteil der Sabcllaria-Röhren am Sediment;

c) durch die rolative Scltenheit von Chione ovata- und Chlamys-Schalen und dem mengenmäBigen Rückgang der Schneckenarten, besonders Giblula tumida und Lunatia nitida.

d) durch die relativ stärkere Beimischung von Elementen der Amphiura-Endobiose, bedingt durch den Mangel an kleinen Bruchstucken und dem dadurch gegebenen größeren Anteil an sandigem Schlick.

Fs sei hier am Platze, dio Frage nach der Herkunft der vielen Austernsehalen aufzuwerfen, die sich auf der II e ly ol ä n d e r D i n e finden ${ }^{1}$ ). Die Austernlank kommt als Lieferungsgebiet kaum in Frage, da von dort nach den Strömungs- und Scegangsverhältnissen nichts zuwandern kann, wie aus der kürzlich erschieneuen sehr eingehenden Arbeit von BaIr (1939) zu ersehen ist. Es ist auch am Meeresboden kein möglicher Transportwrg festzustellen; im Gegenteil sind die um die Austernbank und die Tiefe Rinne sich erstreckenden Zonen fast vollig frei von Austernschalen. Die Gerölle der Dune stammen von diluvialen Banken, die Feuersteine überwiegend aus dem östlichen Diunenklippenzug (vergl. Bank, S. 20). Die Austernschalen schen z. T. sehr frisch aus, meist zeigen sie einen fruheren Belall von Bohrschwamm. Die in den Strandzone zu findenden Schalen werden in wenigen Jabren von der Brandung zwischen dem Geröll aufgearbeitet, und wie mir Dr. Banr mitteilte, sind die tief im Sand liegenden und bei Strandabbrüchen zum Vorschein kommend on Schalen bei den starken Umlagerungen, die die Düne in den letzten Jahrhunderten erfahren hat. alle erst vor verhältnismäßig kurzer Zeit zur Düne gelangt. Als Ursprung der schalen kommt das Gebiot westnordwestlich und nordwestlich ron Helgoland in Frage, wo die Fischereikarte bis zum Nordostauslänfer dor Doggerbank auf $56^{\circ} \mathrm{n}$. Br. Austern cder Austernschalen verzeichnet. Aus diesem Gebiet stammend werden von Bank ja auch die nordischen Geschicbe auf der Dune angesehen. HAGMEIER (1941) schreibt hierzu:

,,Die Austernschalen bleiben wahrscheinlich Hunderte von Jahren am Meeresbcden cdor im Scdiment erhalten, daher ruhrt auch die Anreicherung von Schalen auf einem nur spärlich mit lebenden Tieren besiedelten Standort. Im groben Kies der Helgoländer Düne kann man sehr alte, schon als fossil zu bezeichnende Austernschalen finden, sie stammen wahrscheinlich, wie das Geröll, von den abgetragenen Dünenklippen, wo selten verhältnismäBig diunnschalige Austern (Flachsee-Austern) auf Gestein angewachsen gefurden werden. Auch an der Nordostseite der Insel, im sogenannten Nordhafen, kamen im vorigen Jahrhundert noch Austern vor, die gefischt wurden (Mitteilung ron Fischmeister HoLmanN?."

Es wurde versucht, aus der artlichen Zusammensetzung der sonstigen auf der Insel angespülten Schalen das Herkúnftsgebiet nàher zu crmitteln. Dies würde den einzig möglichen Anhalt hierfür geben, da petrographische Untersuchungen ganz versagt haben. Die vom Verfasser 1938 auf der Düne ausgeführte Sarnmlung hatte folgendes Ergebnis: Neben Austern vorherrschend Cardium edule, Spisula solida und Lucina borealis; ferner vorhanden Cardium fasciatum, Chione gallina, Tellina fabula, Mytilus edulis, Donax vittatus, Saxicava rugosa, Macoma baltica, Chlamys varia. An Schneckengehausen wurden gefunden: vorwiegend Buccinum undatum, Gibbula tumida, Nassa reticulata und Nucella (Purpura) lapillus, ferner Litorina litorea, L. obtusata und Trivia arctica. - Es handelt sich meist um Bewohner sandiger Böden, wie sie sich im Norden bis Westen der Düne erstrecken. Leider ist die Besiedlung des Meeresbcdens in diesem Quadranten recht gleichförmig, so daß eine genauere Analyse nach dem bisher vorliegenden Material noch nicht möglich erscheint ${ }^{2}$ ). Austernzucht

1) Es wurden hier in einem Jahr etwa 15000 Schalen gesammelt als Ansatzkörper für die Larven bei der

2) Bei späteren Untersuchungen muß beachtet werdən, daß neuerdings große Sandmengen von der Loreleysank zur Sicherung der Düne aufgeschüttet wurden. 


\section{4. Änderungen durch den Rïekgang der Austern.}

Die Siebrest-Untersuchungen haben im ganzen ergeben, daß in bezug auf die Reste im Sediment hinterlassenden Tiere nur für Nucula nucleus eine Änderung anzunehmen ist. Die geringe Zahl der Nucula-Schalen kann durch die geringe Widerstandsfähigkeit allein nicht erklärt werden. Vor allem muß die oben behandelte Liste von HErNcke so gedeutet werden, daB Nucula um 1890 auf der Bank seltener (nur ,,begleitende Form") war, was dann mit dem Siebrestbild übereinstimmt. Dagegen hatte Chione ovata nie die Häufigkeit wie in der Rinne: Es ist natürlich schwer eine Entscheidung darüber möglich, ob die heutige Häufigkeit von $N u$ cula mit der Abnahme der Austern zusammenhängt. Man könnte vermuten, daß die oberflächlich liegenden Austern eine schwere Nahrungskonkurrenz für die eingegrabenen Nucula bildeten.

Für die übrige Fauna sind keine Änderungen nachweisbar. Es ist aber anzunehmen, daß die Zahl der Seesterne während der Blüte der Bank größer war. Von den nordfriesischen Bänken ist ja bekannt, wie rasch junge Asterias heranwachsen, wenn ein Massenansatz von $M y$ tilus stattgefunden hat. Nehmen wir das gleiche für Austern an, so fiel durch deren Rückgang diese Nahrungsquelle aus, was eine Verringerung der sich davon ernährenden räuberischen Tiere zur Folge haben mußte.

\section{Die Austern als Glied der Lebensgemeinsehaft.}

An der Austernbank ist von MöBıUs (1877 und 1893) der Begriff der Biocönose aufgestellt und die biologischen Wechselbeziehungen untersucht worden ${ }^{1}$ ); besonders wies er schon damals auf die Wirkungen hin, die der Ausfall einer Art innerhalb des Gefüges der Gemeinschaft zwangsläufig haben mu $B^{2}$ ). Als $A b s c h l u ß$ der vorliegenden Arbeit sollen diese Wechselwirkungen der einzelnen Elemente noch einmal zusammengefaßt werden. Von besonderem Wert hierfür ist eine kürzlich erschienene Abhandlung von A. Thimnwann (1939), in welcher ,,der Hauptinhalt einer allgemeinen Ökologie in kurzen Lehrsätzen dargestellt" ist, ferner der Vortrag von Remane: „Die Gemeinschaft als Lebensform in der Natur" (1939).

Bei dieser Zusammenfassung müssen die Austern im Mittelpunkt stehen, da durch sie der Charakter des untersuchten Lebensraumes und damit auch der ganzen Biocönose gegeben wurde und noch wird. Da die Auster als strudelnder Organismus in ihrer Ernährung nur von den Schwebestoffen des Wassers abhängt, ist die Wirkung auf die Biocönose zunächst indirekt, doch bestehen auch direkte Wechselbeziehungen zu den übrigen Gliedern der Gemeinsehaft.

Durch den Ansatz der ersten Austern und die davon stammenden Schalen war eine Änderung des Sedimentes gegeben, welche die vorher hier vorhandene Endobiose beeinflussen mußte. Die schill-liebenden Arten nahmen stark zu, besonders wurde aber mit der Vermehrung der Ansatzkörper die Zahl der Epibiosetiere vergrößert. Diese durch das Auftreten der Austern bewirkte Änderung geschah zunächst lediglich dadurch, daß die Schalen Hartkörper im Sediment bildeten. Als zweites ist nun aber eine direkte Wirkung der Austern festzustellen, indem diese eine Nahrungskonkurrenz für andere strudelnde Tiere, besonders der Endobiose, bildeten, wie dies für die damals in geringer Häufigkeit vertretene Nucula vermutet wurde. Umgekehrt wirken die anderen Tiere aber auch auf die Austern ein, besonders auf das Junggut, indem einige ihrerseits als Nahrungskonkurrenten wirken, andere direkte räuberische Feinde sind (Asterias); Sabellaria wirkt durch die Sandablagerung hemmend. Durch diese gegenseitige Beeinflussung der Organismen entwickelte sich die Bank bis zu ihrer Hochblüte.

Dieses ,sich in einem beweglichen Gleichgewichtszustand erhaltende Bevölkerungssystem" (Thienemann) ist aber für die Erhaltung der labilen Konstanz von der Stetigkeit der Außenfaktoren abhängig. $\mathrm{Zu}$ diesen müssen zunächst die hydrographischen Verhältnisse gerechnet werden, ferner die durch diese bedingte Menge des herangebrachten Planktcns als Nahrung. Ebenso als Außenfaktor muß aber auch die Zufuhr von ansatzreifen Larven angesehen werden. Damit kommen wir zur Frage der absoluten Grenze der Biocönose als ,natürlich abgegrenzte Einheit des Lebensraums", die ja selbstregulierbar sein muß. Wie Trmenemann betont, besteht bei keiner irdischen Lebensstätte, welchen Umfang șie auch haben mag, eine abso-

1) „Die Organe einer Thierspezies, welche sich in einer bestimmten Biocönose in eigentümlicher Weise ausbilden, sind gewissermaßen miteinander verbundene zusammenarbeitende, äußerst empfindliche Instrumente, wejche alle physilzalischen und biologischen Einwirkungen dieser Biocönose durch eine besordere morphologische urd chemischphysiologische Ausbildung der Form und Farbe, des Geruches und Geschmackes u. a. Merkmale der Individuen dauernd anzeigen" (MöBIUs, 1893, S. 25).

2) „Jede Veränderung irgendei ues mitbedingenden Faktors einer Biocönose bewirkt Veränderungen anderer Faktoren derselben. Wenn irgendeine der äußeren Lebensbedingungen längere Zeit von ihrem früheren Mittel abweicht, so gestaltet sich die ganze Biocönose um; sie wird aber auch anders, wenn die Zahl der Indivjduen einer zuggehörigen Art durch Einwirkungen des Menschen sinkt oder steigt oder wern eine Art ganz ausscheidet oder eine neue Art in die Lebensgemeinde eintritt" (MöBrus, 1877, S. 76). 
lute Autarkie, da alle verkettet, eingeschlossen und einbeschlossen in dem einen großen Lebensraum, als letzte Stufe dem ganzen Kosmos, sind. Hierdurch werden wir zu der Anschauung geführt, daß die benthalen Gemeinschaften im Meer allein durch die am Boden sich findenden Grenzen einzuteilen sind, da die pelagialen Gemeinschaften anderen Gesetzen gehorchen, wie die Grenzen hier auch sehr großräumig gezogen werden mussen. Die Verbindung mit der benthalen Gemeinschaft ist einerseits durch das Plankton als Nahrung, andererseits als Transportweg der Bodentierlarven gegeben, wir müssen sie aber als Außenfaktoren wie die chemisch. physikalischen werten, nicht als Glieder dieser Gemeinschaften (s. hierzu auch Caspers, 1950).

Die Entstehung der Austernbank wurde letztlich auf die besonderen hydrographischen Verhältnisse zurückgeführt, die einmal chemisch-physikalisch, zum zweiten biotisch wirken, da stets eine genügende Zahl von Bodentierlarven herangebracht werden muß, um die Biocönose konstant zu erhalten. Diese Zufuhr von Larven ist besonders auch in Hinblick auf die Austern zu betonen, da nicht angenommen werden kann, daß bei den starken Strömungen auch nur ein geringer Teill der auf der Helgoländer Bank geschlüpften Larven hier ebenfalls zum Ansatz kommt; die Ergänzung wird von Larven erfolgen, die von den Küstenbänken oder den ,, wilden Austern“" der tieferen Nordsee stammen. Diese Ergänzung aus ferneren Gebieten trifft für alle ein planktisches Larvenstadium in die Entwicklung einschaltenden Bodentiere des Meeres zu.

Die Struktur der Biocönose der Helgoländer Austernbank wurde durch den Ausfall eines ihrer wesentlichsten Glieder grundlegend geändert. Die Befischung durch den Menschen vorher hatte wohl kaum eine Veränderung des Gesamtgefüges zur Folge, da zunächst die. Lücken bald wieder durch das im Uberfluß vorhandene Junggut aufgefullt wurden. - Das Verschwinden der Austern mußte sich zunächst unmittelbar dadurch äußern, daß die Zahl der sich von diesen ernährenden Feinden abnahm (vergl. S. 166). Ferner konnten sich alle jene strudelnden Tiere, denen eine größere Ortsdichte durch die Nahrungskonkurrenz der Austern verhindert worden war, stärker entwickeln, wie dies für $N$ ucula vermutet wurde $(S, 162 u, 166)$. Eine zweite Folge des Austernrückganges wirkt sich aber erst allmählich aus: eine Neuzufuhr von Austernschalen zum Sediment findet nicht mehr statt. Mit der allmählichen Verkleinerung der Schalen ändert sich aber der Schillcharakter und damit auch die Biocönose. Als ein späteres Stadium kann wohl der Zustand angenommen werden, wie wir ihn heute in der Tiefen Rinne finden. Die großen Mengen von Sabellaria und Alcyonium werden zurückgehen, während die Änderung in der Endobiose durch ein Zurückweichen der Elemente der Amphiura-Endobiose kenntlich sein wird. Sokanndie Lebensgemeinschatt der Austernbank auch unmittelbar der der Tiefen Rinnegleichgesetzt werden, die nach der in beiden Gebieten häufigsten und nur hier vorkommenden Muschel Nucula nucleus benannt ist. Die Zusammengehorigkeit beider Gebiete.ist also durch die Endobiose gegeben, während die Epibiose der Rinne schon eine spätere ,Succession" (Thieseusx, 1939, Nr.27) bildet, wobei angenommen wird, daB a uch die Rinne früher eine echte Austernbank darstellte (wie sich hier ja auch heute gelegentlich noch lebende Austern finden). ,Die Biocönose wird nicht nur durch die Umwelt ausschlaggebend beeinflußt, sondern wirkt ihrerseits wieder auf ihren Lebensraum ein, indem sie ihn verändert, umgestaltet. So erst wird der Raum im vollen Sinne zum kLebensraum" "Thienemans, 1939 . Nr. 31).

Die weitere Entwicklung wird so verlaufen, daß die Schalen auf der Austernbank wie in der Rinne noch mehr zerstört werden, und damit die Biocönose sich wieder dem Ausgangspunkt vor der Ansiedlung der Austern nähert.

Bei dieser Betrachtung ist von der Annahme ausgegangen worden, daß später kein stärkerer Neuansatz von Austern stattfinden wird. Die Möglichkeit einer Erholung der Bank ist von den allgemeinen hydrographischen Verhältnissen der ganzen südlichen Nordsee abhängig, bei einer Besserung dieser Ümweltsfaktoren, besonders auch bei einer stärkeren Larvenzufuhr, aber nicht ausgeschlossen, wenn auch in keiner Weise vorherzusagen.

,Biotope und Biocönosen sind wie die einzelnen Organismenarten das Ergebnis einer historischen Entwicklung, aus anderen, früher gewesenen, entstanden, nicht starr, sondern in stetem Fluß sich verändernd und umwandelnd" (Thікхемasx. 1939, Nr. 27). Der heutige Zustand der Austernbank-Biocönose entspricht einem solchen durch Wechselwirkung zwischen Biotop und Fauna sich haltenden labilen Gleichgewicht. 


\section{E. Zusammenfassung.}

1. Es war die Aufgabe, die Biocönose der Helgoländer Austernbank näher zu untersuchen, nachdem Mößıus hier und auf den schleswig-holsteinischen Bänken als crster den Begriff der Lebensgemeinschaft herausgearbeitet hat. Ferner sollte ermittelt werden: a) wieweit Übereinstimmungen mit der vom Verfasser früher untersuchten Biocönose der benachbarten Tiefen Rinne bestehen, und b) wieweit der Rückgang der Austern eine Veränderung der übrigen Fauna zur Folge gohabt hat. Unterlage für die Bearbeitung bilden Bodengreifer- und Dretschfänge.

2. Es wurde die weitere Umgebung der Bank mit in die Untersuchung eingeschlossen, im Norden bis zur Loreleybank, im Südwesten bis zur Tiefen Rinne.

3. Die Austernbank liegt in einer Tiefe von $23-28 \mathrm{~m}$ am stidöstlichen Abhang einer Erhebung südlich der Loreleybank am Rande eines Ausläufers der Tiefen Rinne. Für die Lage der Bank können keine weiteren morphologischen Merkmale angegeben werden.

4. Das Sediment besteht auf der Austernbank aus sehr grobem Schill; große Austernschalen herrschen vor, während kleine Schillbestandteile weniger als in der Rinne enthalten sind. Boigemischt sind viele Sabellaria-Röhren (Pümp.).

Durch diese Sediment-Eigenart besitzt die Bank scharfe Grenzen zu den umliegenden Gebieten: Im Osten und Süden zäher Schlick, im Norden sandiger Schlick und weiter das feine Sandgebiet der Loreleybank (Korngröße 0,1-0,25 mm), im Westen grober Sand (0,25-0,5 mm).

5. Die Bank nimmt nur eine Fläche von rund 80 ha ein. Die Bildung an einer nicht durch die Morphologie gekennzeichneten Stelle muß mit besonderen hydrographischen Verhältnissen zusammenhängen, dic sich vielleicht auch in einer günstigen Planktonzufuhr auswirken.

6. Eine Hochblüte der Bank war etwa von 1875-1886, wo jährlich bis 506000 Austern gefischt wurden. Später trat ein allmählicher - wohl durch Überfischung bewirkter - Rückgang ein. Auch ein Mangel an Junggut war festzustellen. 1923-1924 nahm die Produktion der Bank - vielleicht auf Grund eines Austernsterbens - so stark ab, daß die Fischerei nicht mehr lohnte.

7. Die Faunenliste beruht auf dem Bodengreifer-Material, vermehrt durch Dretschfänge und ältere Angaben. Sie umfaßt 208 Arten und enthält autökologische Angaben über Fluktuationen, Wachstum usw. Auch die nur als Schalen bzw. Gehäuse im Siebrest enthaltenen Reste von nicht lebend gefundenen Arten sind mit aufgenommen.

8. Auf Grund der Verbreitung einzelner Arten werden Siedlungen aufgestellt, z. T. mit einem Kerngebiet. Durch diese Leitformen ist in dem untersuchten Gebiet die Biocönose der Austernbank von der umliegenden Amphiura jiliformis-Gemeinschaft zu unterscheiden.

9. Die Biocönose der Austernbank kennzeichnet sich in der Endobiose durch die Muschel Nucula nucleus. Es ist ein Kerngebiet, das sich mit der Epibiose der Austernbank deckt, und ein südwestlicher Ausläufer, der direkt in Verbindung mit der Tiefen Rinne steht, zu trennen. So stellt die Austernbankein abseits gelegenes Variationsgebiet der Nuculanucleus-Gemeinschaft der Tiefen Rinnedar.

10. Die Amphiura filiformis-Endobiose ist in viele Variationsgebiete aufgeteilt, die Abhängigkeit von der Bodenstruktur zeigen. Auch die Sandgebiete können vielleicht als arme Siedlungen hierzu gerechnet werden, weisen jedoch auch eigene Züge und Beimischungen anderer Endobjosen auf.

11. Das Kerngebiet der Nucula nucleus-Endobiose auf der Austernbank ist durch einen sehr großen Arten- und Individuen-Reichtum ausgezeichnet (bis 210 Tiere auf 1/10 qm; insgesamt 75 Arten). Charakteristisch ist die Muschel Tapes pullastra.

12. Es besteht eine Reihe von Unterschieden zwischen der Fauna der Austernbank und der der Tiefen Rinne. Die nur in der Rinne zu findenden Arten kommen dort wegen den besonderen hydrographischen Verhältnissen vor, was auch z. T. für die auf die Austernbank beschränkten Tiere zutrifft. Ferner mögen die Sedimentverschiedenheiten von Einfluß sein, ohne daß hierdurch doch für alle Unterschiede eine Erklärung gegeben werden kann. 
13. In der Epibiose der Austernbank ist besonders die große Ortsdichte des Seeigels Echinus esculentus zu bemerken, ferner die große Entfaltung der Sabellaria- und AlcyoniumKolonien. Im ganzen ist die Epibiose sehr reich. Die lebenden Austern zeigen einen sehr starken Bewuchs.

14. In der Endobiose ist nach dem Rückgang der Austern eine Änderung für Nucula nucleus anzunehmen, die vordem - bedingt vielleicht durch die Nahrungskonkurrenz der Austern - seltener gewesen zu sein scheint. Hierfür sprechen Angaben von Hervors und Siebrest-Untersuchungen.

15. Die im Siebrest enthaltenen Reste zeigen dieselben Verbreitungsgrenzen wie die Jebenden Tiere, so daß die Lage der Biocönosen und ihrer Variationsgebiete konstant ist. Die artliche Zusammensetzung des Austernbank-Schills hat viele gemeinsame Züge mit der Tiefen Rinne. Chlamys-Schalen sind selten; weitere Unterschiede entsprechen denen der lebenden Fauna (außer Nucula).

16. Durah den Ansatz der ersten Austern wurde langsam der Charakter der Endobiose geändert, indirekt durch die Schillanreicherung im Sediment, fermer direkt durch Nahrungskonkurrenz und Heranziehung von Feinden. So bildete sich ein labiles Gleichgewicht heraus, das abhängig von der Stetigkeit der Außenfaktoren war, zu denen auch die Zufuhr ansatzreifer Larvien, die meist aus entfernten Gebieten kommen, gerechnet wird. Eine benthale Biocönose im Meer kann nur durch die am Boden sich findenden Grenzen eingeteilt werden; die pelagialen Gemeinschaften unterliegen anderen Gesetzen.

Die Folge des Rückgangs der Austern war eine Änderung der Struktur der Biocönose durch den Wegfall der Nahrungskonkurrenz und der Abnahme der von den Austern sich ernährenden Tiere. Der heutige Zustand der Tiefen Rinne wird als eine spätere "Succession" gedeutet, wobei anzunehmen ist, daß auch diese früher eine Austernbank darstellte. Durch die Verkleinerung der Schalen im Sediment wird sich später - abgesehen von der Möglichkeit einer nicht vorauszusagenden Erholung der Bank - die Biocönose wieder dem Ausgangspunkt vor der Ansiedlung der Austern nähern. Der heutige Zustand ist ein durch Wechselwirkung zwischen Biotop und Fauna sich haltendes labiles Gleichgewicht.

\section{F. Schriftenverzeichnis.}

Es sind nur die im Text angegebenen Arbeiten aufgeführt. Für alle weitere Literatur siehe das Verzeichnis in CASPERS, 1938.

BAMr, M., 1938. Die Veränderungen der Helgoländer Düne und des umgebenden Seegebietes. Jahrb. Hafenbautechn. Gesellschaft, Bd. 17.

Bock, S., 1913. Studien über Polycladen. Zool. Bidrag Uppsala, Bd. 2.

Caspers, H., 1938. Die Bodenfauna der Helgoländer Tiefen Rinne. Helgol. Wiss. Meeresunters., Bd. 2, Heft 1. Auf diese Arbeit beziehen sich die im Text als (C., S. -) gegebenen Hinweise.

-, 1939. Zwei neue Epicariden-Arten aus der Nordsee. Zool. Anz., Bd. 125, Heft 9/10.

-, 1940. Utber Nahrungserwerb und Darmverlauf bei Nucula. Zool. Anz., Bd. 129, Heft 1/2.

-, 1950. Der Biozönose- und Biotopbegriff vom Blickpunkt der marinen und limnischen Synökologie. Biol. Zbl., Bd. 69, Heft $1 / 2$

Friedrich, H., 1938. Polychaeten. Grimpe \& Wagler, Tierw. d. Nord- und Ostsee, Bd. VI b.

GosDrcke, E., 1939. Beitrag zur Hydrographie der Helgoland umgebenden Gewässer. I. Die Oberflächenverhältnisse bei Helgoland-Reede. II. Die mittleren hydrographischen Verhältnisse bei den Helgoländer Terminstationen. Ann. d. Hydrographie und maritimen Meteorologie, Bd. 67, H. 4 n. 5.

-, 1940. Die heutige Kenntnis von der Morphologie und Hydrographie der Helgoländer Tiefen Rinne im Zusammenhang mit entsprechenden Verhältnissen der südöstlichen Deutschen Bucht. Ebenda, Bd. 68, Heft 12.

Haqmemer, A., Die intensive Nutzung des nordfriesischen Wattenmeeres durch Austern- und Muschelkultur. Ztschr. f. Fischerei, Bd. 39, Heft 2

HAGMEIER, A., und KäNDLER, R., 1927. Neue Untersuchungen im nordfriesischen Wattenmeer und auf den fiskalisehen Austernbänken. Wiss. Meeresunters., N. F.; Abt. Helgoland, Bd. 16.

Henncke, Fr., 1894. Die Mollusken Helgolands. Wiss. Meeresunters., N. F., Abt. Helgoland, Bd. 1.

Möвrus, K., 1877. Die Auster und die Austernwirtschaft. Berlin.

-, 1893. Über die Thiere der schleswig-holsteinischen Austernbänke, ihre physikalischen und biologischen Lebensverhältnisse. Sitz.-Ber. Kgl. Pr. Akad. Wissensch., Berlin, Bd. 8.

ORTon, J. H., 1937. Oyster Biology and Oyster Culture. London.

Remane, A., 1939. Die. Gemeinschaft als Lebensform in der Natur. Kieler Blätter, Bd. 2, Heft 2

SchNAKEnsECK, W., 1927. Die Helgoländer Fischerei im Lichte einer alten Statistik aus den Jahren 1875-1894. Der Fischerbote, Bd. 19.

SpÄrck, R., 1924. Studies on the biology of the oyster (Ostrea edulis) in the Limfjord, with special reference to the influence of temperature on the sex change. Rep. Dan. Biol. Stat. Vol. 30

Thren emann, A., 1039. Grundzüge einer allgemeinen Ôkologie. Arch. f. Hydrobiologie, Bd. 35. 